University of Rhode Island

DigitalCommons@URI

Open Access Master's Theses

2016

\title{
An Electrochemical Process for Simultaneous Treatment of Metal and Cyanide Bearing Wastewater
}

Mathew Thomas Jodoin

University of Rhode Island, mathewjodoin@gmail.com

Follow this and additional works at: https://digitalcommons.uri.edu/theses

\section{Recommended Citation}

Jodoin, Mathew Thomas, "An Electrochemical Process for Simultaneous Treatment of Metal and Cyanide Bearing Wastewater" (2016). Open Access Master's Theses. Paper 881.

https://digitalcommons.uri.edu/theses/881

This Thesis is brought to you for free and open access by DigitalCommons@URI. It has been accepted for inclusion in Open Access Master's Theses by an authorized administrator of DigitalCommons@URI. For more information, please contact digitalcommons-group@uri.edu. 
AN ELECTROCHEMICAL PROCESS FOR SIMULTANEOUS TREATMENT OF METAL AND CYANIDE BEARING WASTEWATER

BY

MATHEW THOMAS JODOIN

A THESIS SUBMITTED IN PARTIAL FULFILLMENT OF THE

REQUIREMENTS FOR THE DEGREE OF

MASTER OF SCIENCE

IN

CHEMICAL ENGINEERING

UNIVERSITY OF RHODE ISLAND

2016 
MASTER OF SCIENCE THESIS

OF

MATHEW THOMAS JODOIN

\section{APPROVED:}

Thesis Committee:

Major Professor Otto Gregory

Everett Crisman

Alan Davis

Nasser H. Zawia

DEAN OF THE GRADUATE SCHOOL

UNIVERSITY OF RHODE ISLAND

2016 


\begin{abstract}
Heavy metal and cyanide contamination in electroplating wastewater can pose a serious environmental problem if not removed prior to discharge (Rajeswari and Sailaja 2014). Electrocoagulation has been shown to effectively remove many of these contaminants separately using batch treatment systems (Adhoum et al. 2004). The present study seeks to test the technologic efficacy of mixed electrocoagulation and hydroxide precipitation to simultaneously treat metals common to the electroplating industry $\left(\mathrm{Ni}^{+2}, \mathrm{Cu}^{+2}, \mathrm{Sn}^{+2}\right)$, and cyanide $\left(\mathrm{CN}^{-}\right)$. The ultimate goal of the study is to offer a process which has the potential for use in continuous treatment.

Cyanide ion $\left(\mathrm{CN}^{-}\right)$begins to form volatile and dangerous hydrogen cyanide ( $\mathrm{HCN}$ ) in increasing concentrations as the $\mathrm{pH}$ drops below 11. At the same time, literature shows a drop-off in metal removal efficiencies using electrocoagulation at pH's above 10 (Kobya et al. 2010). To overcome this drop, process variables such as current density, agitation rate, and volumetric flow rate of air were optimized using removal speed and final concentration as the chosen metrics. The data followed first and pseudo-first order kinetics which allowed the rate constants to gauge the relative rates of removal.
\end{abstract}

The present work was able to reduce $\mathrm{Ni}^{+2}, \mathrm{Cu}^{+2}, \mathrm{Sn}^{+2}$ and $\mathrm{CN}^{-}$concentrations below the discharge limits set forth by the United States Environmental Protection Agency (EPA). The electrocoagulation cell conditions were optimized at a current density of 50 ASF, spin speed of 0 RPM, and volumetric flowrate of air of 0.0022 $\mathrm{ft}^{3} / \mathrm{min}$. This, along with a treatment time of 112 minutes, yielded an electricity consumption of $0.0206 \mathrm{kwh} / \mathrm{L}$ and an iron consumption of $3.83 \mathrm{~g} / \mathrm{L}$. 
The study showed aeration to be necessary in achieving EPA discharge limits for complex cyanide removal. The use of aeration decreased the final concentration of complex cyanide from 4.1 to $0.91 \mathrm{mg} / \mathrm{L}$ after 2 hours of treatment. Testing also revealed direct reduction of metallic contaminants to the cathode to be another method of removal. Overall, the study shows electrocoagulation to be technologically and economically viable when treating high speed electroplating effluent. Due to the chosen conditions, the process also has the possibility of being extended to continuous treatment in the future. 


\section{ACKNOWLEDGMENTS}

First I would like to thank my major professor Dr. Otto Gregory. Not only were the 2 classes I took with you, both undergraduate and graduate, some of my favorites in the Chemical Engineering curriculum, but you showed support and lent advice to a student who wanted to take the next step in his education but wasn't quite sure which way to go.

Next I would like to thank the management team at Materion Technical Materials in Lincoln RI. Trying to further your education while working full time is a difficult endeavor. The support and understanding they showed during the past 3 years has been critical to both my academic and industrial success. Hopefully the skills I have learned will be beneficial to the strength of the company, and we will all continue to grow.

Finally, I would also like to thank family and friends for their continuing support, especially Kim Maleski. Without her leading through example and showing constant encouragement I would not have been able to make it to this point. 


\section{TABLE OF CONTENTS}

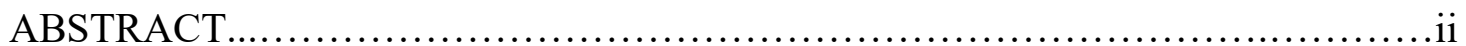

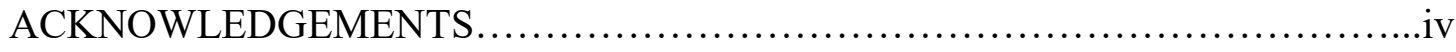

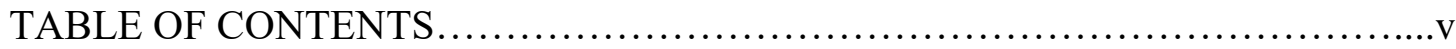

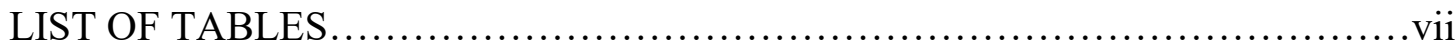

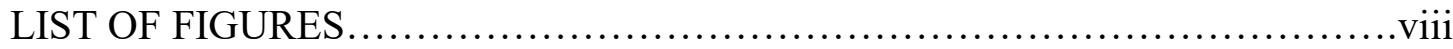

GLOSSARY OF TERMS ........................................................

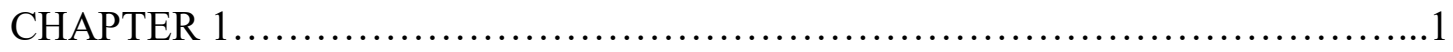

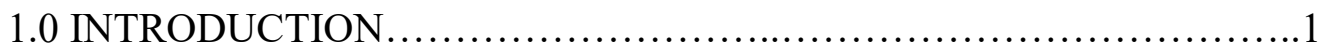

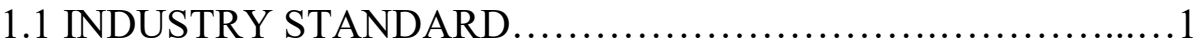

1.2 ELECTROCOAGULATION BASICS...........................4

1.3 BASICS OF COAGULATION AND FLOCCULATION............7

1.4 CHEMICAL REACTION KINETICS..........................11

1.5 IDEAL SALT CONCENTRATION...............................14

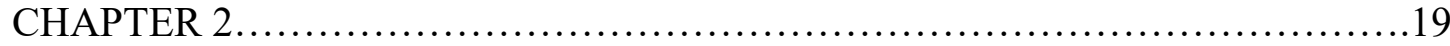

2.0 REVIEW OF LITERATURE..........................................19

2.1 TREATMENT OF METALS..................................19

2.2 TREATMENT OF FREE CYANIDE...........................28

2.3 TREATMENT OF METAL-CYANIDE COMPLEXES............32

2.4 AGITATION IN SWEEP FLOCCULATION.....................36

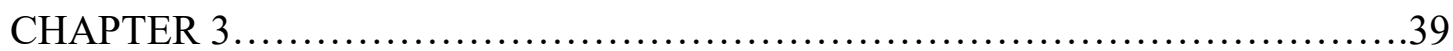

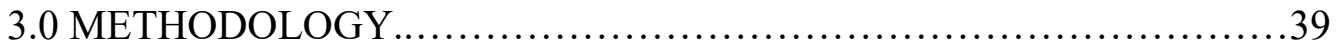

3.1 REAGENTS AND APPARATUS................................39 
3.2 SAMPLING PROCEDURE................................42

3.3 CHOICE OF TEST VARIABLES ...........................45

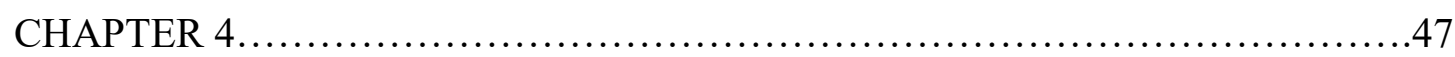

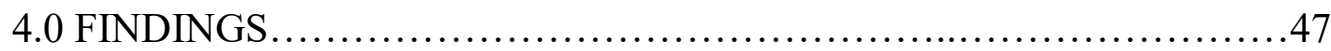

4.1 HYPOTHESES.........................................47

4.2 TIN SOLUBILITY DATA.$\ldots \ldots \ldots \ldots \ldots \ldots \ldots \ldots \ldots \ldots \ldots \ldots$

4.3 EFFECT OF CYANIDE CONCENTRATION ON METAL

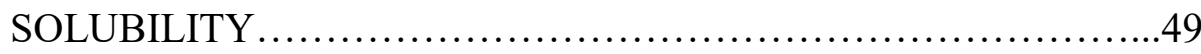

4.4 EFFECT OF CURRENT DENSITY ON METAL REMOVAL...50

4.5 EFFECT OF STIRRING AGITATION...........................56

4.6 DEPARTURE FROM FIRST ORDER KINETICS...............61

4.7 CYANIDE REMOVAL: NO AERATION......................64

4.8 CYANIDE REMOVAL: WITH AERATION ..................66

4.9 METAL REMOVAL: WITH AERATION.....................70

4.10 INSOLUBLE ANODE.................................72

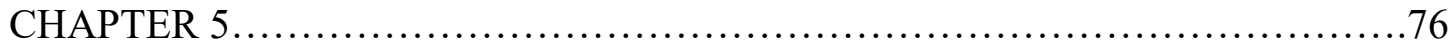

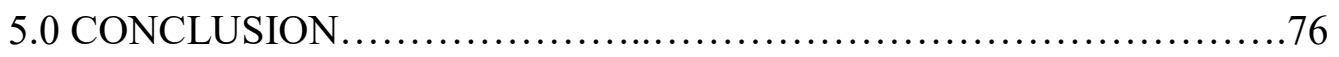

5.1 FUTURE WORK............................................. 77

APPENDIX A: ATOMIC ABSORPTION PROCEDURE...........................79

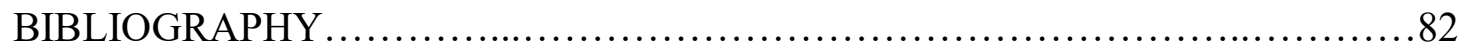




\section{LIST OF TABLES}

TABLE

PAGE

Table 1: Wastewater contaminant profile (Akbal and Camci 2011).................21

Table 2: First/second order reaction coefficients and $\mathrm{R}^{2}$ values for contaminant

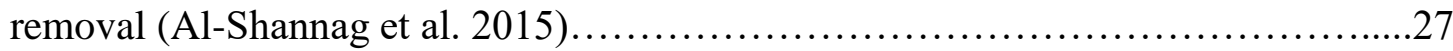

Table 3: Pseudo-First order reaction coefficient and $\mathrm{R}^{2}$ values for contaminant

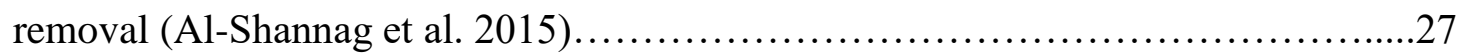

Table 4: EPA Wastewater Discharge Limits.................................44

Table 5: Standard Atomic Absorption Conditions for $\mathrm{Cu}, \mathrm{Ni}, \mathrm{Sn} . . . \ldots \ldots \ldots \ldots \ldots . . . . . . . .79$

Table 6: Standard Concentrations Utilized During Experimentation.................80

Table 7: AAS Detection Limit for Tin Metal.................................... 81 


\section{LIST OF FIGURES}

FIGURE

PAGE

Figure 1: Equilibrium concentrations of various metal ions in aqueous solution verses $\mathrm{pH}$.

(U.S. Environmental Protection Agency Office of Water Programs)...................2

Figure 2: Percent Formation of $\mathrm{CN}$ - and $\mathrm{HCN}$ as a function of $\mathrm{pH}$ (Parga et al. 2013)

Figure 3: Chemical reactions for the standard 2 stage process for the treatment of cyanide $($ Amarnath et al. 2014) ...........................................

Figure 4: Formation of iron and hydroxide ions during electrocoagulation (Kobya et

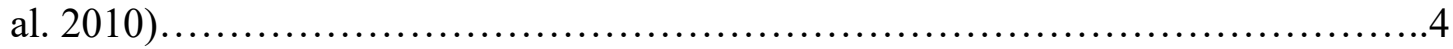

Figure 5: Iron hydroxide polymerization/condensation reaction. (Kobya et al. 2010)...5

Figure 6: Proposed mechanism for pollutant removal during electrocoagulation.

(Kobya et al. 2010) ..........................................................5

Figure 7: Physical processes occurring within electrocoagulation (Holt et al. 2002)...6

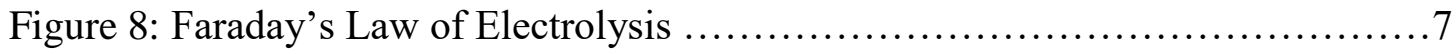

Figure 9: Equation for Electrostatic Repulsion Force Between 2 Spheres ............8

Figure 10: Equation for Van Der Waals Attractive Force Between 2 Spheres .........8

Figure 11: Summation of Forces in a Colloidal System (Zeta-Meter Inc. 1993)........9

Figure 12: Schematic representation of polymer bridging as a form of coagulation

(Zeta-Meter Inc. 1993)...............................................

Figure13: Illustration of double layer compression mechanism for colloidal destabilization. (Zeta-Meter Inc. 1993) ...................................... 10 
Figure14: Illustration of Colloidal Destabilization through Sweep Flocculation (Zeta-

Meter Inc. 1993) ..................................................... 11

Figure 15: Differential Form of a Zero Order Reaction ............................... 12

Figure 16: Integration of Differential Zero Order Reaction .......................12

Figure 17: Linear Form of a Zero Order Reaction ..............................12

Figure 18: Rearrangement of equation 17 for Half Life Calculation ................. 12

Figure 19: Half Life of a Zero Order Reaction ............................... 12

Figure 20: Differential Form of a First Order Reaction .................................12

Figure 21: Integration of Differential First Order Reaction .......................12

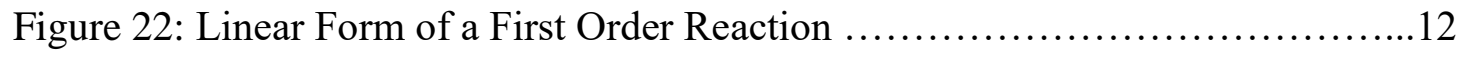

Figure 23: Rearrangement of equation 22 for Half Life Equation ...................13

Figure 24: Rearrangement of equation 23 for Half Life Equation ..................13

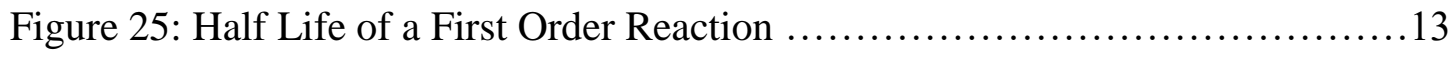

Figure 26: Differential Form of a Second Order Reaction ..........................13

Figure 27: Integration of Differential Second Order Reaction .....................13

Figure 28: Linear Form of a Second Order Reaction $\ldots \ldots \ldots \ldots \ldots \ldots \ldots \ldots \ldots \ldots \ldots \ldots$

Figure 29: Rearrangement of equation 28 for Half Life Equation ...................14

Figure 30: Rearrangement of equation 28 for Half Life Equation ................... 14

Figure 31: Rearrangement of equation 28 for Half Life Equation .................. 14

Figure 32: Half Life of a First Order Reaction .............................. 14

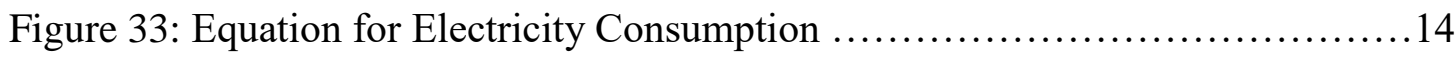

Figure 34: Curve fit for Solution Resistivity as a Function of Salt Concentration ....15

Figure 35: Formula for Electrical Resistance from Resistivity $\ldots \ldots \ldots \ldots \ldots \ldots \ldots \ldots 15$ 
Figure 36: Resistivity as a function of Salt Concentration 16

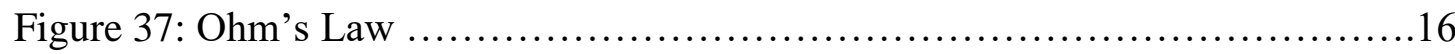

Figure 38: Voltage as a Function of Salt Concentration..............................16

Figure 39: Faraday’s Law of Electrolysis .......................................16

Figure 40: Total Operating Cost in Electrocoagulation Cell .......................16

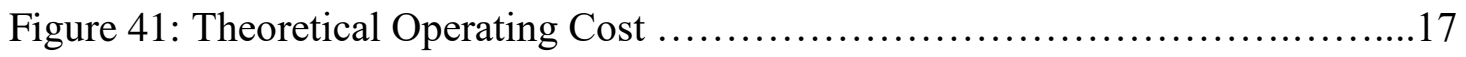

Figure 42: Theoretical Optimum Salt Concentration ...............................17

Figure 43: Removal rate of $\mathrm{Cu}^{+2}$ (a), $\mathrm{Zn}^{+2}$ (b), and $\mathrm{Cr}(\mathrm{VI})$ (c) (Adhoum et al. 2004)..19

Figure 44: Graph relating Initial pH to contaminant removal efficiency (Adhoum et

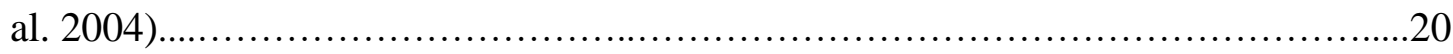

Figure 45: Effect of conductivity and anode configuration on copper removal (Akbal

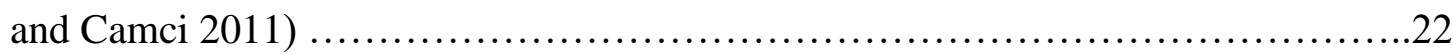

Figure 46: Effect of conductivity and anode configuration on chromium removal

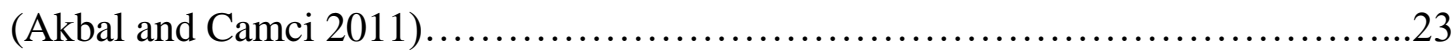

Figure 47: Effect of conductivity and electrode configuration on nickel removal

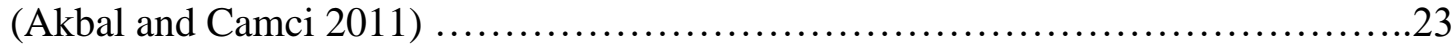

Figure 48: Effect of $\mathrm{pH}$ on contaminant removal (a) before electrocoagulation (b) after electrocoagulation (Al-Shannag et al. 2015)...................................25 Figure 49: Removal efficiency of $\mathrm{Cu}, \mathrm{Ni}, \mathrm{Cr}$, and $\mathrm{Zn}$ as a function of current density

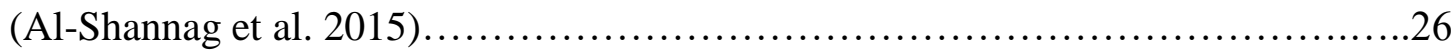

Figure 50: Differential form of a pseudo-first order reaction.......................26

Figure 51: Integration of pseudo-first order reaction equation.....................26

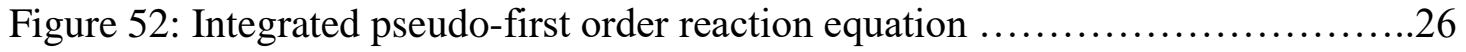


Figure 53: Linear form of pseudo-first order reaction equation...................26

Figure 54: Non-linear form of pseudo-first order reaction equation.................26

Figure 55: Removal Efficiency as a Function of anode-cathode material (Moussavi et

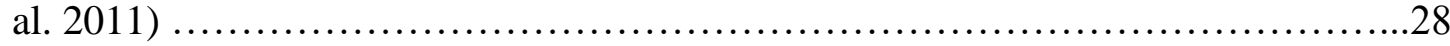

Figure 56: Cyanide removal rate with varying current density (Moussavi et al. 2011)

Figure 57: Effect of Aeration on Cyanide Removal Efficiency (Moussavi et al. 2011)

Figure 58: Effect of starting voltage on cyanide removal efficiency. CN Concentration

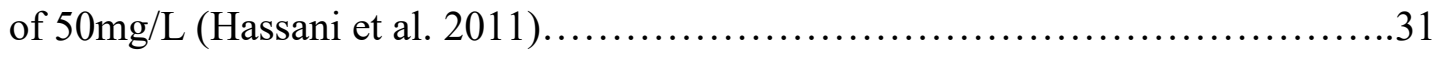

Figure 59: Optimum $\mathrm{pH}$ for cyanide destruction A. Cadmium Cyanide B. Nickel

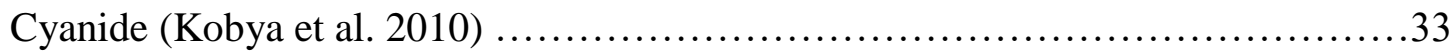

Figure 60: Effect of initial $\mathrm{pH}$ on (a) cyanide and (b) zinc removal efficiency

(c) Effect of electrode material on Zinc and Cyanide Removal (Senturk 2013) ......35

Figure 61: Effect of current density on cyanide (a) and zinc (b) removal efficiency at a

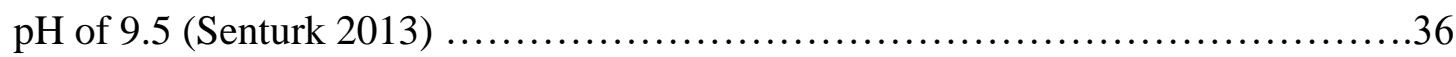

Figure 62: Size difference of floccules with rapid and slow mixing times (Ghernaout and Ghernaout 2012) .37

Figure 63: Difference in ability of charge neutralization and sweep flocculation to break and re-flocculate (Ghernaout and Ghernaout 2012) .........................

Figure 64: Lab Scale Testing Apparatus: Illustration ...........................39

Figure 65: Lab Scale Testing Apparatus: Photograph ...........................40

Figure 66: $\mathrm{pH}$ and Temperature Probe Suspended by Ring Stand..................41 
Figure 67: Sludge generated during sampling allowed to settle.

Figure 68: Concentrated Floc Generated on top of Solution Through Flotation......43

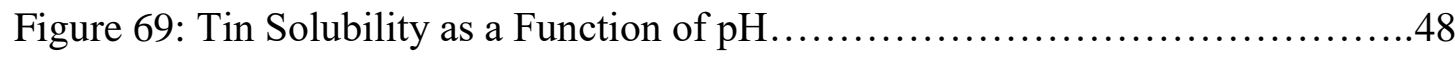

Figure 70: Copper Hydroxide Equilibrium Equation............................49

Figure 71: Nickel Hydroxide Equilibrium Equation..............................49

Figure 72: Tin Hydroxide Equilibrium Equation.............................49

Figure 73. Copper Cyanide Equilibrium Equation............................49

Figure 74: Nickel Cyanide Equilibrium Equation..............................49

Figure 75: Tin Cyanide Equilibrium Equation.................................49

Figure 76: Dependence of Metal Concentration on Cyanide Concentration............50

Figure 77: Metal Removal at 25 ASF..........................................51

Figure 78: First Order Rate Constant Plot: Full Data, 25 ASF...................51

Figure 79: First Order Rate Constant Plot: Linear Region, 25 ASF................52

Figure 80: Metal Removal at 50 ASF ......................................52

Figure 81: First Order Rate Constant Plot: Full Data, 50 ASF....................53

Figure 82: Metal Removal at 75 ASF ......................................53

Figure 83: First Order Rate Constant Plot: Full Data, 75 ASF.....................54

Figure 84: First Order Rate Constant Plot: Linear Region, 75 ASF.................54

Figure 85: Rate Constant Plot for Optimization of Current Density $\ldots \ldots \ldots \ldots \ldots \ldots . \ldots 55$

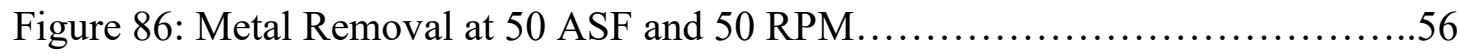

Figure 87: First Order Rate Constant Plot: Full Data, 50 ASF, 50 RPM............57

Figure 88: First Order Rate Constant Plot: Linear Region, 50 ASF, 50 RPM........57

Figure 89: Metal Removal at 50 ASF and 100 RPM..........................58 
Figure 90: First Order Rate Constant Plot: Full Data, 50 ASF, 100 RPM............58

Figure 91: First Order Rate Constant Plot: Linear Region, 50 ASF, 100 RPM.......59

Figure 92: Metal Removal at $50 \mathrm{ASF}$ and 300 RPM...........................59

Figure 93: First Order Rate Constant Plot: Full Data, 50 ASF, 300 RPM...........60

Figure 94: First Order Rate Constant Plot: Linear Region, 50 ASF, 300 RPM.......60

Figure 95: Rate Constant Plot for Optimization of Spin Speed....................61

Figure 96: Copper Removal Plot demonstrating departure from first order kinetics at

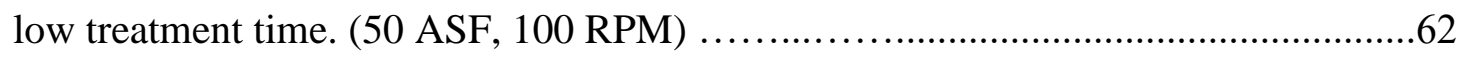

Figure 97: First Order Coefficient plot demonstrating departure from first order

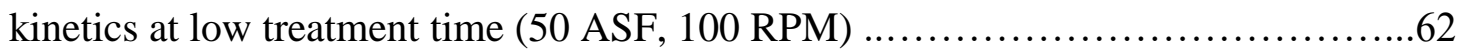

Figure 98: Influence of Initial Copper Concentration on First Order Reaction Kinetics

Figure 99: Cyanide Removal at 50 ASF, 0RPM............................65

Figure 100: First Order Rate Constant Plot: Cyanide, Full Data, 50 ASF, 0 RPM....65

Figure 101: Cyanide Removal at 50 ASF, 0RPM, $0.0021 \mathrm{ft}^{3} / \mathrm{min}$ Air Flow..........66

Figure 102: Pseudo-First Order Rate Constant Plot: Cyanide, Full Data, 50 ASF,

0 RPM, $0.0021 \mathrm{ft}^{3} / \mathrm{min}$ Air Flow, Equilibrium Concentration $0.72 \mathrm{mg} / \mathrm{L} \ldots \ldots \ldots . . .67$

Figure 103: Cyanide Removal at 50 ASF, 0RPM, $0.0042 \mathrm{ft}^{3} / \mathrm{min}$ Air Flow..........67

Figure 104: First Order Rate Constant Plot: Cyanide, Full Data, 50 ASF, 0 RPM,

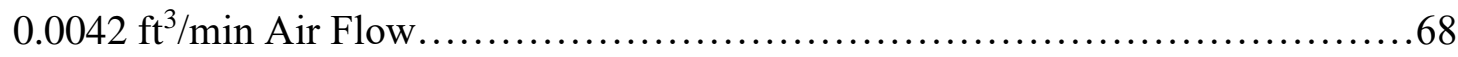

Figure 105: Cyanide Removal at 50 ASF, 0RPM, $0.0069 \mathrm{ft}^{3} / \mathrm{min}$ Air Flow..........68

Figure 106: First Order Rate Constant Plot: Cyanide, Full Data, 50 ASF, 0 RPM,

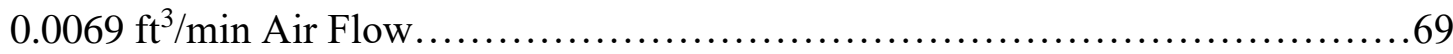


Figure 107: Metal Removal at 50 ASF, 0 RPM, $0.0021 \mathrm{ft}^{3} / \mathrm{min}^{3}$ Air Flow Rate.

Figure 108: First Order Rate Constant Plot: Metals, Full Data, 50 ASF, 0 RPM,

$0.0021 \mathrm{ft}^{3} / \mathrm{min}$ Air Flow

Figure 109: First Order Rate Constant Plot: Metals, Linear Region, 50 ASF,0 RPM,

$0.0021 \mathrm{ft}^{3} / \mathrm{min}$ Air Flow

Figure 110: Anode (Left) Cathode (Right) After Electrocoagulation Trials showing copper plating. .72

Figure 111: Metal Removal at 50 ASF, 300 RPM, Platinized Titanium Anode........73

Figure 112: First Order Rate Constant Plot: Metals, Full Data, 50 ASF, 300 RPM,

Platinized Titanium Anode.

Figure 113: First Order Rate Constant Plot: Metals, Linear Region, 50 ASF, 300 RPM, Platinized Titanium Anode.................................................... 74

Figure 114: Zero Order Reaction Kinetics Displayed for Copper Removal Using an Insoluble Anode.............................................................. 75

Figure 115: Formula for AAS Detection Limit Using 3 Standard Deviations..........81 


\section{GLOSSARY OF TERMS}

A

Aggregation - In colloidal chemistry aggregation is the collection of units or parts into a mass or whole after destabilization has occurred.

Amphoteric - A species which which can react by either donating or accepting a proton.

ASF - English unit for current density equal to amps $/ \mathrm{ft}^{2}$

B

Bipolar Connection - An electrode configuration in which sufficiently high electric field induces both cathodic and anodic reactions at the same electrode. Only 1 electrode is electrically connected to the power source.

Boltzmann Constant - Equal to the ideal gas constant $(\mathrm{R})$ divided by avogadro's constant $\left(\mathrm{N}_{\mathrm{A}}\right)$, it relates thermal energy at the microscopic level.

Polymer Bridging - In wastewater treatment polymeric substances are often used to flocculate suspended particles from solution. The main mechanism for this action is active sites on the polymer which can be tuned to target specific contaminants. Once absorbed to the polymer it can settle out of solution due to the large molecular weight. Bulk Concentration - In electrochemistry the bulk concentration is the analyte concentration far enough from a charged surface where virtually no concentration gradient exists.

$\mathrm{C}$

Characteric Concentration - In atomic absorption spectrometry the characteristic concentration is the analyte concentration which produces a $1 \%$ absorbance signal. This corresponds to 0.0044 absorbance units.

Characteristic Concentration Check - In atomic absorption spectrometry the characteristic concentration check is the analyte concentration which produces a signal of 0.2 absorbance units. It represents a concentration which is high enough to reduce natural variation and is used to determine that the device is reading correctly. Charge Neutralization - Usually accomplised by relatively small salt additions, charge neutralization is accomlished when ions adsorb to the surface of a colloidal particle reducing the charge and allowing aggregation.

Coagulation - In colloidal chemistry coagulation is the reduction of the repulsive forces keeping microscopic colloidal particles apart inducing flocculation. It can be accomplised by double layer compression, polymer bridging, charge neutralization or sweep flocculation.

Colloid - A solution in which one microscopic substance is dispersed within another. It occurs in particles with a high surface area to mass ratio where intermolecular forces dominate the force of gravity.

Colloidal Destabilization - See Coagulation

Condensation Reaction - A polymerization reaction in which two molecules combine to form a larger molecule releasing smaller one. Most commonly this smaller entity is water.

Current Density - A common metric in electrochemistry, current density is the current being passed through an electrode divided by the surface area of the electrode. It is used to estimate and compare mass transport limitations. 


\section{$\mathrm{D}$}

DLVO Theory - A theory describing the forces present within colloids. It is named using the initials of its founders Boris Derjaguin, Lev Landau, Evert Verwey, and Theodoor Overbeek. Attractive forces are commonly modeled using van der Waals interactions. Repulsive forces are commonly modeled using electrostatic repulsion. At the center of the theory it uses the net attraction or repulsion derived by summing these 2 forces to predict the state of the colloid.

Debye length - A measure of the distance from an electric charge in solution in which electrostatic effects still persist. At distances larger than this length the charge is effectively screened.

Double Layer Compression - When a large amount of salt is added to a colloidal dispersion the charges begin to oppose the electrical double layer which in turn compresses its effects. Once a threshold is reached the colloid destabilizes and begins to aggregate.

$\mathrm{E}$

Electrical Double Layer - In solution electrochemistry an electrical double layer is the approximately two atom thick layer of oppositely charged particles which forms on a charged surface in solution.

Electrocoagulation - The use of a dissolving iron or aluminum anode to electrochemically treat wastewater through sweeping hydroxide flocculation.

Electrostatic Repulsion - The repulsive force which arises when 2 like charges approach each other in solution. It is an exponential function of distance for 2 small spheres.

$\mathrm{F}$

Ferric Ion - Iron containing materials in which the iron oxidation state is +3 .

Ferrous Ion - Iron containing materials in which the rion oxidation state is +2 . Flocculation - Reversible association in which individual particles aggregate after destabilization.

Floccule - A group of reversibly aggregated particles.

G

Ground State Atom - The electron configuration of an atom at its lowest energy state $\mathrm{H}$

Half Life - In reaction chemistry it is the amount of time required for an analyte to reach half of its initial value.

Hamaker Constant - In colloidal chemistry the hamaker constant is a numerical value, derived from experimentation, that represents the attractive van der Waals forces between 2 objects through a specific medium.

Hydroxide Precipitation - The use of $\mathrm{pH}$ to drive dissolved metal equilibrium toward hydroxide formation. It is often used in waste water treatment.

I

Inverse Debye Length -1 divided by the debye length.

L

Linear Range - In Atomic absorption spectrometry, the linear range represents the maximum analyte concentration for a particular wavelength in which the absorption in still linear with respect to concentration. 
Monopolar Connection - An electrical connection in which the positive and negative electrodes are separated by the working solution and connected. Both electrodes are connected to the electrical source.

$\mathrm{R}$

Relative Noise - In atomic absorption spectrometry the relative noise is a neumerical value used to represents the instability inherent in each wavelength. It is used to decide the best wavelength for the sample being tested.

$\mathrm{S}$

Sedimentation - A physical process in which gravity causes suspended particles to settle out of solution.

Slit Size - In atomic absorption spectrometry the slit size is the physical measurement of the orifice through which the wavelength passes for measurement. Often on the order of nanometers, larger slit sizes usually offer higher sensitivity.

Stern Layer - See electrical double layer

U

Ultrafiltration - A type of filtration which employs size exclusion through the use of membranes and a pressure gradient to separate materials.

$\mathrm{V}$

Van der Waal Forces - Attractive forces which arise at short distances. Can be the result of induced dipoles, permanent dipoles or hydrogen bonding. 


\section{CHAPTER 1}

\subsection{INTRODUCTION}

Wastewater treatment represents a substantial cost associated with electroplating facilities. As such there will always be an economic driver to reduce its cost. Even though there is a financial incentive to treating wastes and reducing contaminants in wastewater streams, the more important issue is the protection of the environment. Treating effluent is the final step in any industrial electroplating process. Therefore, it becomes paramount to remove any heavy metals and cyanide from waste streams, which would otherwise damage the environment. As such, it must not only be an economically viable process, but must be technologically able to meet the stringent regulations set forth by the United States EPA.

\subsection{INDUSTRY STANDARD}

Hydroxide precipitation is the main method of heavy metal water purification used in industry today (U.S. Environmental Protection Agency Office of Water Programs). The capacity of metals to form insoluble hydroxides is strongly dependent on $\mathrm{pH}$. The following diagram shows the equilibrium concentrations of metal ions present in aqueous solution at different $\mathrm{pH}$ values: 


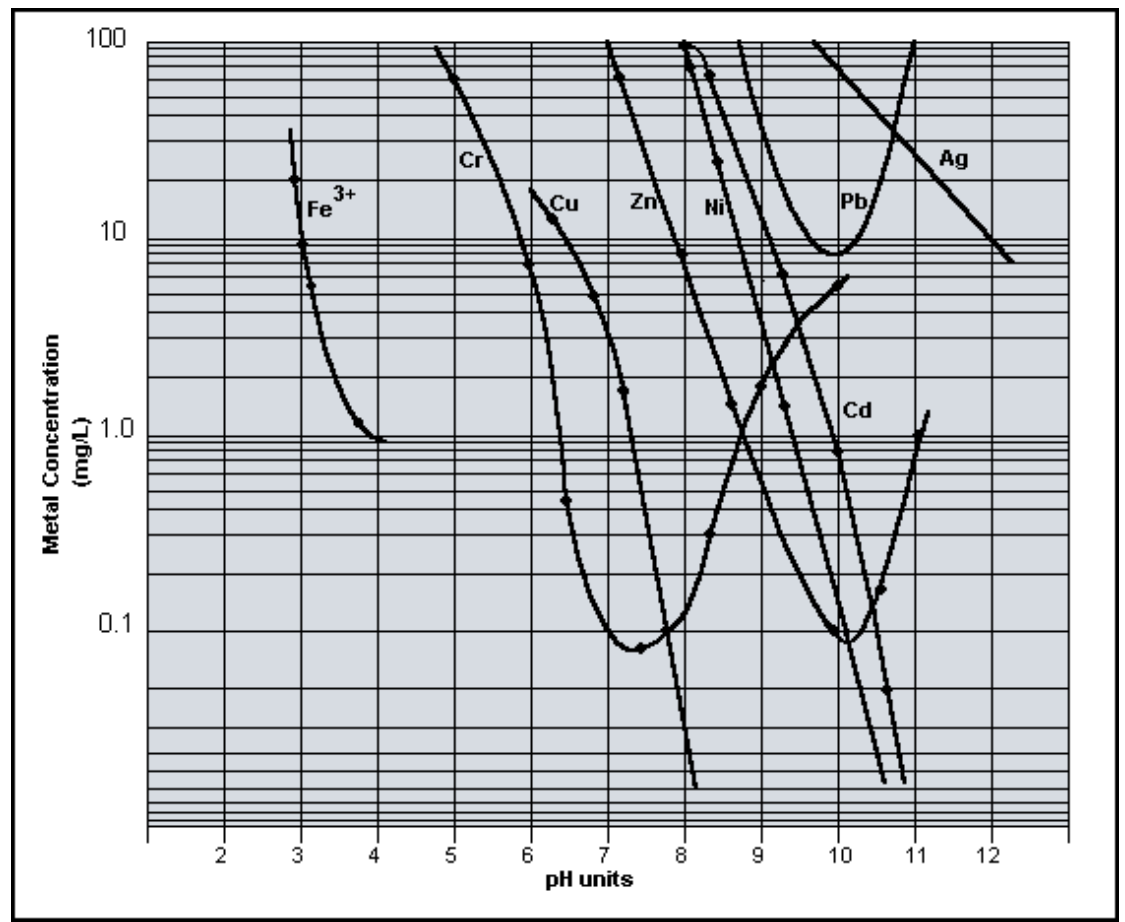

Figure 1: Equilibrium concentrations of various metal ions in aqueous solution verses $\mathrm{pH}$ (U.S. Environmental Protection Agency Office of Water Programs)

As shown in figure 1 , there is no single $\mathrm{pH}$ value which will remove all the metals above to EPA permissible levels. Depending on the target metals, this may lead to multiple $\mathrm{pH}$ adjustments followed by sedimentation and filtration to remove the insoluble hydroxides separately. The duplication of equipment necessary to insure precipitation and removal only serves to increase the capital cost with these systems. The $\mathrm{pH}$ adjustments are typically done using $\mathrm{Ca}(\mathrm{OH})_{2}$ (lime) or $\mathrm{NaOH}$ (caustic). Calcium hydroxide is usually preferred due to its lower cost but comes with the caveat of increasing sludge generation. This sludge must be removed through sedimentation and ultrafiltration or bridging polymers prior to discharge.

Wastewater from most precious metal electroplating plants will typically contain cyanide (Amarnath et al. 2014). This is because cyanide forms complexes with gold and silver and are widely used in precious metal electroplating baths 
(Schesinger and Paunovic 2010). Cyanide is a poisonous chemical which readily forms strong complexes with many non-precious metals as well. This causes treatment to be more difficult. It also forms dangerous and volatile hydrogen cyanide gas according to the conditions shown in figure 2 below.

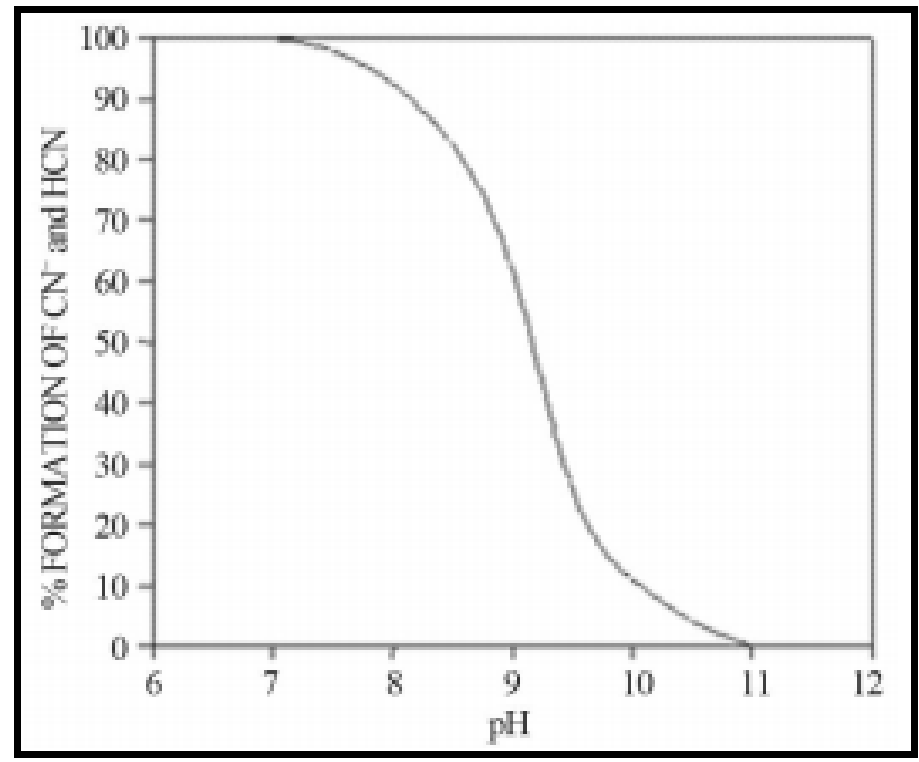

Figure 2: Percent Formation of HCN as a function of $\mathrm{pH}$ (Parga et al. 2013)

As shown, the concentration of hydrogen cyanide created is a function of $\mathrm{pH}$. Above a $\mathrm{pH}$ of 11, the cyanide remains completely dissolved in the form of $\mathrm{CN}^{-}$. Below a pH of 7, all of the cyanide present is converted to molecular $\mathrm{HCN}$. $\mathrm{HCN}$ has a boiling point of $299 \mathrm{~K}$ at atmospheric pressure, and a vapor pressure of $0.80 \mathrm{ATM}$ at room temperature (20 C) (National Institute of Standards and Technology). This information gives some insight into the high evaporation rate of hydrogen cyanide under ambient processing conditions.

The standard chemical process for the treatment of cyanide involves two steps. The first step is oxidation of cyanide ion to cyanate ion at a $\mathrm{pH}$ of at least 10 using sodium hypochlorite (chlorine bleach). The second step is the conversion of the 
cyanate ion to volatile and non-poisonous carbon dioxide and nitrogen gas using additional sodium hypochlorite. This reaction occurs fastest at a $\mathrm{pH}$ of 8.5 (Amarnath et al. 2014).

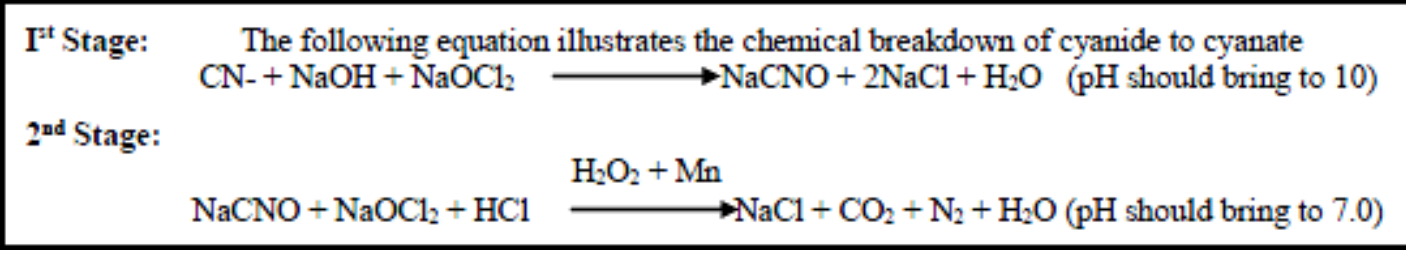

Figure 3: Chemical reactions for the standard 2 stage process for treatment of cyanide (Amarnath et al. 2014)

\subsection{ELECTROCOAGULATION BASICS}

Electrocoagulation, or the use of electricity and iron plates to treat wastewater, is not a new idea. The concept dates back to the late 1800's with the first patent for "purification of wastewater by electrolysis using corroding electrodes" submitted in 1909 (Vik 1984). In electrocoagulation, a sacrificial anode is used to supply metal ions to an aqueous solution. Aluminum and iron are the most widely used anode/cathode plate materials. Since iron has shown greater removal efficiency and is less expensive, we will focus on reactions involving it as the electrode material in the proposed study (Moussavi et al. 2011).

The reactions based on an iron plate electrode proceed as follows:

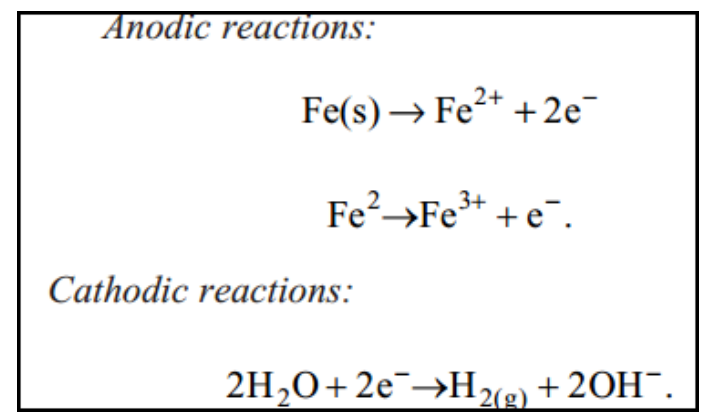

Figure 4: Formation of iron and hydroxide ions during electrocoagulation (Kobya et al. 2010) 
Iron ions generated at the anode combine with hydroxide ions, either generated at the cathode or present in solution by starting $\mathrm{pH}$, to form insoluble iron hydroxides. These hydroxides can undergo polymerization/condensation reactions as follows:

$$
\begin{gathered}
\mathrm{Fe}(\mathrm{OH})_{2}+\mathrm{Fe}(\mathrm{OH})_{2} \rightarrow(\mathrm{OH}) \mathrm{Fe}-\mathrm{O} \\
-\mathrm{Fe}(\mathrm{OH})+\mathrm{H}_{2} \mathrm{O} .
\end{gathered}
$$

Figure 5: Iron hydroxide polymerization/condensation reaction (Kobya et al. 2010) The polymerized iron hydroxides form large three-dimensional structures, which are largely insoluble and precipitate from solution. Metal ions and colloidal particles adsorb onto these surfaces as the coagulation process proceeds. This mechanism is responsible for destabilization and final aggregation of the material targeted for removal (Kobya et al. 2010).

$$
\begin{gathered}
\mathrm{Fe}(\mathrm{OH})_{2}+\mathrm{Me}^{\mathrm{z}+} \Leftrightarrow \mathrm{Fe}(\mathrm{OH})_{(2-\mathrm{z})} \\
(\mathrm{O})_{\mathrm{z}} \mathrm{Me}_{(\mathrm{s})}+\mathrm{zH}^{+}
\end{gathered}
$$

Figure 6: Proposed mechanism for pollutant removal during electrocoagulation (Kobya et al. 2010)

In addition to the chemical aspects of metal removal, the conditions in the electrocoagulation cell can also be optimized to concentrate the metals based on hydrodynamics. This is illustrated in the following figure. 


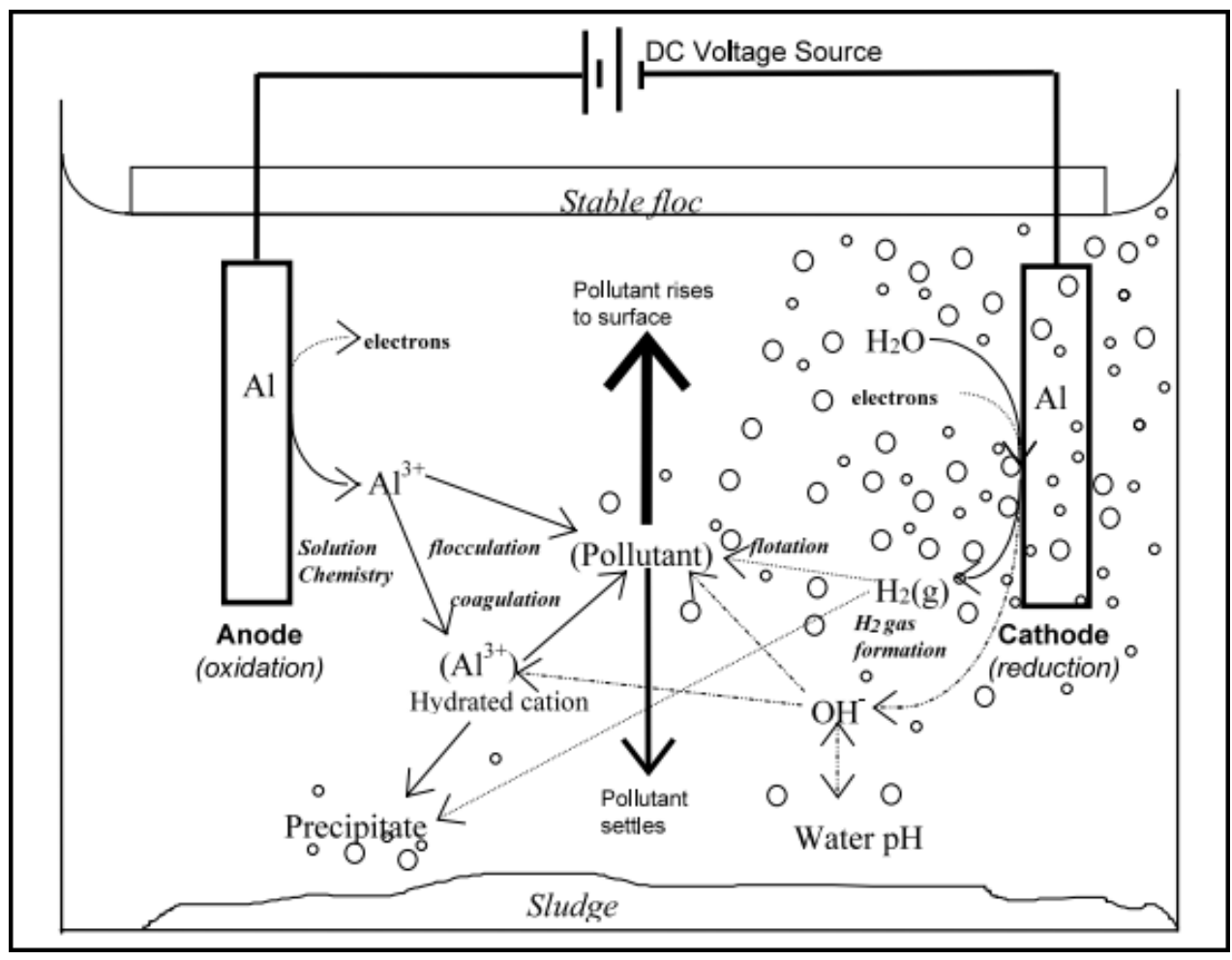

Figure 7: Physical processes occurring within electrocoagulation (Holt et al. 2002)

As shown in Figure 7, the hydrolysis of water creates two regions of concentrated floc. Hydrogen gas formed at the cathode rises to the surface in the reactor. This motion tends to move or sweep the newly formed floccules towards the surface as they become entrained by the gas bubbles. If the floccule does not become entrained, it will eventually settle to the bottom of the tank in a more typical fashion. The relative amounts of surface vs. bottom sludge can be controlled by gas generation. This is typically a function of current density at the cathode and solution agitation (Holt et al. 2002). Having areas of concentrated waste can be beneficial by streamlining subsequent filtration steps.

In addition to increased agitation through gas bubble generation, higher current densities also increase the rate of contaminant removal through anode dissolution. 
This rate of anode dissolution follows Faraday's Law of Electrolysis according to the equation below:

$$
\begin{array}{lll}
\qquad m=\frac{I t M}{Z F} & \\
\text { m=mass of iron dissolution }(\mathrm{g}), & \mathrm{t}=\text { Time } \\
\mathrm{I}=\text { Current }(\mathrm{A}), & \mathrm{M}=\text { Molar Mass of } \mathrm{Fe}(55.845 \mathrm{~g} / \mathrm{mol}) \\
\mathrm{Z}=\text { Oxidation state of Fe (2 or 3) } & \mathrm{F}=\text { Faradays constant }(96486 \mathrm{C} / \mathrm{mol})
\end{array}
$$

It stands to reason that as you increase the current in the system your anode will dissolve quicker. This leads to higher concentrations of iron hydroxide floc at shorter treatment times which in turn can reduce total treatment time (Dermentzis et al. 2011).

\subsection{BASICS OF COAGULATION AND FLOCCULATION}

Electrocoagulation has been shown to effectively treat both dissolved and colloidal material (Matteson et al. 1995, Kobya et al. 2010). A colloid is a homogeneous mixture where one insoluble phase is dispersed in another. Extremely small particles $(0.001$ to $10 \mu \mathrm{m})$ tend to have a large surface area to mass ratio. Under these conditions intermolecular forces dominate the force of gravity and thus the dispersed phase remains dispersed (Ghernaout and Ghernaout 2012). Coagulation is the irreversible reduction of the forces which serve to keep these particles apart. Flocculation is the reversible agglomeration of the particles into larger particles once coagulation has occurred.

DLVO theory can be used to help explain the forces in a typical colloidal system. In this theory, the 2 main forces at work are electrostatic repulsion and Van der Waals attraction. Electrostatic repulsion is a function of the surface charge of the colloid. It increases exponentially as the 2 surfaces approach each other. The 
following is the equation for electrostatic repulsion of 2 charged spherical objects at very small separations (kh>>1, R1 and R2 >> h) (Evans and Hakan 1999):

$$
F=128 \pi \frac{R_{1} R_{2}}{R_{1}+R_{2}} \frac{k T}{\kappa} c^{*} \Gamma_{10} \Gamma_{20} \exp (-\kappa h)
$$

$\mathrm{R} 1=$ Radius of first sphere

$\mathrm{R} 2=$ Radius of second sphere $\mathrm{k}=$ Boltzmann constant

$\mathrm{C}^{*}=$ Bulk concentration
$\mathrm{T}=$ Temperature $\kappa=$ Inverse Debye Length $\mathrm{h}=$ Separation distance

$\Gamma_{10} \Gamma_{20}=$ Geometric Means $=\tanh \left(\mathrm{z}^{*} \mathrm{e}^{*} \phi \mathrm{o} / \mathrm{kt}\right)$

Van der Waals forces are forces which arise between individual molecules and atoms and occur at extremely short distances. Depending on the system, they can be the result of induced dipoles, permanent dipoles or hydrogen bonding. Modeling these forces are a function of the individual materials, through Hamaker Constants, and inversely proportional to six times the separation distance squared for 2 spheres at short distances (Evans and Hakan 1999):

$$
F=\frac{H_{12}}{6 h^{2}} \frac{R_{1} R_{2}}{R_{1}+R_{2}}
$$

H12=Hamaker Constant $\mathrm{h}=$ Separation Distance
R1=Radius of first sphere $\mathrm{R} 2=$ Radius of second sphere

Both the electrostatic repulsion force and Van der Waals Forces can be added and plotted as a function of inter-particle distance. If an energy barrier exists, the 2 surfaces will not be able to get close enough to flocculate and a colloid is formed. 


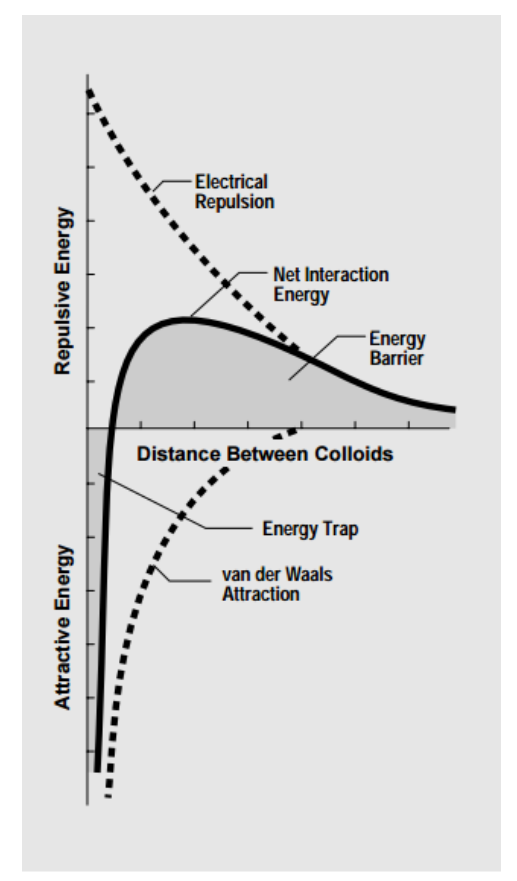

Figure 11: Summation of Forces in a Colloidal System (Zeta-Meter Inc. 1993)

Destabilization of a colloidal system can be achieved through 1 of 4 mechanisms; adsorption/bridging between particles, electrical double layer compression, charge neutralization, and entrapment of particles in precipitate (sweep flocculation) (Ghernaout and Ghernaout 2012).

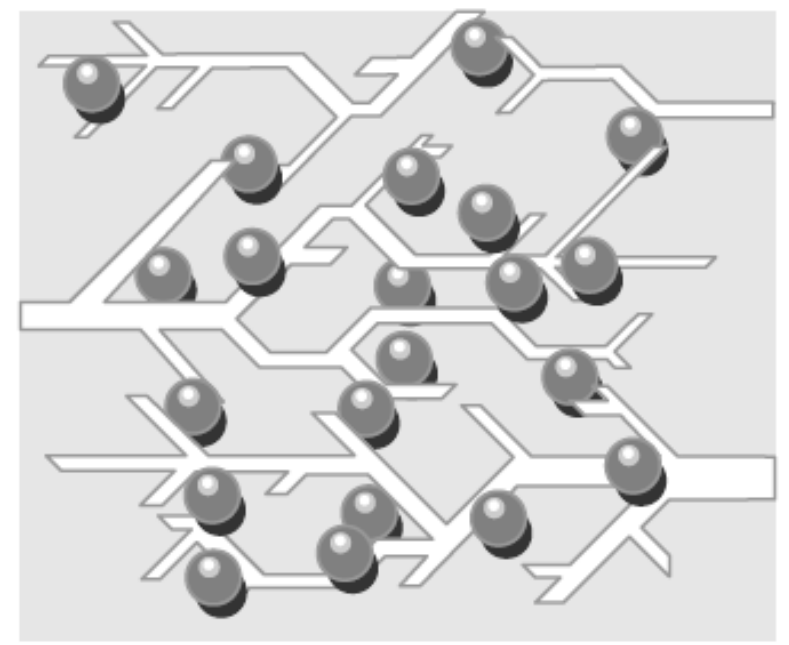

Figure 12: Illustration of polymer bridging as a form of coagulation (Zeta-Meter Inc. 1993) 
Polymer bridging uses long chain polymers to intertwine colloidal particles (Figure 12). Longer chain polymers work better than small chain and active groups can be adjusted to target specific contaminants for removal.

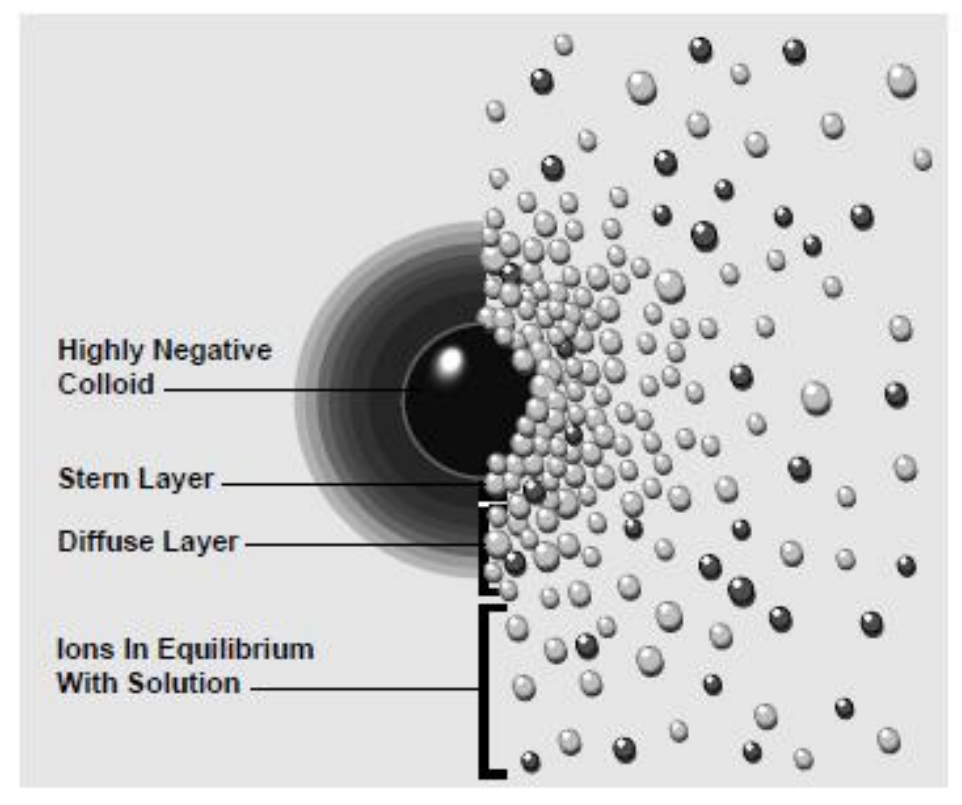

Figure13: Illustration of double layer compression mechanism for colloidal destabilization (Zeta-Meter Inc. 1993)

Double layer compression and charge neutralization are both achieved by the addition of salts but in varying amounts. In double layer compression, large amounts of salt are added to the colloidal solution. Ions are not adsorbed to the surface but rather oppose the double layer around the colloidal particle. This causes the double layer to shrink/compress lowering the energy barrier and allowing flocculation. In charge neutralization much smaller amounts of salt are added which adsorb to the particle surface. This serves to reduce (neutralize) the opposing charges of the colloidal particles and is usually more economical due to the relatively small amount of salt required. 
Sweep flocculation is the main mechanism responsible for contaminant removal in electrocoagulation. In sweep flocculation this energy barrier is overcome through the addition of large amounts of insoluble metal salts. As these salts precipitate and settle out of solution the contaminants become enmeshed and swept into the sludge (Zeta-Meter Inc. 1993). Combinations of the mechanisms above can be present at the same time when treating waste water (Ghernaout and Ghernaout 2011).

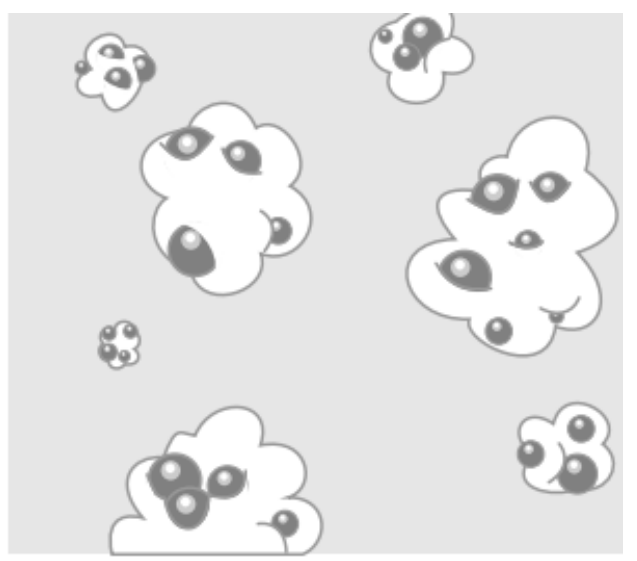

Figure14: Illustration of Colloidal Destabilization through Sweep Flocculation (Zeta-Meter Inc. 1993)

\subsection{CHEMICAL REACTION KINETICS}

Classical reaction kinetic theory shows it is possible to assign constants indicative of the reaction rate. Reactions are classified by the order in which they depend on reactant concentration and will be explained in detail in the following paragraphs. It is possible to use timed conversion data to solve for these constants graphically. Ultimately these constants can be used to compare reaction rates which becomes a good gauge of reaction speed.

The differential form of a zero order reaction can be written and integrated as follows: 


$$
\begin{gathered}
\frac{d C}{d t}=-k \\
\int_{C o}^{C} d C=-k \int_{t=0}^{t} d t \\
C=-k t+C_{0}
\end{gathered}
$$

In a zero order reaction the reactant concentration decreases linearly with time. A plot of the concentration of these reactants vs. time will yield a straight line. The slope of this line is the kinetic rate constant. In many fields the half-life of a reaction is also a popular metric. Half-life is the amount of time it takes for the reactant concentration to decrease by half the starting concentration. Through rearrangement of terms we see that the half-life of a zero order reaction will always be the initial concentration divided by 2 times the rate constant.

$$
\begin{aligned}
& \text { Half Life } \\
& c=\frac{1}{2} c_{0} \\
& t_{\frac{1}{2}}=\frac{C_{0}}{2 k}
\end{aligned}
$$

In a first order reaction, the decrease in concentration of reactants with respect to time is proportional to the concentration. This means that as the reactant concentration decreases, so too does the apparent contaminant removal rate. The differential form of a first order reaction can be written and integrated as follows:

$$
\begin{gathered}
\frac{d C}{d t}=-k C \\
\int_{C o}^{C} \frac{d C}{C}=-k \int_{t=0}^{t} d t \\
\ln C=-k t+\ln C_{0}
\end{gathered}
$$


As you can see, in a first order reaction a plot of the natural log of concentration vs. time yields a straight line. The slope of this straight line is the kinetic constant and the $\mathrm{y}$-intercept is the natural $\log$ of the initial concentration.

$$
\begin{gathered}
\text { Half Life } \\
\ln C-\ln C_{0}=-k t \\
\ln \left(\frac{C}{C_{0}}\right)=-k t \\
t_{\frac{1}{2}}=-\frac{\ln \left(\frac{1}{2}\right)}{k}=\frac{0.639}{k}
\end{gathered}
$$

In a second order reaction the reaction rate is proportional to the reactant concentration to the second power. These reactions tend to move faster due to the inverse relationship which appears after integration. The differential form of a second order reaction can be written and integrated as follows:

$$
\begin{gathered}
\frac{d C}{d t}=-k C^{2} \\
\int_{C o}^{C} \frac{d C}{C^{2}}=-k \int_{t=0}^{t} d t \\
\frac{1}{C}=k t+\frac{1}{C_{0}}
\end{gathered}
$$

As you can see, a plot of the inverse concentration vs. time yields a straight line. The slope of this line is the kinetic constant and the y-intercept is equal to the inverse initial concentration. 


$$
\begin{gathered}
\text { Half Life } \\
\frac{1}{\frac{1}{2} C_{0}}=k t+\frac{1}{C_{0}} \\
\frac{1}{\frac{1}{2} C_{0}}-\frac{1}{C_{0}}=k t \\
\frac{2}{C_{0}}-\frac{1}{C_{0}}=k t \\
t_{\frac{1}{2}}=\frac{1}{k C_{0}}
\end{gathered}
$$

\subsection{IDEAL SALT CONCENTRATION}

Upon starting the experiments in this report, it was quickly apparent that the conductivity of DI water $(<20 \mu \mathrm{S} / \mathrm{cm})$ was insufficient to carry the current necessary to reach the 75 ASF target. Sodium chloride was chosen to increase the conductivity due to low cost and availability. A theoretical analysis on ideal salt concentration was then performed. It took into account 3 factors of operation; salt cost, electricity consumption, and iron consumption.

Electricity consumption is measured in watt hours or more typically kilowatt hours. A kilowatt hour is equal to;

$$
1 \text { Kilowatt Hour }=\frac{\text { Amperage } x \text { Voltage } x \text { Time }(\mathrm{hr})}{1000}
$$

The average electricity cost for the United States in 2015 was $\$ 0.1096$ per kilowatt hour (eia.gov/electricity/monthly electricity).

In electrocoagulation the amperage and time are fixed by ideal cell operation. Changing one of these factors can negatively affect the contaminant removal efficiency which will become apparent in the following sections. The only variable of 
the 3 listed which can be modified to reduce cost is voltage. Conductivity of salt water solution increases linearly with salt concentration (Lide 1994).

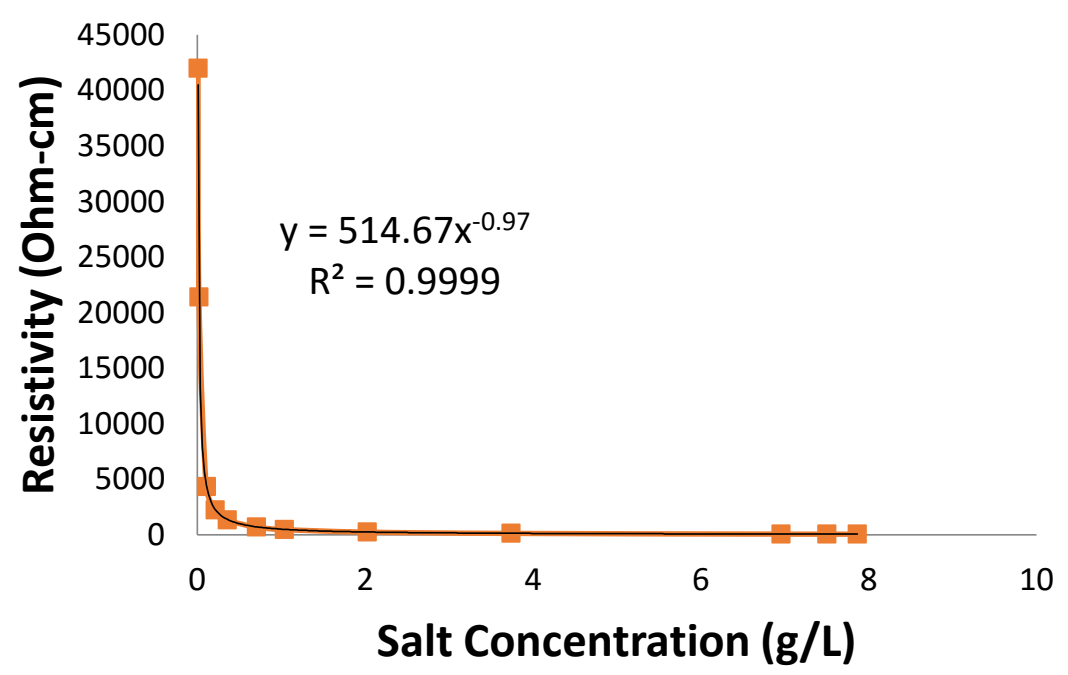

Figure 34: Curve fit for Solution Resistivity as a Function of Salt Concentration As you can see from the graph, a logarithmic relationship develops between resistivity and salt concentration. Said a different way, initial additions of salt will decrease the resistivity very quickly and thus electricity cost. After this initial period further additions begin to affect the resistivity much less and the cost of the salt begins to dominate operating cost. A salt cost of 5.51e-5 \$/g (Sigma Aldrich) was used in the calculation.

Resistivity can be used to find total cell resistance if a few characteristics of the cell are known.

$$
\begin{array}{ll}
R & =\rho \frac{L}{A} \\
\text { R= Electrical Resistance } & \mathrm{L}=\text { Length between Anode and Cathode } \\
\rho=\text { Electrical Resistivity } & \mathrm{A}=\text { Cross Sectional Area Between Electrodes }
\end{array}
$$


From figure 34 we know that resistivity varies with salt concentration according to the following equation with an $\mathrm{R}^{2}$ of 0.9999 :

$$
\rho=514.67 C^{0.97}
$$

Finally, the cell voltage is related to the resistance and amperage using ohms' law:

$$
\begin{gathered}
V=I R \\
V=I * 514.67 C^{0.97} \frac{L}{A}
\end{gathered}
$$

Iron consumption was estimated using Faradays law of electrolysis outlined earlier in this section. In this equation, the time and current applied is directly related to the amount of metal dissolved. This amount of metal is then related to cost by the market price of iron. In September 2015 the price of cold rolled steel is approximately $0.28 \$ / \mathrm{LB}$.

$$
m=\frac{I t M}{Z F}
$$

Combining all of the equations above, total cost related to salt concentration is equal to:

Total Cost $=\frac{I x I * 514.67 C^{\wedge} 0.97 \text { L/AX Time }(h r)}{1000} * \frac{\$}{\text { Kilowatt } \mathrm{Hr}}+$

$\frac{I t M}{Z F} * \frac{\$}{\text { Gram Iron }}+C *$ Volume $* \frac{\$}{\text { Gram Salt }}$

We can combine the amperage and time term in the equation above and call it metal dose. This allows us to plot the equation as a function of 2 important design variables, dose and salt concentration. Plotted on a 3 dimensional axis below you can see the operating cost as function of these variables. 


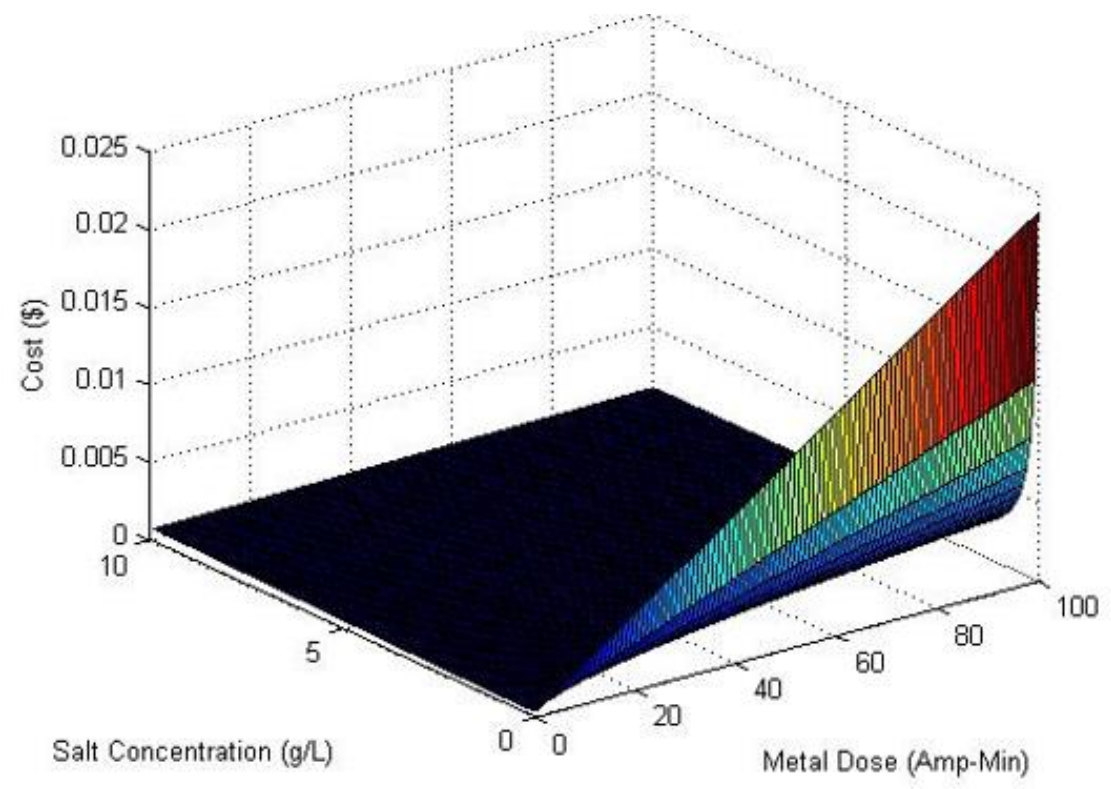

Figure 41: Theoretical Operating Cost

Taking the lowest cost at each salt concentration, the data can be plotted 2dimensionally as follows:

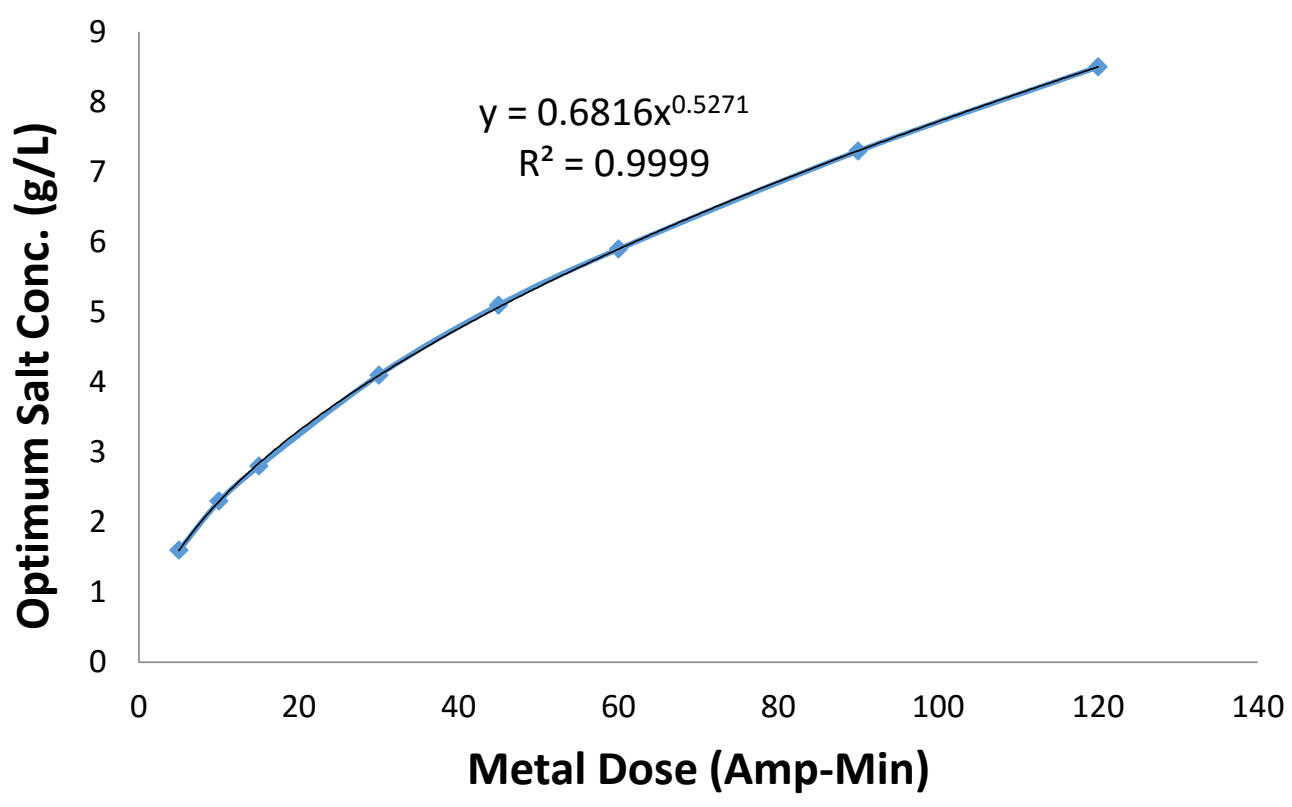

Figure 42: Theoretical Optimum Salt Concentration

This data is important for 2 reasons. First, the literature shows that increased salt concentration can lead to increased removal efficiency (Akbal and Camci 2011). 
Second, once you know the removal time and current it can be used to optimize the process. At the design phase of the project it was unknown how long it would take to treat the proposed contaminant profile. A central value of $5 \mathrm{~g} / \mathrm{L}$ was chosen for the remainder of experimentation realizing that optimization can be done in future testing. 


\section{CHAPTER 2}

\subsection{REVIEW OF LITERATURE}

\subsection{TREATMENT OF METALS}

Much of the previous electroplating electrocoagulation literature can be split into 3 different categories; Treatment of metals, Treatment of Cyanide, and treatment of metal-cyanide complexes. Metals alone will be explored first.

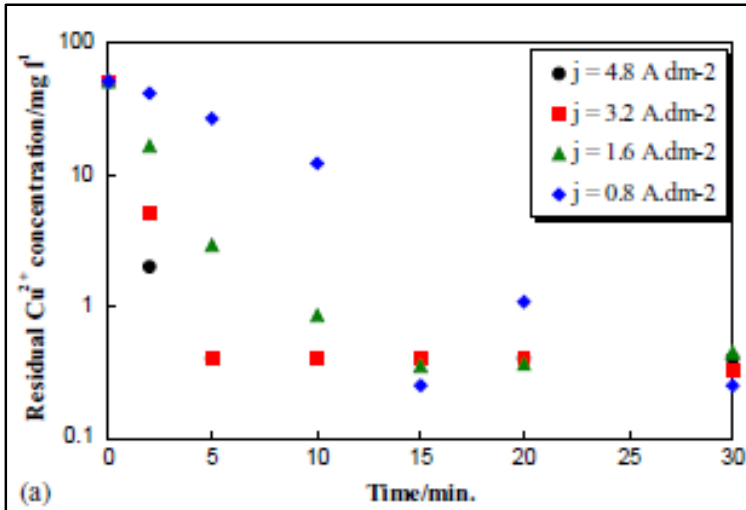

(a)
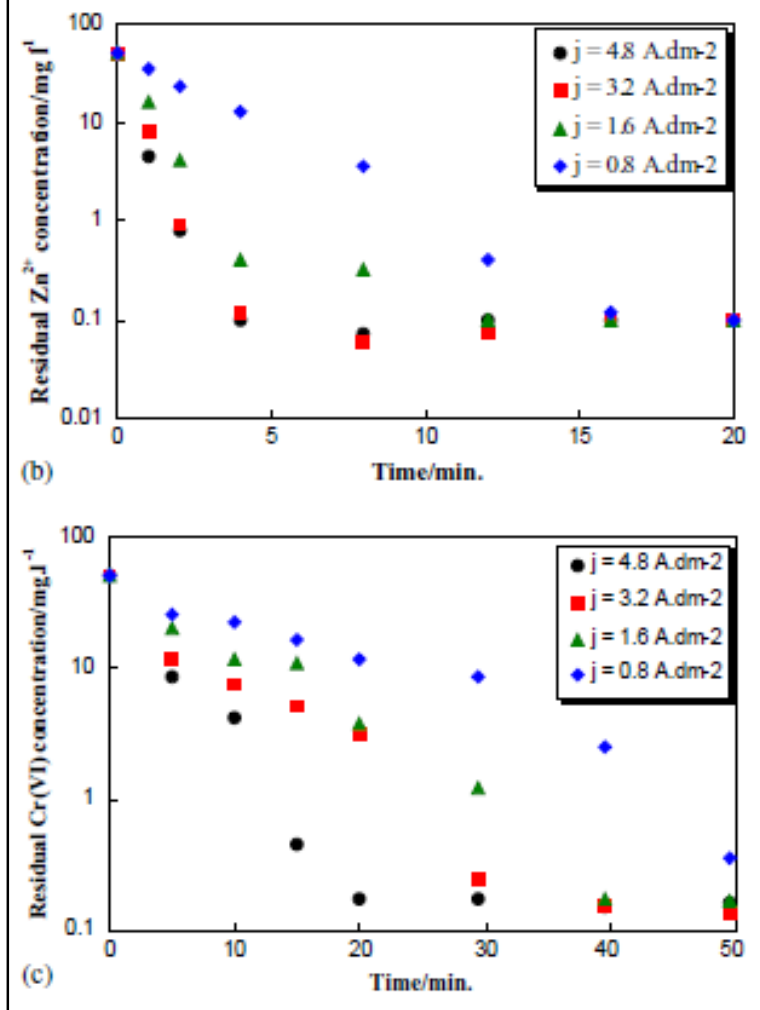

Figure 43: Removal rate of $\mathrm{Cu}^{+2}$ (a), $\mathrm{Zn}^{+2}$ (b), and $\mathrm{Cr}$ (VI) (c) (Adhoum et al. 2004) 
Shown in figure 43, Adhoum et al. 2004 was able to show reduction in $\mathrm{Cu}^{+2}, \mathrm{Zn}^{+2}$, and Cr(IV) concentrations below legal discharge limits in under 20 minutes by electrocoagulation. These results were achieved only at the highest current density tested $\left(4.8 \mathrm{~A} / \mathrm{dm}^{2}=44.59 \mathrm{ASF}\right)$. Their experiment utilized an aluminum electrode setup, $200 \mathrm{ml}$ aliquots, and 3.7g/L potassium chloride to increase solution conductivity and stop the formation of an electrode passive layer. The electrode surface area was $50 \mathrm{~cm}^{2}$ yielding a surface area to volume ratio of $250 \mathrm{~cm}^{2} / \mathrm{L}$. They also showed that both copper and zinc could effectively be treated up to an initial $\mathrm{pH}$ of 9 , but did not explore any higher.

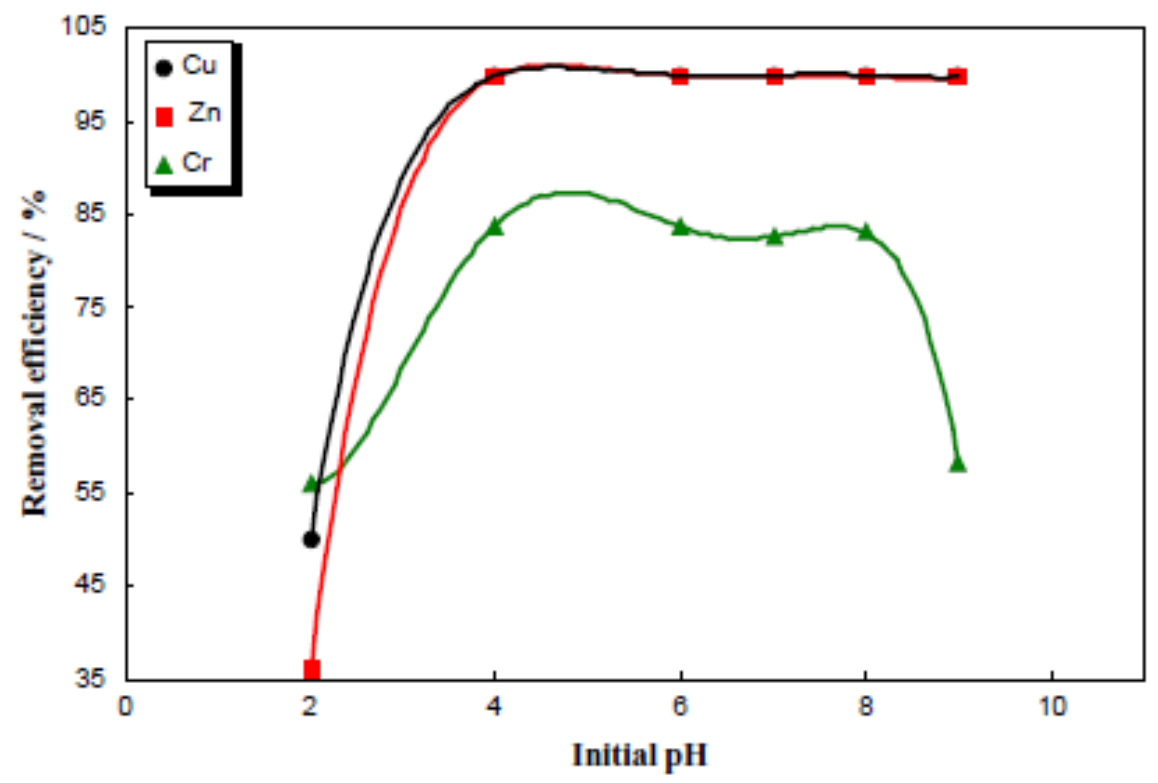

Figure 44: Graph relating Initial $\mathrm{pH}$ to contaminant removal efficiency (Adhoum et al. 2004)

Akbal and Camci 2011 tested electrocoagulation in the removal of copper, chromium, and nickel from an operating electroplating shop. Each variable (initial $\mathrm{pH}$, current density, and electrical conductivity) was tested using all possible combinations of aluminum and iron electrodes. The reactor consisted of 6 plates 
$\left(4.5 \times 7.5=33.75 \mathrm{~cm}^{2}\right.$ per side $)$ connected in monopolar mode and submerged in 650 milliliters of operating volume. This yields a surface area to volume ratio of 311.5 $\mathrm{cm}^{2} / \mathrm{L}$. Effluent collected had the following contaminant profile:

\begin{tabular}{|lc|}
\hline Characteristics of wastewater. & \\
\hline Characteristics & Value \\
\hline $\mathrm{Cu}(\mathrm{mg} / \mathrm{L})$ & 45 \\
$\mathrm{Cr}(\mathrm{mg} / \mathrm{L})$ & 44.5 \\
$\mathrm{Ni}(\mathrm{mg} / \mathrm{L})$ & 394 \\
$\mathrm{pH}$ & 3.00 \\
Conductivity $(\mathrm{mS} / \mathrm{cm})$ & 2.00 \\
\hline
\end{tabular}

Table 1: Wastewater contaminant profile (Akbal and Camci 2011)

The first test conducted showed the effects of current density on waste removal. The chosen current densities were $2.5,5,7.5$, and $10 \mathrm{~mA} / \mathrm{cm}^{2}$. The results showed that the ideal anode-cathode configuration is dependent on the type of metal targeted for removal. Copper removal occurred fastest using an iron anode and cathode. Nickel and chromium removal occurred fastest under the iron-anode aluminum-cathode configuration. The iron-iron configuration was also comparable in reducing contaminants to permissible levels. All tests showed $10 \mathrm{~mA} / \mathrm{cm}^{2}$ to be the best current density for contaminant removal.

Next an initial $\mathrm{pH}$ of $3,5,7$, and 9 were tested under the different configurations. Again the iron anode and cathode achieved the greatest copper removal efficiency, while the iron-anode aluminum-cathode worked best for chromium and nickel. And again, the iron-iron combination was not far off in terms of removal efficiency and speed of removal. Tests showed optimal removal conditions occurred at a $\mathrm{pH}$ of 9. 
Finally, the effects of solution conductivity were tested. Sodium chloride was used to achieve conductivities of 2,4 , and $6 \mathrm{mS} / \mathrm{cm}$. As you can see below, increasing conductivity increased the removal efficiency under most conditions.

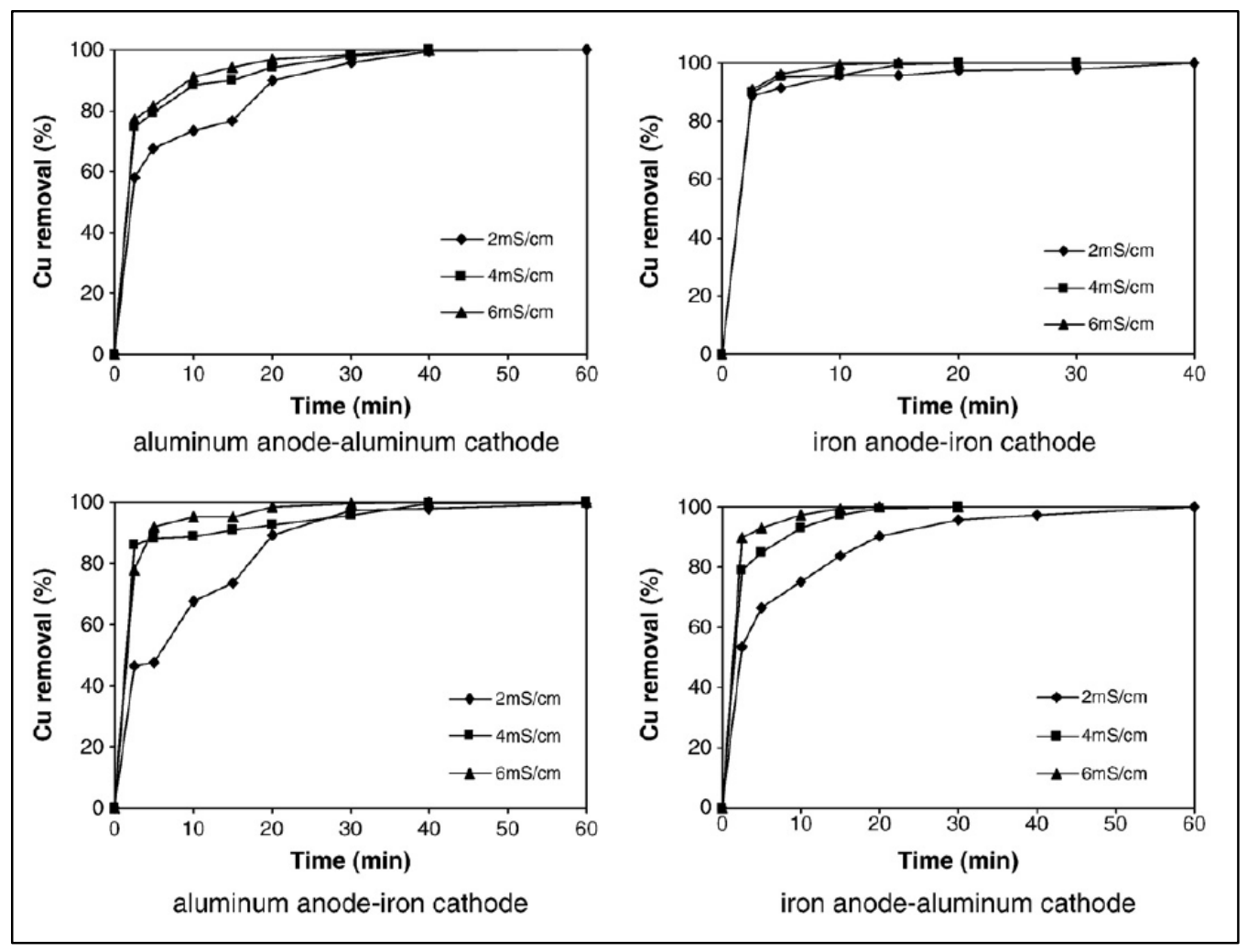

Figure 45: Effect of conductivity and anode configuration on copper removal (Akbal and Camci 2011) 


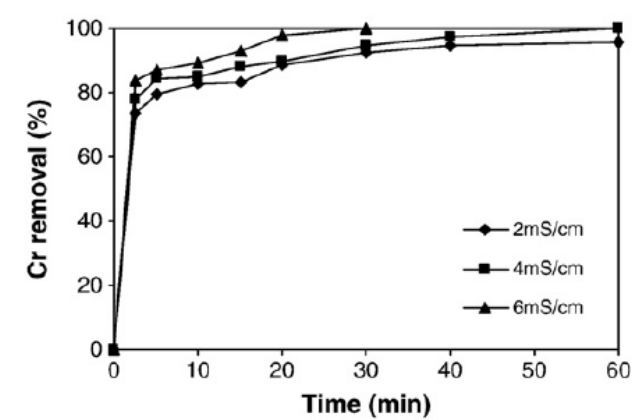

aluminum anode-aluminum cathode

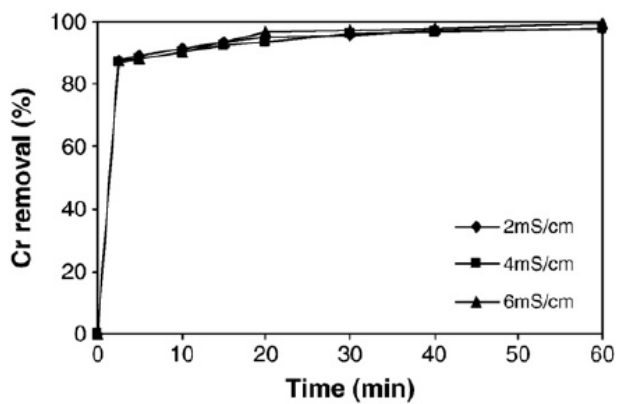

aluminum anode-iron cathode

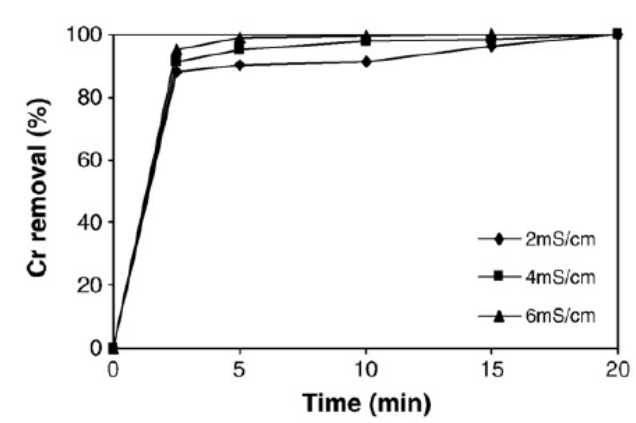

iron anode-iron cathode

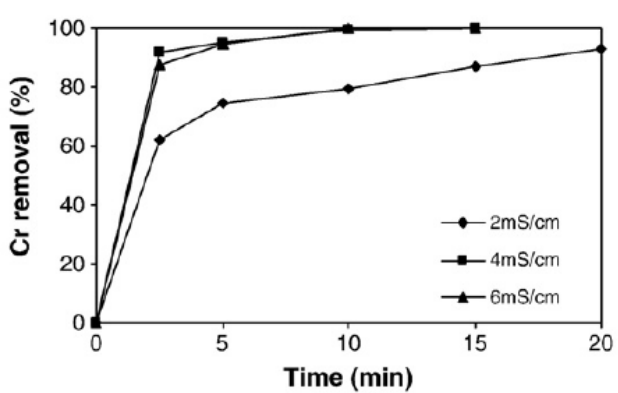

iron anode-aluminum cathode

Figure 46: Effect of conductivity and anode configuration on chromium removal (Akbal and Camci 2011)

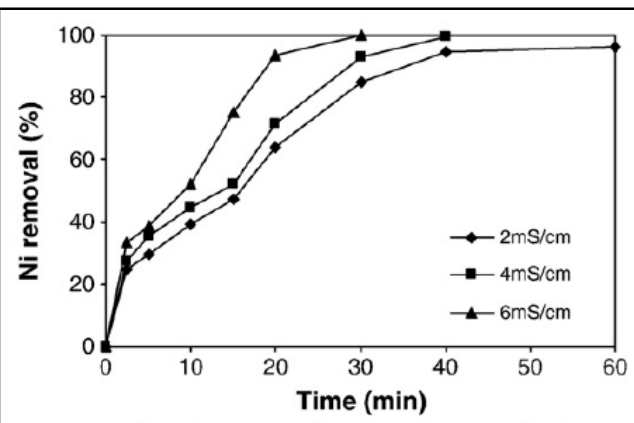

aluminum anode-aluminum cathode

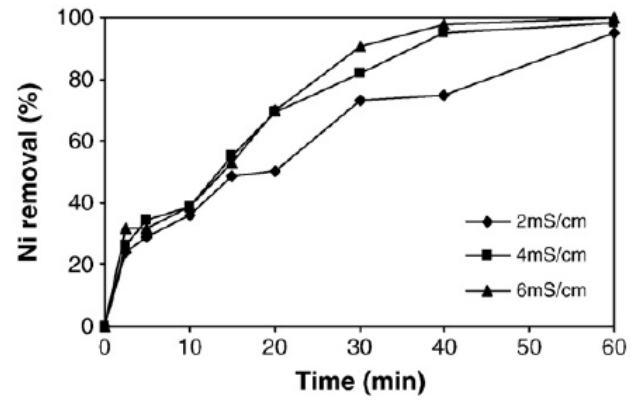

aluminum anode-iron cathode

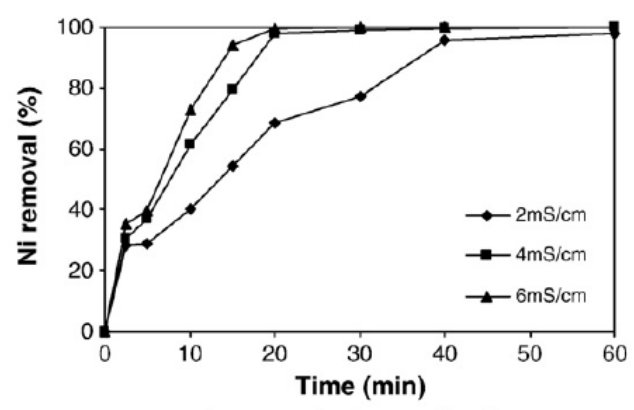

iron anode-iron cathode

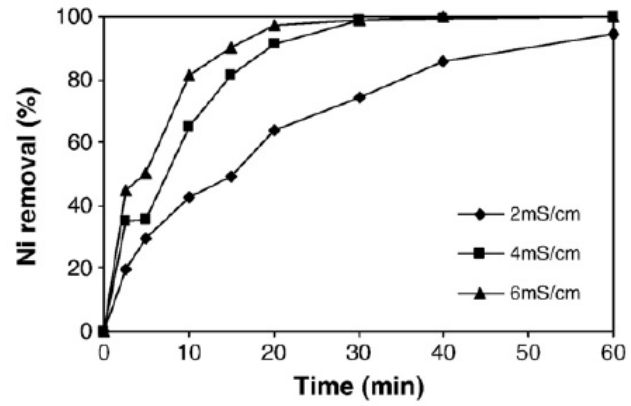

iron anode-aluminum cathode

Figure 47: Effect of conductivity and electrode configuration on nickel removal (Akbal and Camci 2011) 
Finally, the electricity and metal consumption were calculated using the same method outlined in the introduction section. This includes using Faradays Law of Electrolysis for metal consumption and current/voltage/time requirements for energy consumption. For chromium, copper, and nickel removal greater than $99 \%$ an energy and electrode consumption of $10.07 \mathrm{Kwh} / \mathrm{m}^{3}$ and $1.08 \mathrm{~kg} / \mathrm{m}^{3}$ was required respectively.

Al-Shannag et al. 2015 studied the removal of copper, chromium, nickel, and zinc from electroplating waste water using electrocoagulation. This testing was performed at an initial $\mathrm{pH}$ of 9.56 , current density of $4 \mathrm{~mA} / \mathrm{cm}^{2}$, and 45 minutes of operating time. The cell itself consisted of 6 monopolar plates with a combined surface area of $247.5 \mathrm{~cm}^{2}$ per side, in a $1,196.16 \mathrm{~cm}^{3}$ Plexiglas cell filled to $600 \mathrm{ml}$ operating volume. This yielded a surface area to volume ratio of $412.5 \mathrm{~cm}^{2} / \mathrm{L}$.

The first variable investigated was initial $\mathrm{pH}(6.56,7.89,9.56,10.68)$. As you can see in the figure below, without electrocoagulation, chromium and zinc showed a removal efficiency of approximately $40 \%$ at a $\mathrm{pH}$ of 6.56 , and negligible removal at all others (a). After electrocoagulation there was a much greater removal efficiency of all contaminants at all pH's with 9.56 proving to be the highest for all elements (b). 

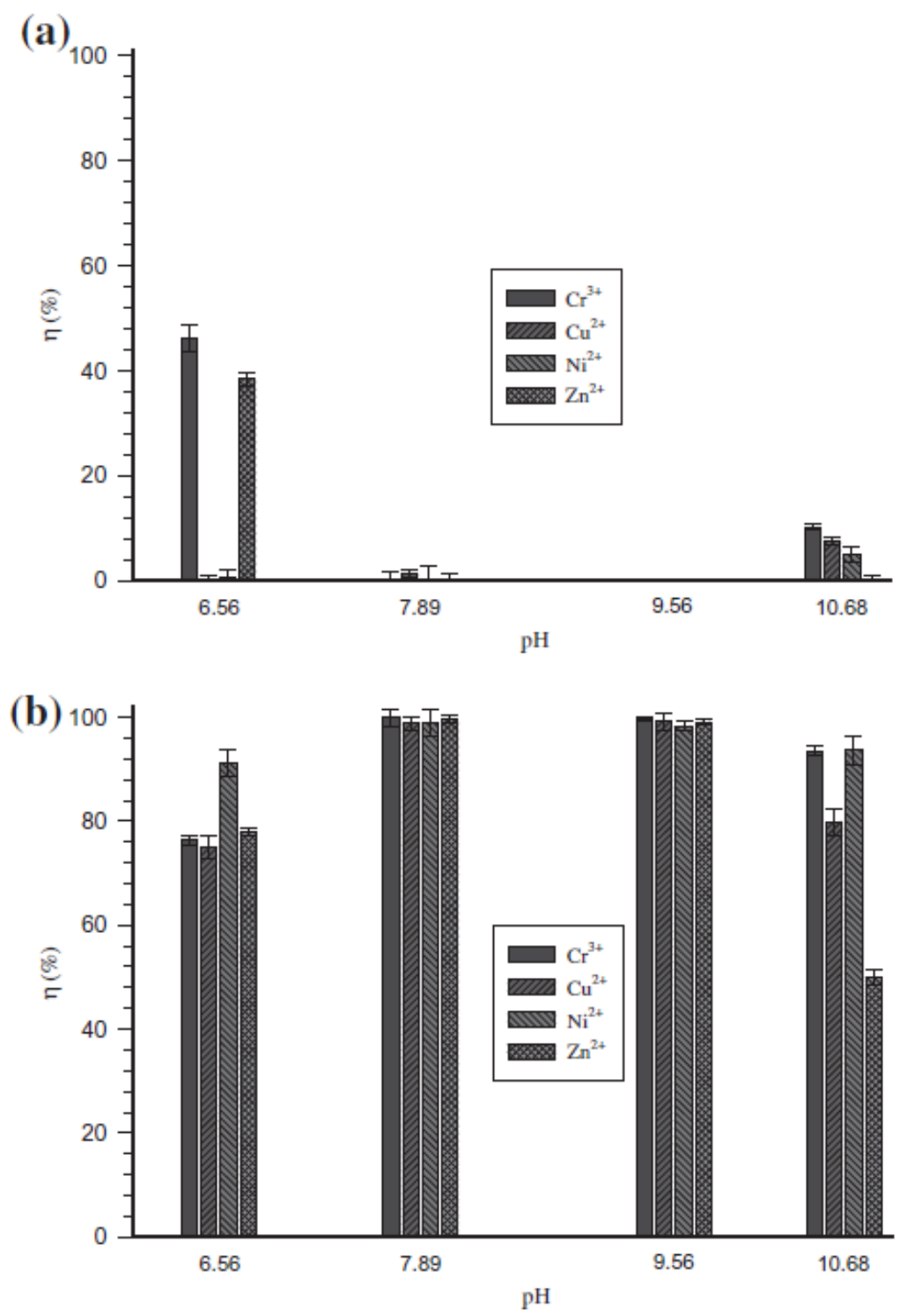

Figure 48: Effect of $\mathrm{pH}$ on contaminant removal (a) before electrocoagulation (b) after electrocoagulation (Al-Shannag et al. 2015)

Al-Shannag et al. 2015 also tested the effects of current density on removal efficiency. Each current density test was run for 1 hour utilizing the $\mathrm{pH}$ which yielded the highest removal from the previous experiment of 9.56. They found efficiencies of $23-29 \%, 52-62 \%, 75-83 \%$ and $98-100 \%$ for current densities of $1,2,3$ and 4 $\mathrm{mA} / \mathrm{cm}^{2}$ respectively. This is demonstrated in figure 49 . 


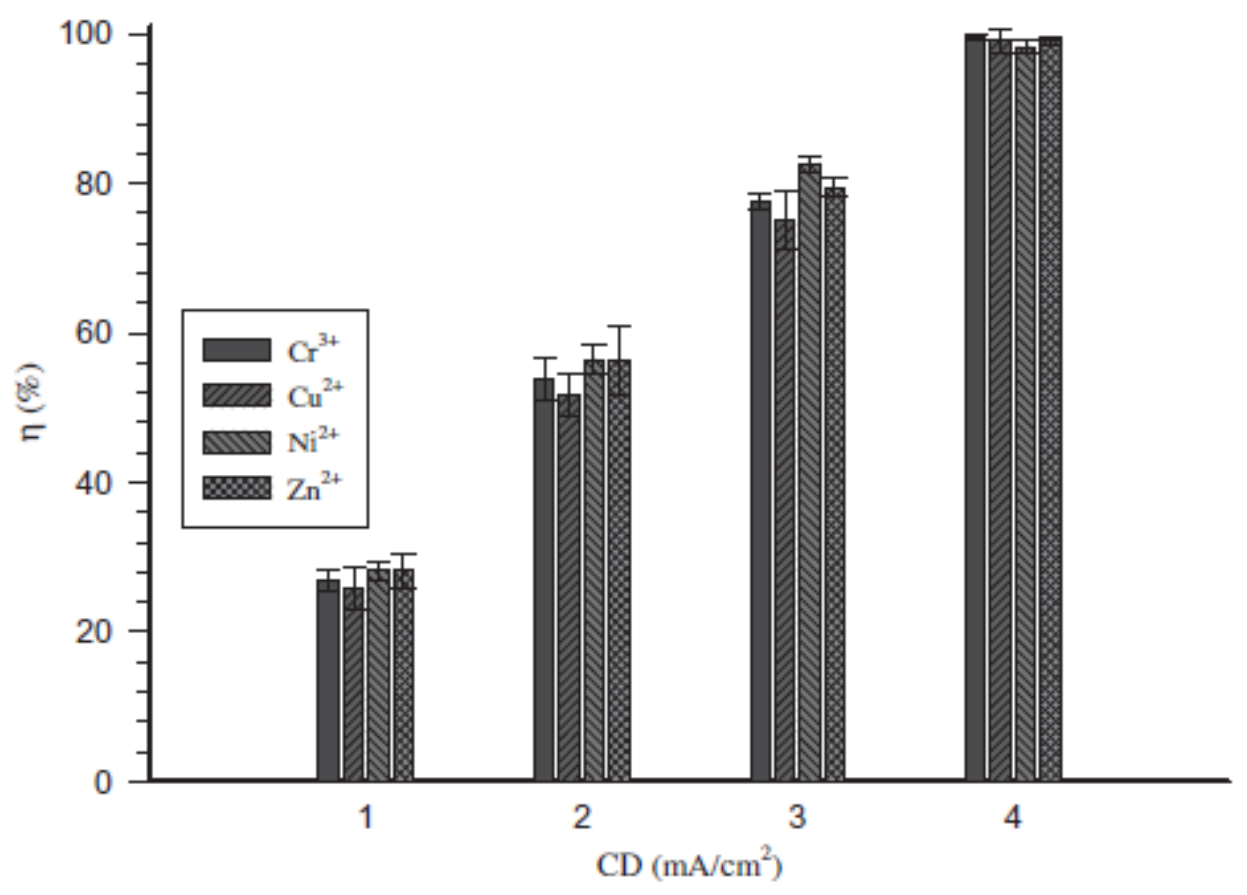

Figure 49: Removal efficiency of $\mathrm{Cu}, \mathrm{Ni}, \mathrm{Cr}$, and $\mathrm{Zn}$ as a function of current density (Al-Shannag et al. 2015)

After the removal efficiencies had been established, the study proceeded to investigate the reaction kinetics. This was done by fitting curves to the time dependent data and using a least-square method to determine the best fit. Three of the more common fits were explored in the introduction section of this paper. They found the best fit for the data was the pseudo-first order model which predicts the contaminant concentration approaches an equilibrium value $(\mathrm{Ce})$ rather than zero.

$$
\begin{gathered}
\frac{d C}{d t}=k(C-C e) \\
\int_{C o}^{C} \frac{d C}{(C-C e)}=-k \int_{t=0}^{t} d t \\
\ln (C-C e)-\ln (C o-C e)=-k t \\
\ln (C-C e)=-k t+\ln (C o-C e) \\
C=(C o-C e) e^{-k t}+C e
\end{gathered}
$$




\begin{tabular}{|clllll|}
\hline Heavy metal & $\mathrm{CD}\left(\mathrm{mA} / \mathrm{cm}^{2}\right)$ & $\begin{array}{l}\text { First-order model } \\
-\mathrm{d} C / \mathrm{d} t=k_{1} C \\
k_{1}\left(\mathrm{~min}^{-1}\right)\end{array}$ & $R^{2}(-)$ & $\begin{array}{l}\text { Second-order model } \\
-\mathrm{dC} / \mathrm{d} t=k_{2} \mathrm{C}^{2} \\
k_{2}\left(\mathrm{ppm}^{-1} \mathrm{~min}^{-1}\right)\end{array}$ & $R^{2}(-)$ \\
\hline $\mathrm{Cr}^{3+}$ & 2 & 0.0114 & 0.7476 & 0.0002 & 0.8283 \\
& 3 & 0.0218 & 0.7686 & 0.0006 & 0.8904 \\
$\mathrm{Cu}^{2+}$ & 4 & 0.0856 & 0.6619 & 0.0616 & 0.8228 \\
& 2 & 0.0123 & 0.9338 & 0.0006 & 0.9627 \\
& 3 & 0.0246 & 0.9487 & 0.0017 & 0.9720 \\
$\mathrm{Ni}^{2+}$ & 4 & 0.0787 & 0.9772 & 0.0465 & 0.7043 \\
& 2 & 0.0133 & 0.6696 & 0.0004 & 0.7573 \\
$\mathrm{Zn}^{2+}$ & 3 & 0.0281 & 0.8219 & 0.0015 & 0.9248 \\
& 4 & 0.0671 & 0.9565 & 0.0168 & 0.9177 \\
& 2 & 0.0116 & 0.6855 & 0.001 & 0.7669 \\
& 3 & 0.0263 & 0.8150 & 0.0036 & 0.8783 \\
& 4 & 0.0763 & 0.9294 & 0.0723 & 0.7753 \\
\hline
\end{tabular}

Table 2: First/second order reaction coefficients and $\mathrm{R}^{2}$ values for contaminant removal (Al-Shannag et al. 2015)

\begin{tabular}{|c|c|c|c|c|}
\hline \multirow[t]{2}{*}{ Heavy metal } & \multirow[t]{2}{*}{$\mathrm{CD}\left(\mathrm{mA} / \mathrm{cm}^{2}\right)$} & \multicolumn{2}{|c|}{$\begin{array}{l}\text { Pseudo first-order model } \\
-\mathrm{d} C / \mathrm{d} t=k^{\mathrm{app}}\left(C-C_{\mathrm{e}}\right)\end{array}$} & \multirow[t]{2}{*}{$R^{2}(-)$} \\
\hline & & $k^{\mathrm{app}}\left(\min ^{-1}\right)$ & $C_{\mathrm{e}}(\mathrm{ppm})$ & \\
\hline \multirow[t]{3}{*}{$\mathrm{Cr}^{3+}$} & 2 & 0.0939 & 43.89 & 0.9859 \\
\hline & 3 & 0.1165 & 22.52 & 0.9933 \\
\hline & 4 & 0.2740 & 00.33 & 0.9991 \\
\hline \multirow[t]{3}{*}{$\mathrm{Cu}^{2+}$} & 2 & 0.0504 & 16.00 & 0.9823 \\
\hline & 3 & 0.0539 & 08.10 & 0.9866 \\
\hline & 4 & 0.0560 & 00.31 & 0.9921 \\
\hline \multirow[t]{3}{*}{$\mathrm{Ni}^{2+}$} & 2 & 0.1224 & 22.53 & 0.9965 \\
\hline & 3 & 0.0983 & 09.82 & 0.9998 \\
\hline & 4 & 0.1180 & 01.73 & 0.9939 \\
\hline \multirow[t]{3}{*}{$\mathrm{Zn}^{2+}$} & 2 & 0.1168 & 09.02 & 0.9972 \\
\hline & 3 & 0.0878 & 03.81 & 0.9980 \\
\hline & 4 & 0.0928 & 00.16 & 0.9949 \\
\hline
\end{tabular}

Table 3: Pseudo-First order reaction coefficient and $\mathrm{R}^{2}$ values for contaminant removal (Al-Shannag et al. 2015).

Finally, the electrode and energy consumption were calculated. This was done using faradays law of electrolysis and the Amperage/voltage/time requirements normalized to treatment volume (see introduction). They found that full treatment required an energy and electrode consumption of $6.25-8.33 \mathrm{kWh} / \mathrm{m}^{3}$ and $1.31-1.74$ $\mathrm{kg} / \mathrm{m}^{3}$ respectively. 


\subsection{TREATMENT OF FREE CYANIDE}

The next category is treatment of cyanide alone. Moussavi et al. 2011 were able to show a maximum of $98 \%$ cyanide removal using an iron-aluminum electrode arrangement as the anode and cathode respectively. Agitation was also tested utilizing aeration of the electrocoagulation cell. All experiments were carried out at an initial $\mathrm{pH}$ of 11.5, a current density between 2 and $15 \mathrm{~mA} / \mathrm{cm}^{2}(1.86-13.94 \mathrm{ASF})$, and a reaction time between 20 and $50 \mathrm{~min}$. The initial $\mathrm{pH}$ was presumably selected to ensure non-volatile ionic cyanide was present in the reactor.

The reactor itself was $250 \mathrm{~mL}$ in volume. It contained a total submerged surface area of $40 \mathrm{~cm}^{2}$ giving a surface area to reactor volume ratio of $160 \mathrm{~cm}^{2} / \mathrm{L}$. An electrode separation distance of $3 \mathrm{~cm}$ was chosen and the samples pulled periodically from the reactor were filtered through 0.45 -micron filter paper prior to analysis. Since there are no free metals present in solution to complex the cyanide, the standard $\mathrm{AgNO}_{3}$ titration was used to determine cyanide concentration (Environmental Protection Agency Method 9014-5).

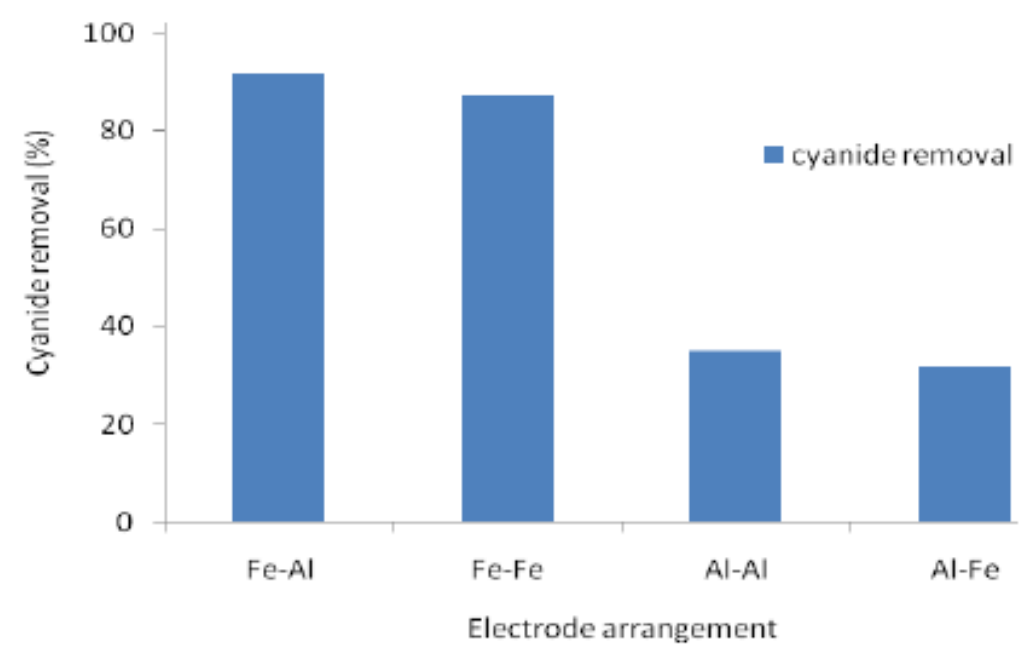

Figure 55: Removal Efficiency as a Function of anode/cathode material (Moussavi et al. 2011) 
Although the best results were achieved using the iron-aluminum couple, as you can see from the figure above, the iron-iron electrode achieved similar results. Both of these arrangements performed markedly better than the aluminum-aluminum and aluminum-iron pairings (Moussavi et al. 2011).

An important result arises when examining the effects of increased current density in the following figure.

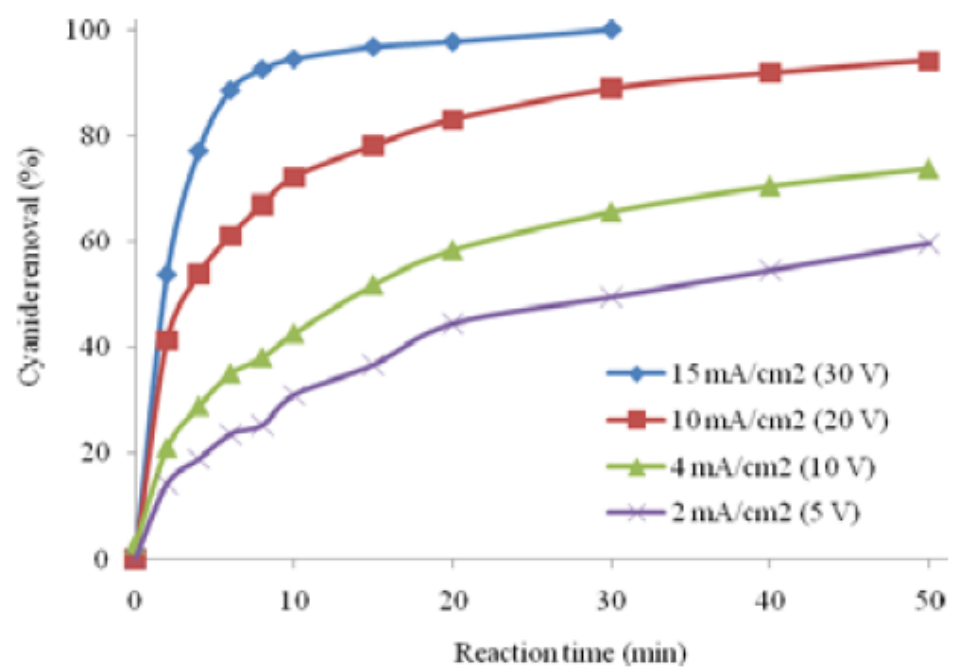

Figure 56: Cyanide removal rate with varying current density (Moussavi et al. 2011) This chart was generated using the iron-aluminum electrode pairing. As you can see, when the current density is increased the treatment time required to achieve a certain percentage of removal is decreased. It would take trials run with increased treatment time to determine if overall removal percentages at lower current density ever reach that of the higher current density.

Moussavi et al. investigated the effect of aeration on cyanide removal. This was done using the $\mathrm{Fe}-\mathrm{Al}$ anode-cathode configuration at a current density of 15 $\mathrm{mA} / \mathrm{cm}^{2}$. Cyanide removal without aeration in this configuration reached 
approximately $94 \%$. Addition of aeration brought the removal efficiency to $100 \%$ in the 30-minute time frame which was tested.

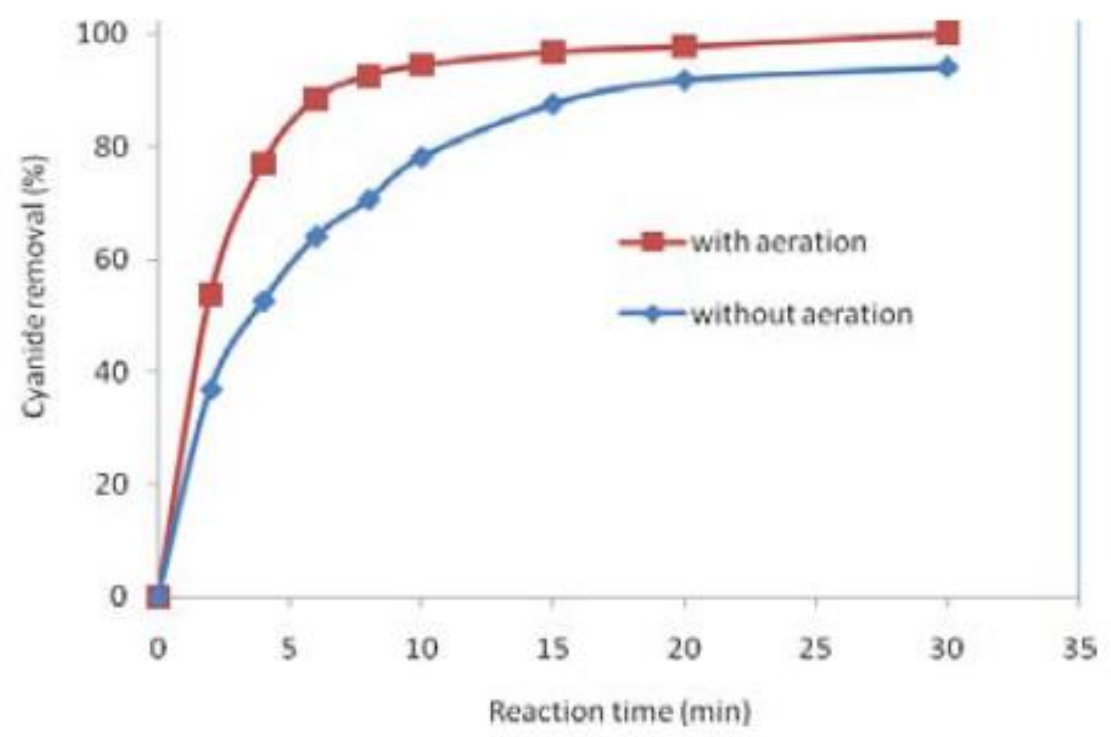

Figure 57: Effect of Aeration on Cyanide Removal Efficiency (Moussavi et al. 2011)

In an attempt to explain the increase in removal efficiency the team ran another set of experiments quantifying the amount of sludge generated. To do this, trials were run with and without aeration for 20 minutes. They found that under aerated conditions the system produced approximately twice as much sludge. They theorized that the increase in sludge generation resulted from the oxidation of ferrous to ferric ion in the increased oxygen environment. This in turn led to a more gelatinous hydroxide precipitate and an increase in efficiency. It was pointed out that "The higher the precipitate (adsorbent) formation and effective contact of precipitates with the contaminant, the greater the adsorption rate and thus removal" (Moussavi et al. 2011). Aeration of the cell seems to serve both of these mechanisms in a positive way. 
Hassani et al. 2011 also investigated the removal of cyanide through electrocoagulation using iron electrodes. Sodium bisulfite at a concentration of 300 $\mathrm{mg} / \mathrm{L}$ was utilized to keep the oxidation state of iron to +2 and stabilize the cyanide in solution (Hassani et al. 2011). This then allowed them to run the reactor at a $\mathrm{pH}$ between 4.5 and 6 without fear of converting the free cyanide to hydrogen cyanide gas. After electrocoagulation was complete, the $\mathrm{pH}$ was again adjusted using sodium hydroxide between 8 and 8.5 to facilitate hydroxide precipitation and free cyanide removal by sweep flocculation.

The reactor consisted of 8 monopolar plates spaced $10 \mathrm{~mm}$ apart. The main variables examined were operating voltage and starting concentration. As you can see in the following figure, the removal percentage maxed out at $97 \%$ after 90 minutes. This was only achieved at cell voltages greater than 30 which adds to operating cost.

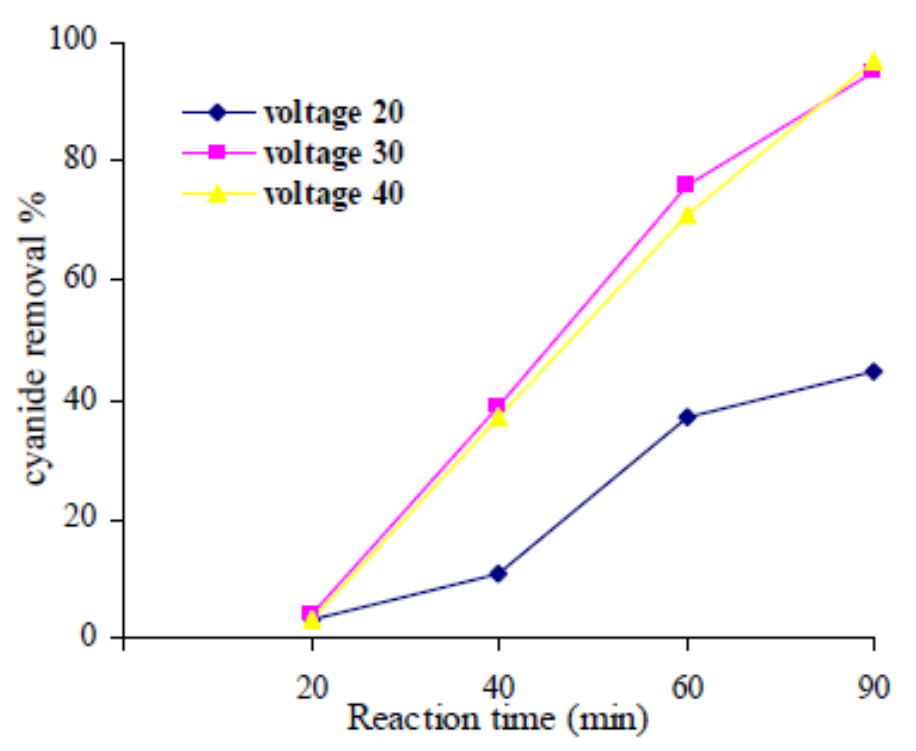

Figure 58: Effect of starting voltage on cyanide removal efficiency. $\mathrm{CN}^{-}$ Concentration of 50mg/L (Hassani et al. 2011) 


\subsection{TREATMENT OF METAL-CYANIDE COMPLEXES}

The final category most resembles the present work. The use of electrocoagulation to treat metal-cyanide complexes is important because of the large number of electroplating bath formulations which employ them (Schesinger and Paunovic 2010). Kobya et al. (2010) used electrocoagulation to treat cadmium and nickel cyanide solution in a batch reactor. Optimum process variables such as initial $\mathrm{pH}$, current density, and reaction time were determined. They were able to achieve a removal efficiency of $99.4 \%$ for Cadmium, $99.1 \%$ for nickel, and $99.7 \%$ for cyanide. This occurred at $30 \mathrm{~A} / \mathrm{m}^{2}$ (2.79 ASF), $30 \mathrm{~min}$, and $\mathrm{pH}$ 8-10 for Cadmium, and $60 \mathrm{~A} / \mathrm{m}^{2}$ (5.57 ASF), $80 \mathrm{~min}$, and $\mathrm{pH}$ 8-10 for nickel. 

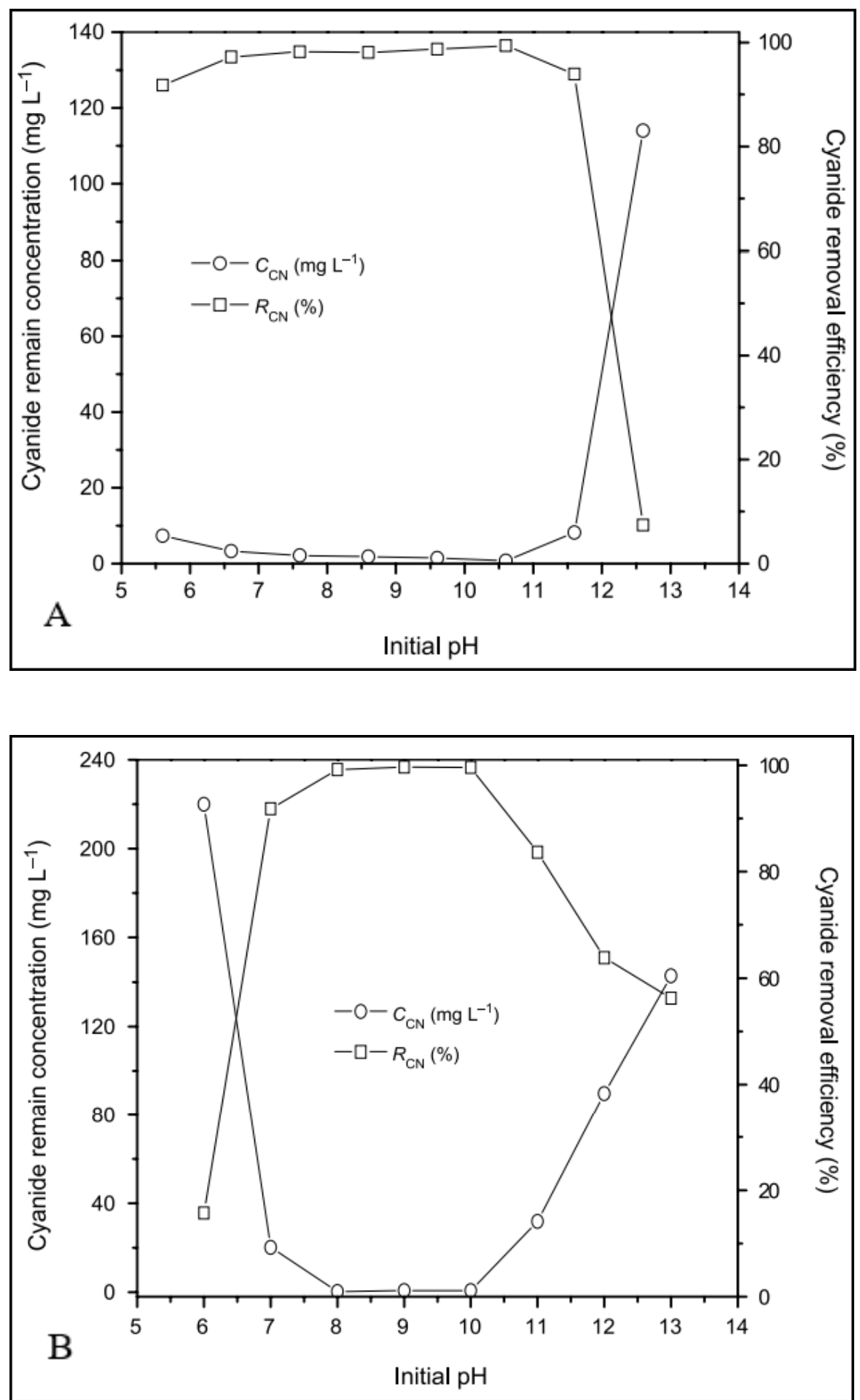

Figure 59: Optimum $\mathrm{pH}$ for cyanide destruction A. Cadmium Cyanide B. Nickel Cyanide (Kobya et al. 2010) 
As you can see from the figures above, the initial $\mathrm{pH}$ for optimal cyanide removal from the nickel cyanide solution was between 8 and 10 with a sharp decrease in removal efficiency outside this range. The initial $\mathrm{pH}$ for optimal cyanide removal from the cadmium cyanide solution was between 6.5 and 10.5 with a much slower rate of drop outside this range. This difference may be an artifact of the different starting metal-cyanide concentrations. It may also indicate that the type of metal complex affects the ideal electrocoagulation operating conditions. It is also important to note that both graphs show a decrease in removal efficiency at $\mathrm{pH}$ 's greater than $10-10.5$.

Senturk (2013) investigated electrocoagulation for the treatment of zinccyanide exploring a few more operating variables than Kobya et al. (2010). The focus of this paper was current density, 2.5-40 $\mathrm{A} / \mathrm{M}^{2}$, operating time (0-60min), initial $\mathrm{pH}$ (5-12) and electrode connection mode (monopolar parallel, monopolar series, and bipolar series). They utilized electrodes with a total area of $225 \mathrm{~cm}^{2}$, spaced $10 \mathrm{~mm}$ apart in a $1 \mathrm{~L}$ electrocoagulation unit yielding a surface area to volume ratio of 225 $\mathrm{cm}^{2} / \mathrm{L}$. 

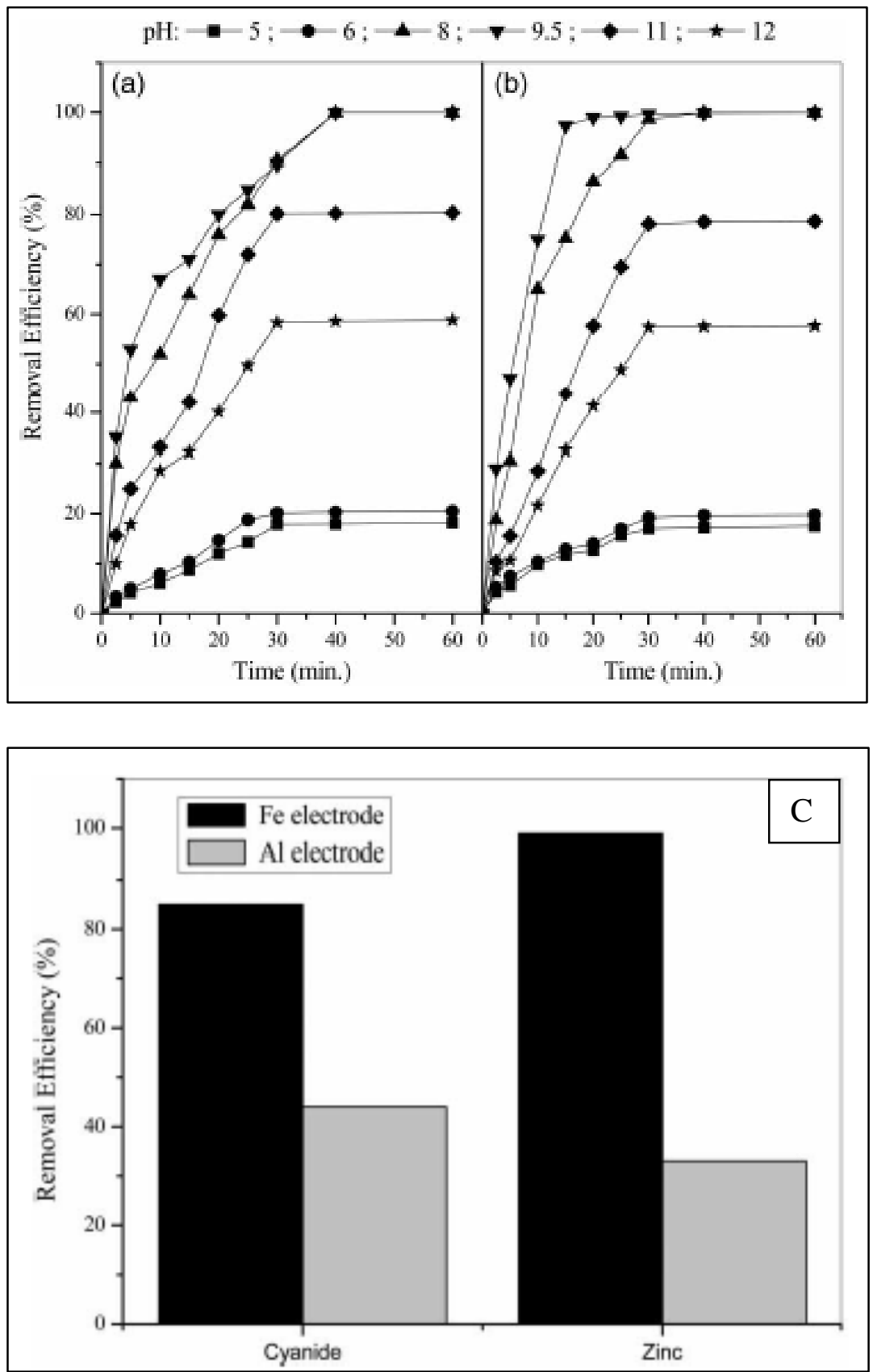

Figure 60: Effect of initial $\mathrm{pH}$ on (a) cyanide and (b) zinc removal efficiency (c) Effect of electrode material on Zinc and Cyanide Removal (Senturk 2013)

In these experiments the maximum removal efficiency occurred at an initial $\mathrm{pH}$ of 9.5 using iron electrodes. These conditions were then used in the next experiment testing the effects of current density. 


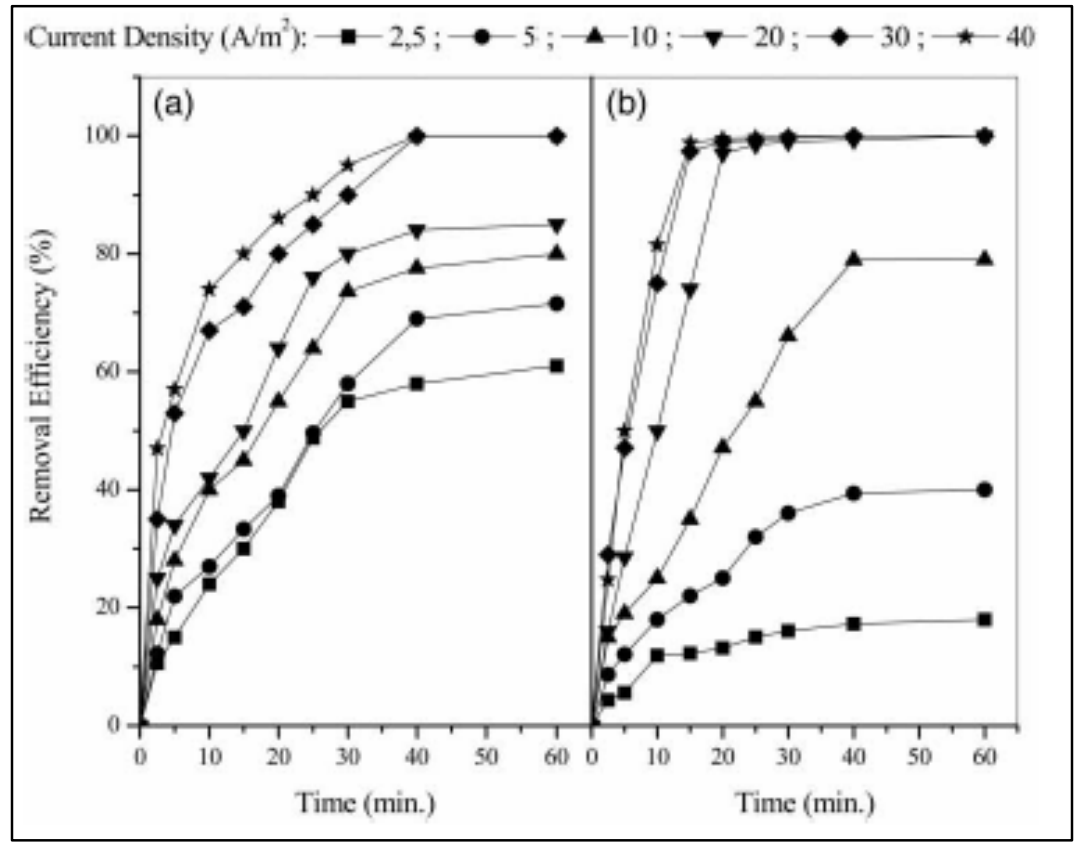

Figure 61: Effect of current density on cyanide (a) and zinc (b) removal efficiency at a $\mathrm{pH}$ of 9.5 (Senturk 2013)

As you can see in the figures above, increasing the current density resulted in greater removal efficiency and decreased treatment time. The conditions which optimized the process were determined to be $30 \mathrm{~A} / \mathrm{m}^{2}$ (2.79 ASF), $40 \mathrm{~min}$, iron electrodes, and an initial $\mathrm{pH}$ of 9.5. At these conditions removal percentages were 85 and $99 \%$ for cyanide and zinc respectively.

\subsection{AGITATION IN SWEEP FLOCCULATION}

Agitation of the working solution is another important variable in sweep flocculation. For flocculation to occur, the growing floccules must collide with each other. This can be accomplished through Brownian motion or artificial agitation. Eventually the flocs reach a size where collision induced breakage dominates and growth no longer occurs (Ghernaout and Ghernaout 2012). The following is a graph representing this concept in a Kaolin suspension flocculated with ferric chloride. 


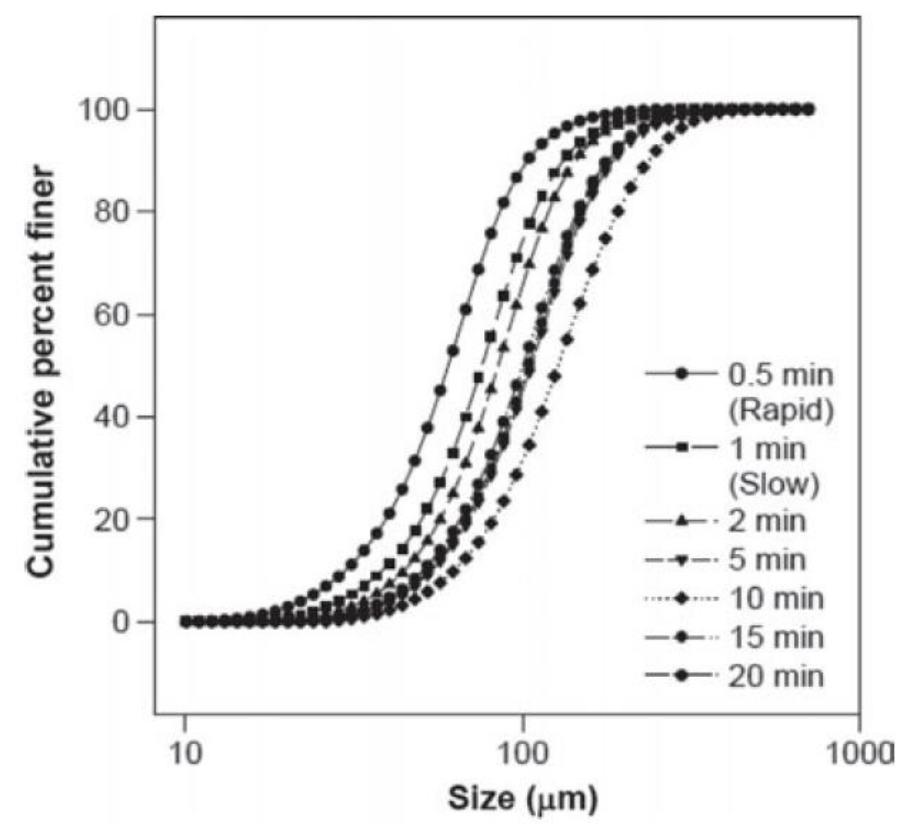

Figure 62: Size difference of floccules with rapid and slow mixing times (Ghernaout and Ghernaout 2012)

Ghernaout and Ghernaout also reviewed the available literature on reversibility of floccule breakage in both charge neutralization and sweep flocculation. They noted extreme differences in the ability of floccules to regrow between the two treatment methods and offered an explanation based on mechanism which is best illustrated in the following figure.

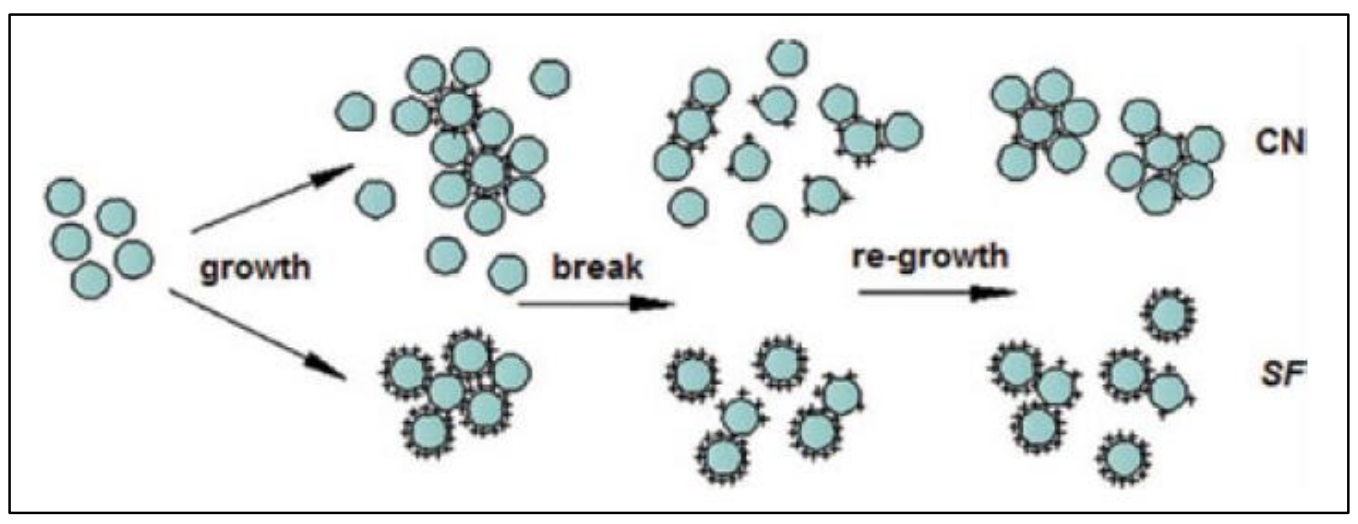

Figure 63: Difference in ability of charge neutralization and sweep flocculation to break and re-flocculate (Ghernaout and Ghernaout 2012) 
In charge neutralization $(\mathrm{CN})$ a few particles absorb positive charges and attract the rest of the particles to flocculate. When this bond is broken through shear stress the relatively few particles with charge will repel each other, but overall much of the solution can re-flocculate. In sweep flocculation (SF) many of the particles adsorb the positive charge through the large branchy sweep flocculent. When these floccules break apart, the large number of positively charged particles tend to repel each other. The net effect is re-flocculation does not occur nearly as readily SF as it does in CN (Ghernaout and Ghernaout 2012). Limiting this breakage through agitation control is a major component of flocculation. 


\section{CHAPTER 3}

\subsection{METHODOLOGY}

From the literature, initial $\mathrm{pH}$ plays an important role in electrocoagulation removal efficiency (Adhoum et al. 2004, Kobya et al. 2010, Moussavi et al. 2011). Since cyanide in solution forms volatile hydrogen cyanide gas below a pH of 11, this forms a necessary lower limit for this study. During operation it would pose a serious threat to safety if any cyanide being treated suddenly became volatile. As was pointed out in the introduction section, different metal-cyanide complexes may affect cyanide removal rates. A major point of the study is to determine how particular mixtures of metal complexes $\left(\mathrm{Ni}^{+2}, \mathrm{Cu}^{+2}, \mathrm{Sn}^{+2}\right)$ affect cyanide removal.

\subsection{REAGENTS AND APPARATUS}

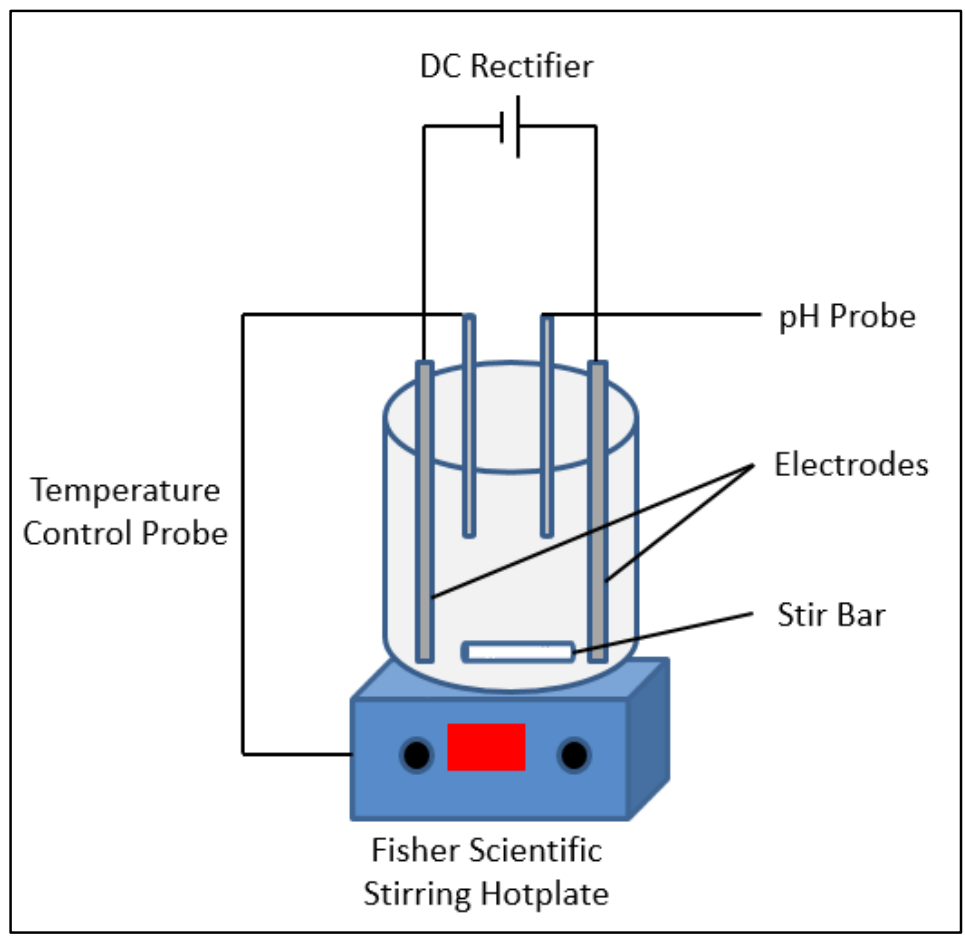

Figure 64: Lab Scale Testing Apparatus: Illustration 
Copper (II) Sulfate (Electropure, 60g/L), Nickel(II) Sulfamate (Palm, 179.4g/L), Tin(II) Methanesulfonate (Technic Inc. 400g/L) and potassium cyanide (JT Baker, Reagent Grade) were added to deionized (DI) water to achieve $\mathrm{Cu}^{+2}, \mathrm{Ni}^{+2}, \mathrm{Sn}^{+2}$ and $\mathrm{CN}^{-}$concentrations between 50 and $160 \mathrm{mg} / \mathrm{L}$. The $160 \mathrm{mg} / \mathrm{L}$ tin concentration was purposely chosen higher than the rest due to the sensitivity of the atomic absorption unit and is further explained in appendix A. DI water with a conductivity less than $20 \mu \mathrm{S} / \mathrm{cm}$ was used to make up the remainder of the operating volume.

Sodium chloride at a concentration of $5 \mathrm{~g} / \mathrm{L}$ was added to increase electrical conductivity.

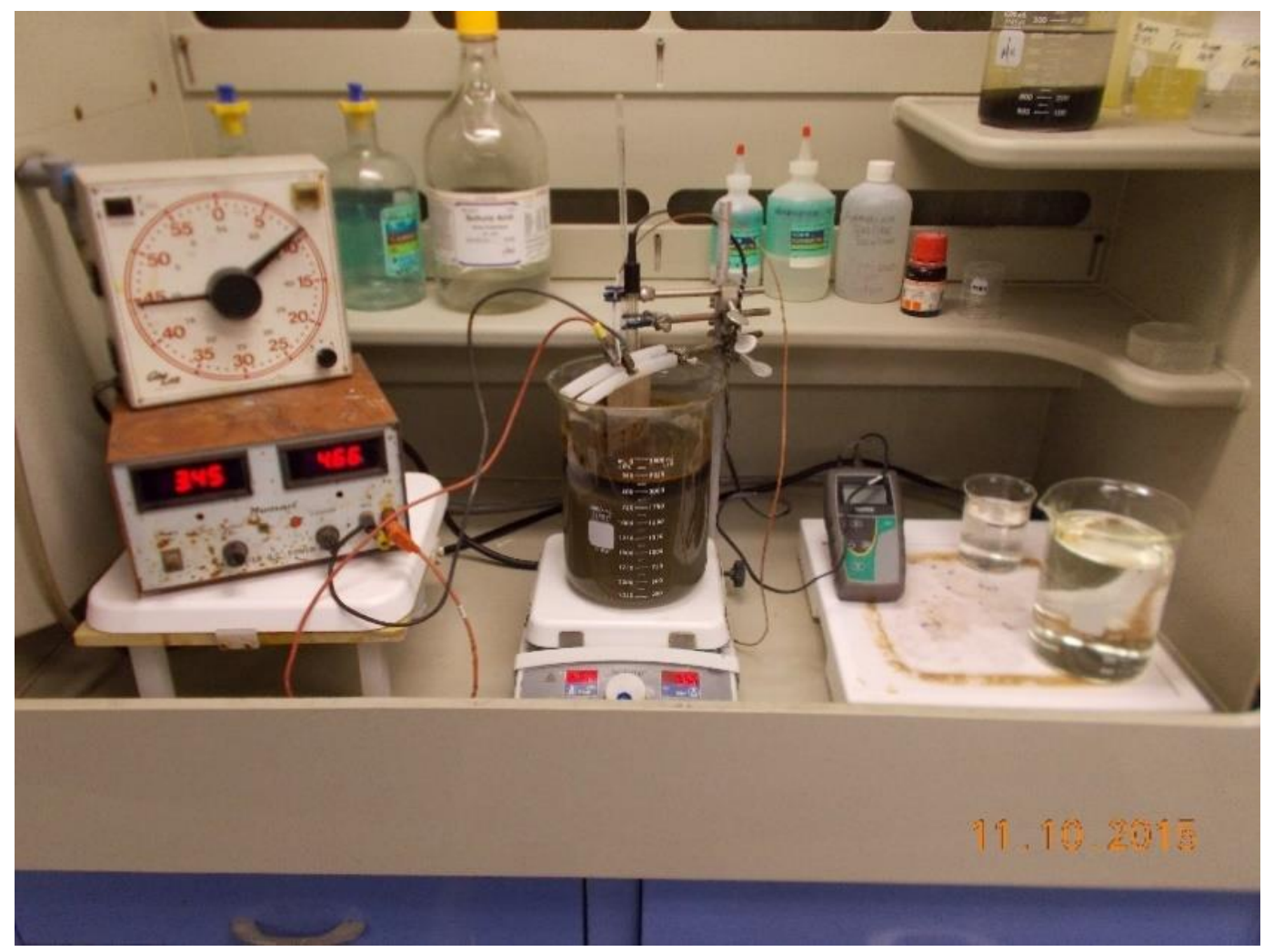

Figure 65: Lab Scale Testing Apparatus: Photograph

All experimentation was carried out in a $3000 \mathrm{~mL}$ beaker filled to a $2500 \mathrm{~mL}$ operating volume using synthetic wastewater. This particular setup was chosen to 
accommodate the size of samples which must be pulled from the reactor for testing. Temperature was measured at $25 \mathrm{C}+6 \mathrm{C}$ using a Fisher Scientific Isotemp hotplate equipped with a temperature probe. The $\mathrm{pH}$ was measured using a portable $\mathrm{pH}$ meter (model $\mathrm{pH} 5+$ made by Oakton Instruments) suspended by ring stand.

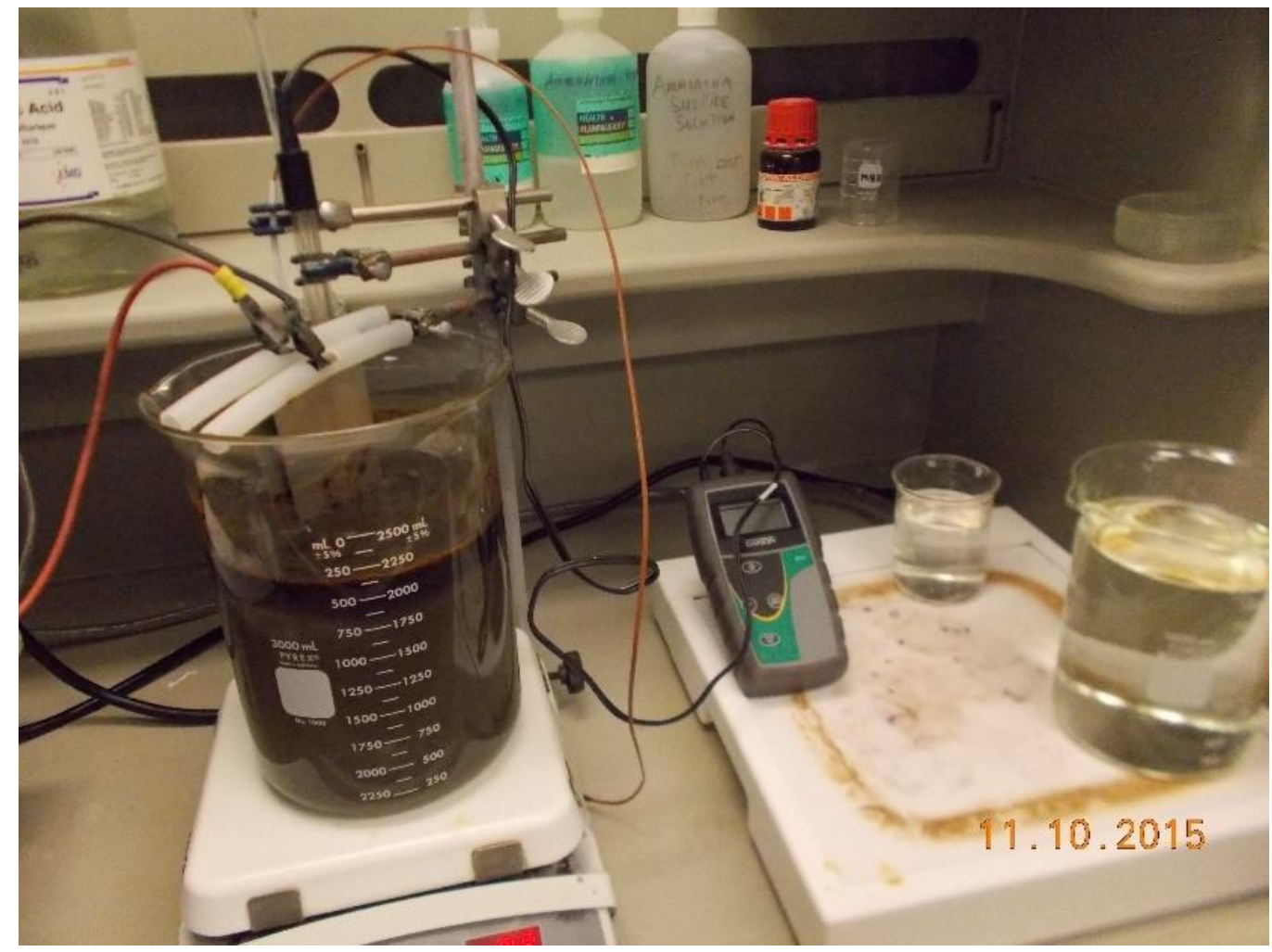

Figure 66: $\mathrm{pH}$ and Temperature Probe Suspended by Ring Stand

Initial $\mathrm{pH}$ adjustments were made using reagent grade hydrochloric acid and sodium hydroxide. Electrical power was supplied using a DC Rectifier (10V, 11A), made by Human Company in current regulation mode. G1000 series steel was used as the anode and cathode material due to low cost, high availability, and high iron content. The plate cross sectional area was approximately 2.25 " x 6" wide and the plates were held 0.25 " apart. Prior to each run the newly cut plates were activated in a $50 \%$ concentrated hydrochloric acid solution for 10 minutes. 


\subsection{SAMPLING PROCEDURE}

$60 \mathrm{~mL}$ samples were taken at selected intervals and the generated sludge was allowed to settle for 20 minutes by sedimentation prior to analysis.

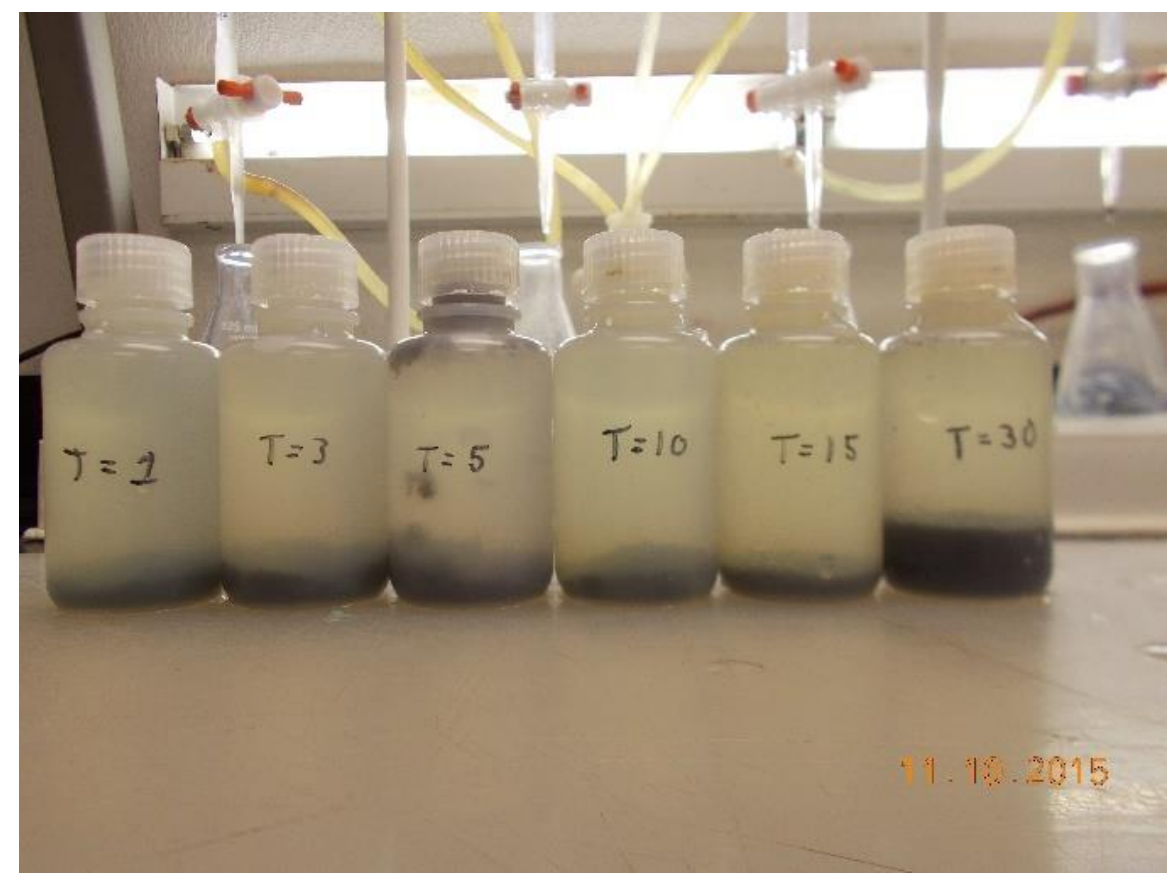

Figure 67: Sludge generated during sampling allowed to settle

Though a much smaller volume is required for atomic absorption spectrometry testing, the extra volume was used to allow for this sludge separation. While pulling samples it was important to avoid the concentrated area of floc which built up on the surface of the solution due to flotation. This was done by reaching through the layer with the sample bottle prior to taking the sample. 


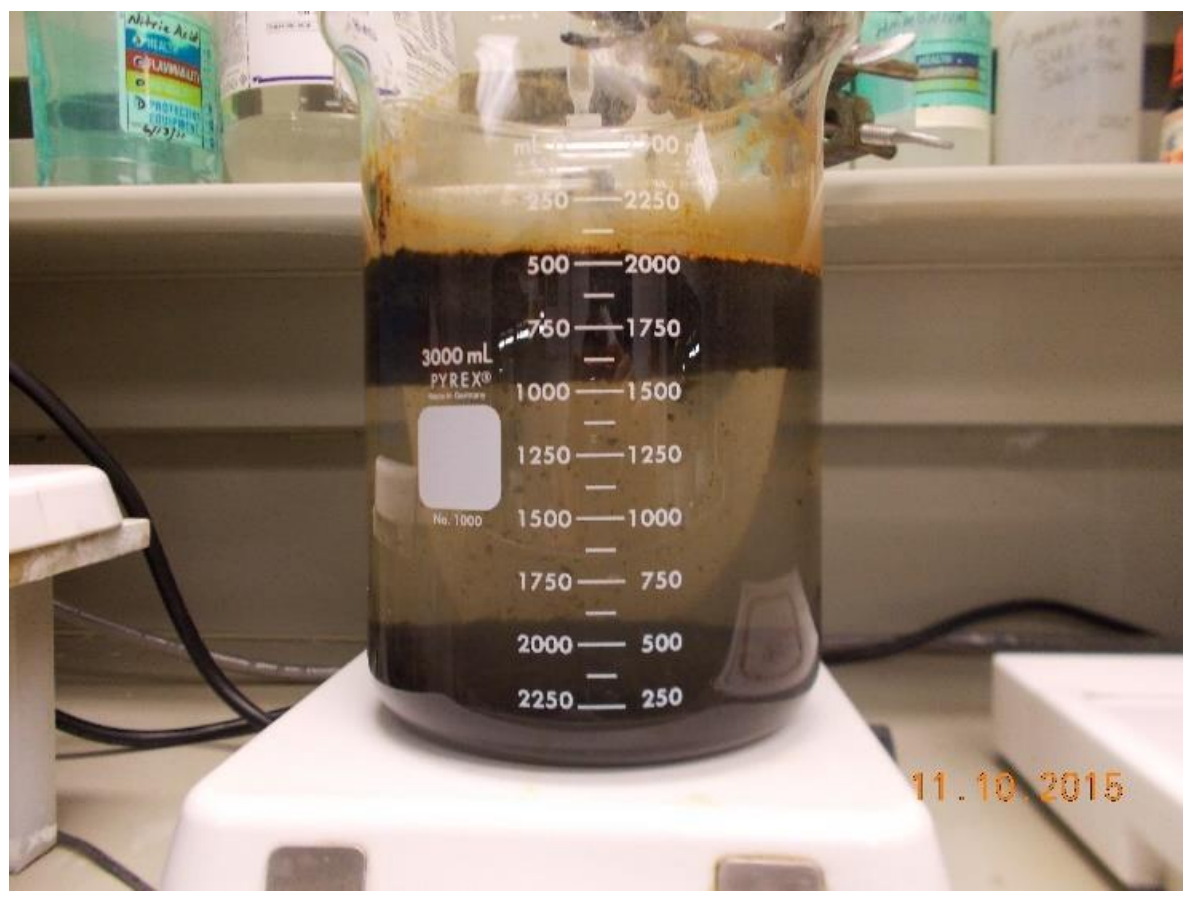

Figure 68: Concentrated Floc Generated on top of Solution Through Flotation

Due to the rate of contaminant removal, samples were pulled at $1,3,5,8,10$, $12,15,20,25,30,45$, and 60 minutes. All concentrations of $\mathrm{Ni}^{+2}, \mathrm{Cu}^{+2}$, and $\mathrm{Sn}^{+2}$ were analyzed using atomic absorption spectrometry (AAS-Perkin Elmer Pinacle 900F) at MTM. A detailed explanation of the AAS testing procedure and capability can be found in appendix A.

Cyanide sampling has extra requirements. A $125 \mathrm{~mL}$ sample was taken at regular intervals out to 2 hours and 40 minutes run time. This is because prior literature has shown cyanide removal to occur much slower than metal removal (Moussavi et al. 2011). The concentration of cyanide will be analyzed using an outside laboratory in accordance with EPA standard SM4500CN-C E 18-21 ed. This testing method uses distillation and an ion selective electrode or silver nitrate titration to measure the total cyanide concentration in solution (Greenberg et al. 1992). According to this standard, the samples must be preserved with sodium 
hydroxide to a pH of at least 11 and refrigerated prior to analysis. Since the initial $\mathrm{pH}$ was already set to 11 and only increases after operation begins, no further sodium hydroxide was needed for preservation. This yields a shelf life of 14 days and thus the analysis is time sensitive. The Plating analysis laboratory at Materion Technical Materials does not have the ability to perform this testing in house. RI analytical in Warwick, Rhode Island was utilized for this purpose.

Wastewater discharge limits are set forth by the United States Environmental Protection Agency. These levels are outlined in the Code of Federal Regulation Title 40 - Protection of the Environment, and separated based on daily discharge volume. For plants discharging greater than $10,000 \mathrm{gal} /$ day the limits are as follows:

\begin{tabular}{|l|l|l|}
\hline Pollutant or pollutant property & Maximum for any $\mathbf{1}$ day & Average of daily values for 4 consecutive monitoring days shall not exceed \\
\hline $\mathrm{CN}, \mathrm{T}$ & 1.9 & 1.0 \\
\hline $\mathrm{Cu}$ & 4.5 & 2.7 \\
\hline $\mathrm{Ni}$ & 4.1 & 2.6 \\
\hline $\mathrm{Cr}$ & 7.0 & 4.0 \\
\hline $\mathrm{Zn}$ & 4.2 & 2.6 \\
\hline $\mathrm{Pb}$ & .6 & .4 \\
\hline $\mathrm{Cd}$ & 1.2 & .7 \\
\hline Total metals & 10.5 & 6.8 \\
\hline
\end{tabular}

Table 4: EPA Wastewater Discharge Limits

Under law, states are allowed to set their own limits as long as they are at least as stringent as those set by the federal government. The Narragansett Bay Commission sets the limits in Rhode Island. As of January 10, 2016, the average monthly limits for metal finishing shops were 1.62, 1.20, 2.00 and 0.65 PPM for nickel, copper, tin, and cyanide respectively. 


\subsection{CHOICE OF TEST VARIABLES}

From previous literature, one of the more important characteristics of electrocoagulation operation seems to be current density (Senturk 2013). The current densities already published in the reviewed literature range from 0.5 to 45 ASF with higher current densities corresponding to decreased operating time, increased efficiency, and reduced costs (Kobya et al. 2010). To extend the data for current density the experiments were run at 25, 50 and 75 ASF.

The stir speed was varied from 0 to 300 RPM to investigate its effect on metal removal after sedimentation. As stated in the review of literature section, agitation is an important variable in electrocoagulation (Ghernaout and Ghernaout 2012). The prior literature shows incomplete removal of nickel and cyanide in a nickel(II) cyanide solution at an initial pH of 11 (Kobya et al. 2010). This increase in stir speed will serve to increase collisions of the flocculent with the targeted contaminants and may help overcome this incomplete removal shown by Kobya et al. 2010.

In addition to agitation by stir bar, the present study added aeration as an alternative. Aeration was shown by Moussavi et al. 2011 to increase both the speed and percentage of free cyanide removal at a $\mathrm{pH}$ of 11.5. The author postulated that oxidation of ferrous to the more gelatinous ferric hydroxide in the increased oxygen environment was to blame for this increase in removal efficiency. It is hypothesized that this effect may help to overcome the incomplete nickel cyanide removal shown by Kobya et al. 2010. A Fisher scientific desktop vacuum filtration pump was used to introduce air to the reactor. The air speed was adjusted via regulator seeking a flow 
rate low enough to prevent shear induced breakage of floccules, but high enough to induce conversion of ferrous to ferric hydroxide.

Attempts were also made to model the data using traditional reaction kinetic theory $\left(0,1^{\text {st }}\right.$, pseudo- $1^{\text {st }}$, or $2^{\text {nd }}$ order $)$. As outlined in the introduction section, one can find the kinetic constants associated with a first order chemical reaction through a plot of the natural log of concentration vs. time which should be a straight line. The negative of the slope is the reaction rate coefficient. These were used to gauge the difference in removal speed for each trial. 


\section{CHAPTER 4}

\subsection{FINDINGS}

\subsection{HYPOTHESES}

The present work set out to develop a process which could be used to treat both heavy metals and cyanide simultaneously and continuously using electrocoagulation and hydroxide precipitation. This goal led to the formation of a few different hypotheses. First, since tin is a vitally important element to the electronics industry, it was hypothesized that at a $\mathrm{pH}$ of 11 electrocoagulation or hydroxide precipitation would be able to reduce tin concentrations below EPA permissible levels.

Moussavi et al. 2011 showed that aeration could be used to increase the removal percentage of free cyanide to 100\%. Kobya et al. (2010) and Akbal and Camci 2011 both showed a decrease in nickel-cyanide removal at pH's greater than 10. They both postulated that at higher $\mathrm{pH}$ 's the iron in solution only forms monomeric iron hydroxide verses the large polymeric hydroxides ideal for sweep flocculation. Since Moussavi et al. 2011 linked the increase in cyanide removal efficiency observed from aeration to the change of ferrous to ferric ion, this transition may be beneficial to nickel-cyanide removal as well. It is therefore hypothesized that aeration could be used to help overcome the apparent decrease in nickel-cyanide removal efficiency observed at high $\mathrm{pH}$, and reduce metal-cyanide complexes to EPA permissable levels.

The final goal of the project was to apply reaction kinetic theory to the data obtained during testing. The hypothesis being that zero, first, or second order reaction kinetics would accurately reflect the data observed. 


\subsection{TIN SOLUBILITY DATA}

The first step of this research was to determine whether hydroxide precipitation or electrocoagulation would be the main method of removal at a $\mathrm{pH}$ of 11 without the presence of cyanide. This was accomplished by creating a solution with approximately $160 \mathrm{mg} / \mathrm{L}$ of $\mathrm{Sn}^{+2}$ in DI water and pulling samples as the $\mathrm{pH}$ is adjusted. The tin hydroxides in these samples were allowed to settle by sedimentation prior to testing. Below is the graph of the data.

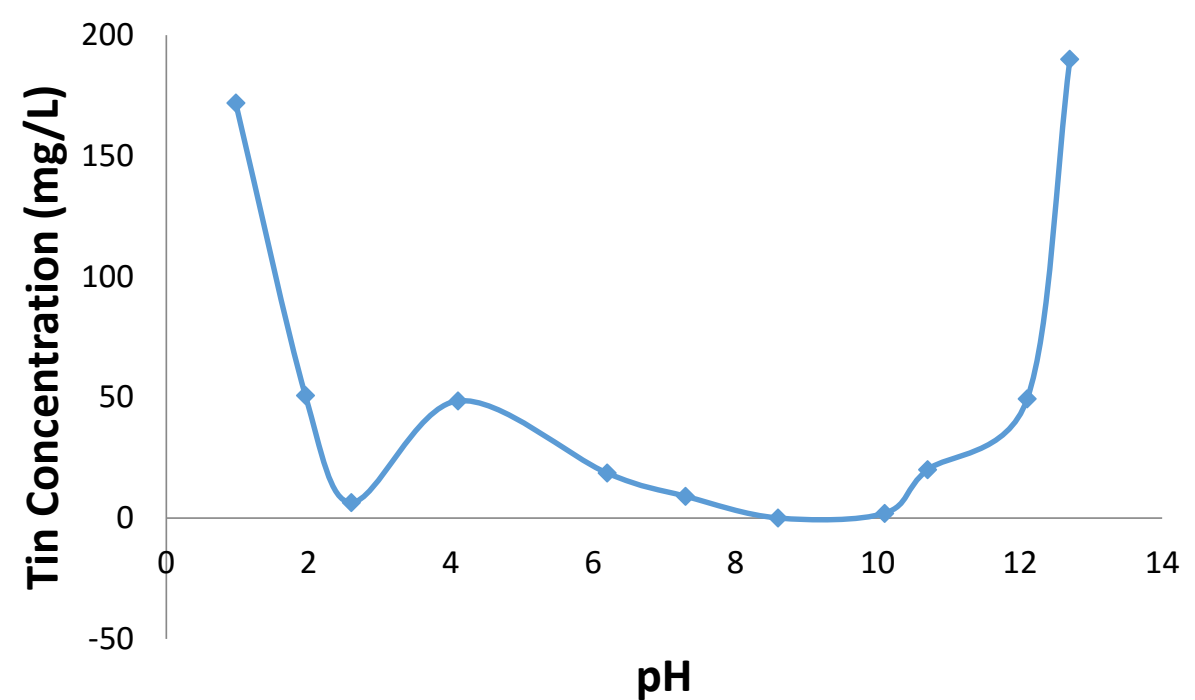

Figure 69: Tin Solubility as a Function of $\mathrm{pH}$

As you can see, tin is amphoteric in nature. This means it can act as an acid or a base depending on $\mathrm{pH}$. More importantly, at a $\mathrm{pH}$ of 11 you can see tin is beginning to show increasing solubility. From this graph we gather that the tin concentration at a pH of 11 will be somewhere between 20 and $49.3 \mathrm{mg} / \mathrm{L}$. This means in a cyanide free environment most of the tin would precipitate out as the corresponding hydroxide.

However, the monthly average discharge limit in Rhode Island is $2.00 \mathrm{mg} / \mathrm{L}$ meaning an alternative form of treatment would be required before discharging. 


\subsection{EFFECT OF CYANIDE CONCENTRATION ON METAL SOLUBILITY}

In a typical electroplating job shop the amount of discharge and concentration of contaminants is constantly changing. This is because all lines do not run $100 \%$ of the time, and the different geometries being processed tend to change contaminant levels incoming to wastewater treatment. In initial experiments it became clear that the addition of cyanide increased the concentration of all metallic contaminants. As stated earlier, cyanide readily forms complexes with various metals in solution (Griffith 1962). It seems that the addition of cyanide favored the formation of these complexes over hydroxides at the $\mathrm{pH}$ being tested. The amount of metal which "redissolved" was a function of cyanide concentration and increased until the starting concentrations of the waste stream were reached.

This ability to re-dissolve originates from the set of equilibrium reactions taking place in the electrocoagulation cell. As you can see below, the equilibrium constants greatly favor the formation of the cyanide complexes, further supporting the data.

Hydroxide Formation (Hill et al. 2005)

$$
\begin{gathered}
\mathrm{Cu}^{+2}+2 \mathrm{OH}^{-} \leftrightarrow \mathrm{Cu}(\mathrm{OH})_{2(\mathrm{~s})} \quad \mathrm{Ksp}=2.2 \mathrm{e}-20 \\
\mathrm{Ni}^{+2}+2 \mathrm{OH}^{-} \leftrightarrow \mathrm{Ni}(\mathrm{OH})_{2(\mathrm{~s})} \mathrm{Ksp}=2.0 \mathrm{e}-15 \\
\mathrm{Sn}^{+2}+2 \mathrm{OH}^{-} \leftrightarrow \mathrm{Sn}(\mathrm{OH})_{2(\mathrm{~s})} \mathrm{Ksp}=1.4 \mathrm{e}-28
\end{gathered}
$$

Complex Ion Formation (Hill et al. 2005)

$$
\begin{gathered}
\mathrm{Cu}^{+}+4 \mathrm{CN}^{-} \leftrightarrow\left[\mathrm{Cu}(\mathrm{CN})_{4}\right]^{-3} \mathrm{Kf}=2.0 \mathrm{e} 30 \\
\mathrm{Ni}^{+2}+4 \mathrm{CN}^{-} \leftrightarrow\left[\mathrm{Ni}(\mathrm{CN})_{4}\right]^{-2} \mathrm{Kf}=2.0 \mathrm{e} 31 \\
\mathrm{Sn}^{+2}+4 \mathrm{CN}^{-} \leftrightarrow\left[\mathrm{Sn}(\mathrm{CN})_{4}\right]^{-2} \mathrm{Kf}=\text { Unavailable }
\end{gathered}
$$




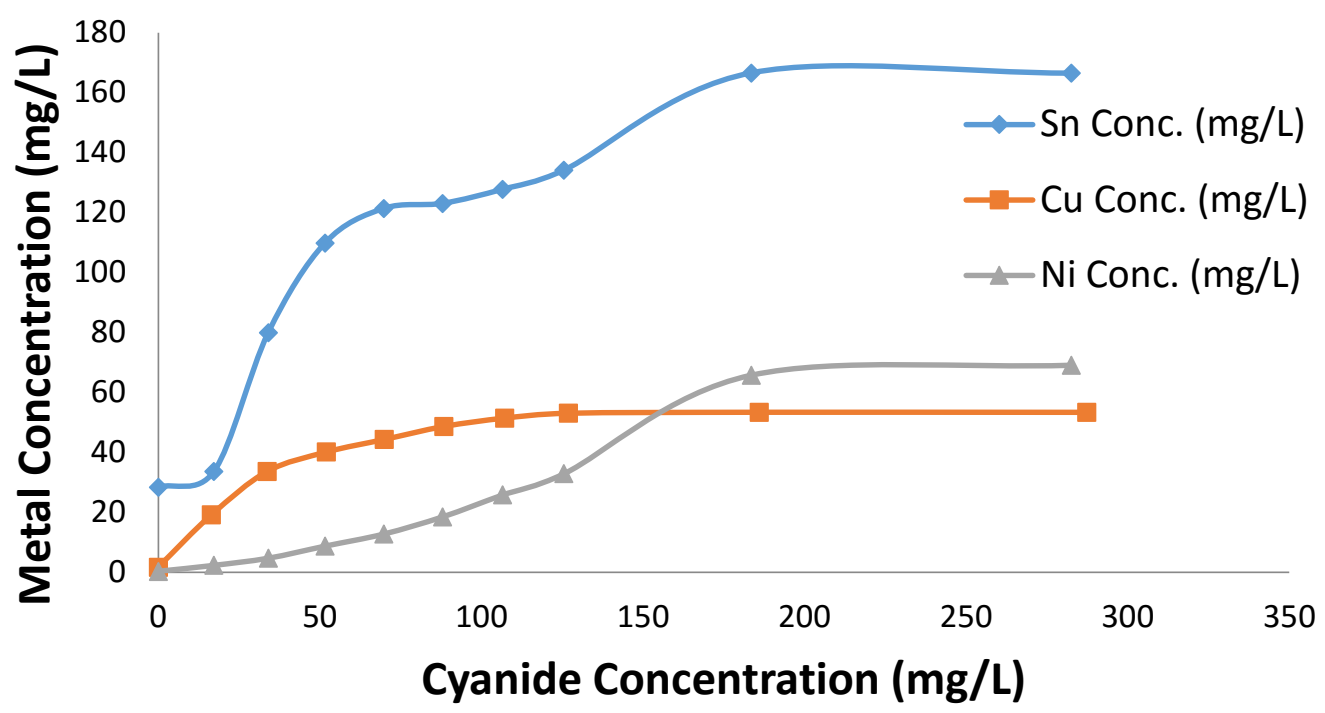

Figure 76: Dependence of Metal Concentration on Cyanide Concentration The graph above shows that cyanide, at the conditions present, favored the formation of Copper Cyanide, then Tin Cyanide before Nickel Cyanide. This is evident since the starting concentration of copper cyanide was reached after just 127 $\mathrm{mg} / \mathrm{L}$ of cyanide was added. For comparison both tin and nickel did not reach starting concentrations until the cyanide concentration had reached $180 \mathrm{mg} / \mathrm{L}$.

A starting cyanide concentration of approximately $50 \mathrm{mg} / \mathrm{L}$ was chosen as it corresponds to measured values at MTM. This led to $\mathrm{Tin}^{+2}, \mathrm{Ni}^{+2}$, and $\mathrm{Cu}^{+2}$ starting concentrations of approximately 110,13 , and $38 \mathrm{mg} / \mathrm{L}$ respectively.

\subsection{EFFECT OF CURRENT DENSITY ON METAL REMOVAL}

The first set of experiments was run varying current density. The chosen metrics were final concentration, first order rate constant, and $\mathrm{R}^{2}$ values for comparison purposes. Again, these experiments were careied out at a $\mathrm{pH}$ of 11 with no agitation. 


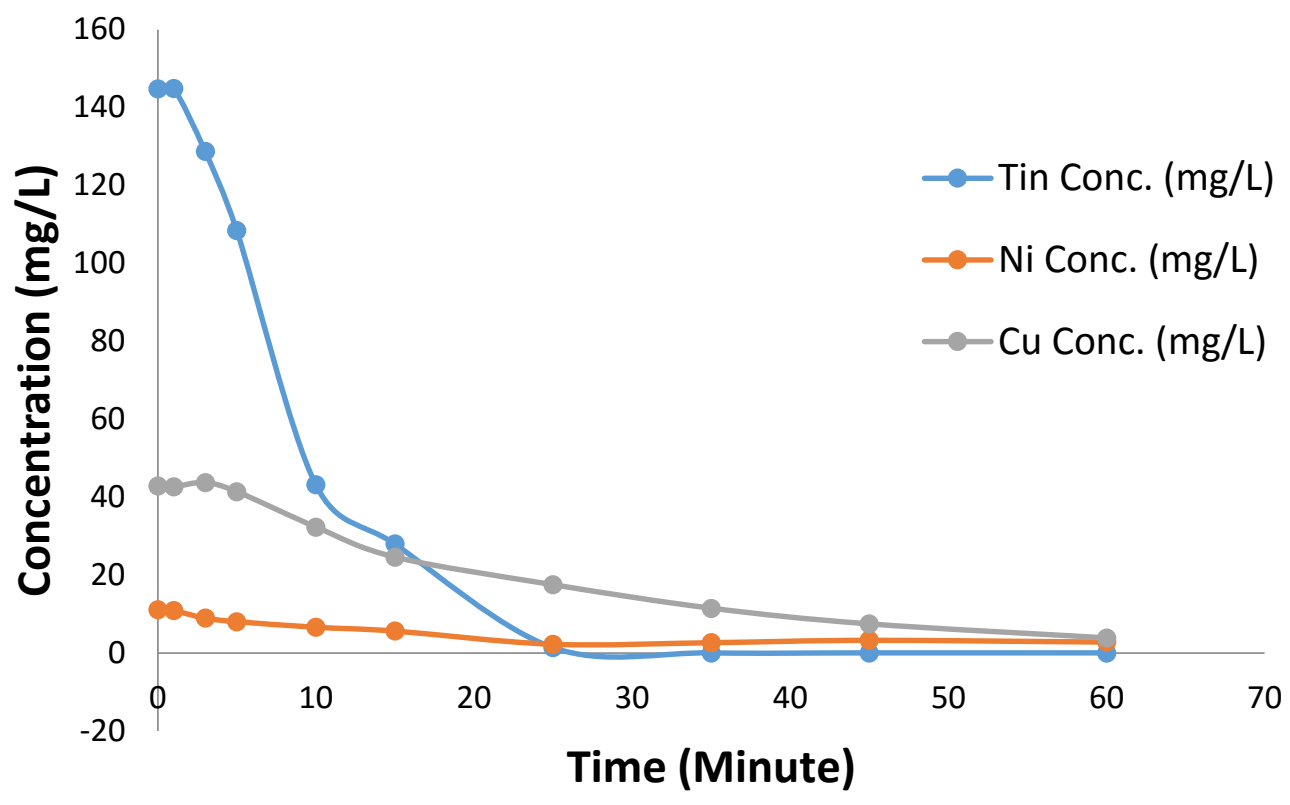

Figure 77: Metal Removal at 25 ASF

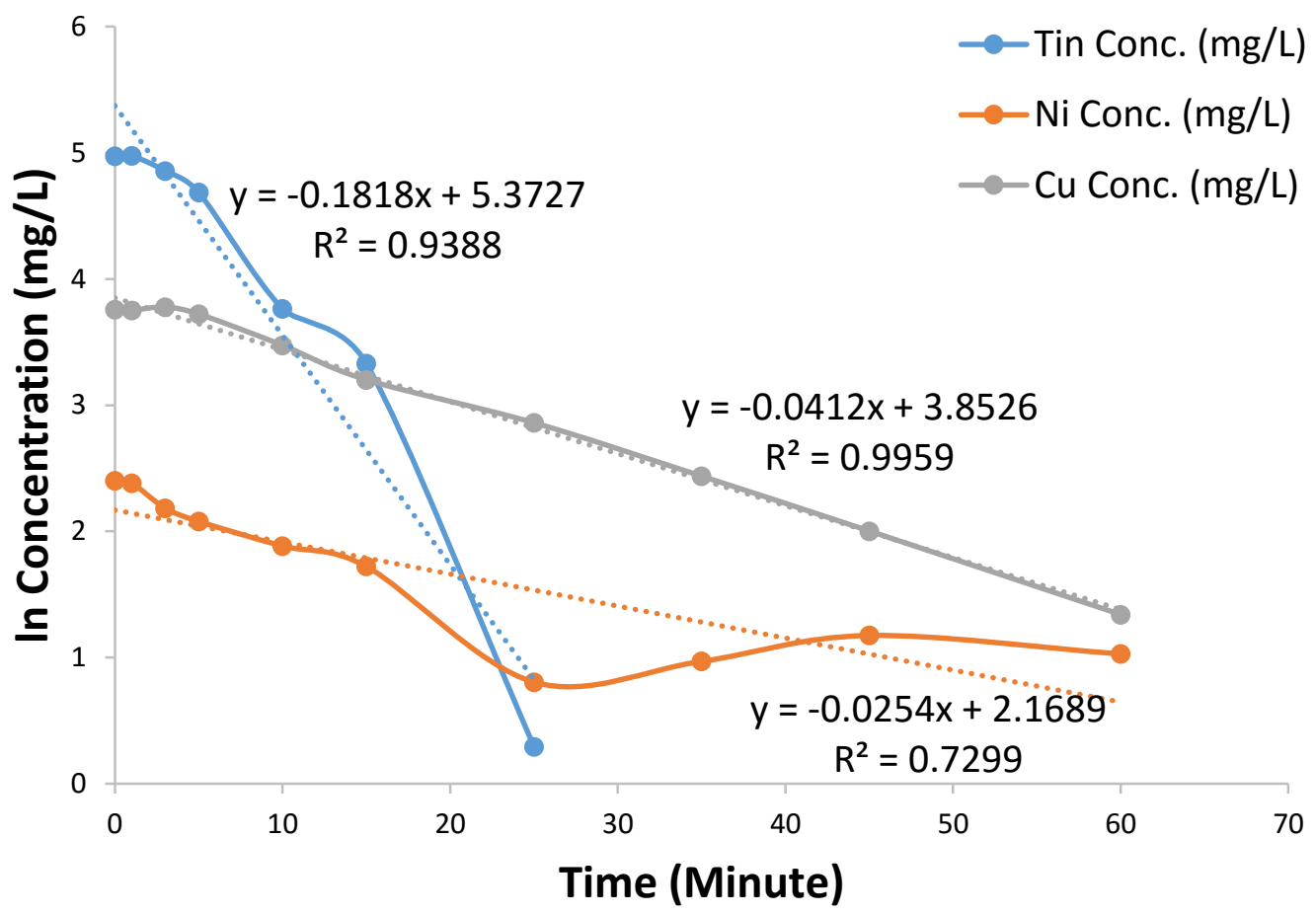

Figure 78: First Order Rate Constant Plot: Full Data, 25 ASF 


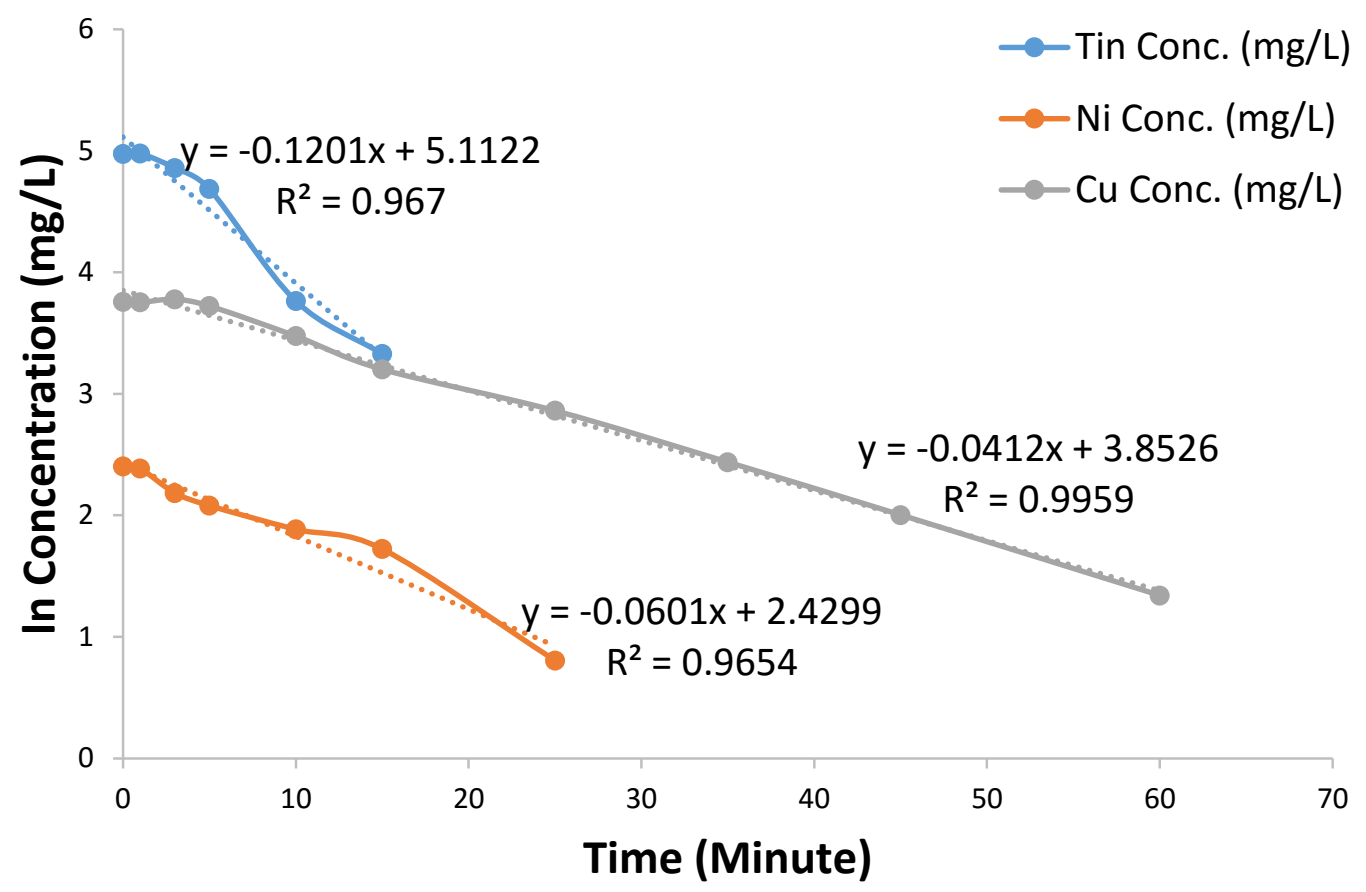

Figure 79: First Order Rate Constant Plot: Linear Region, 25 ASF

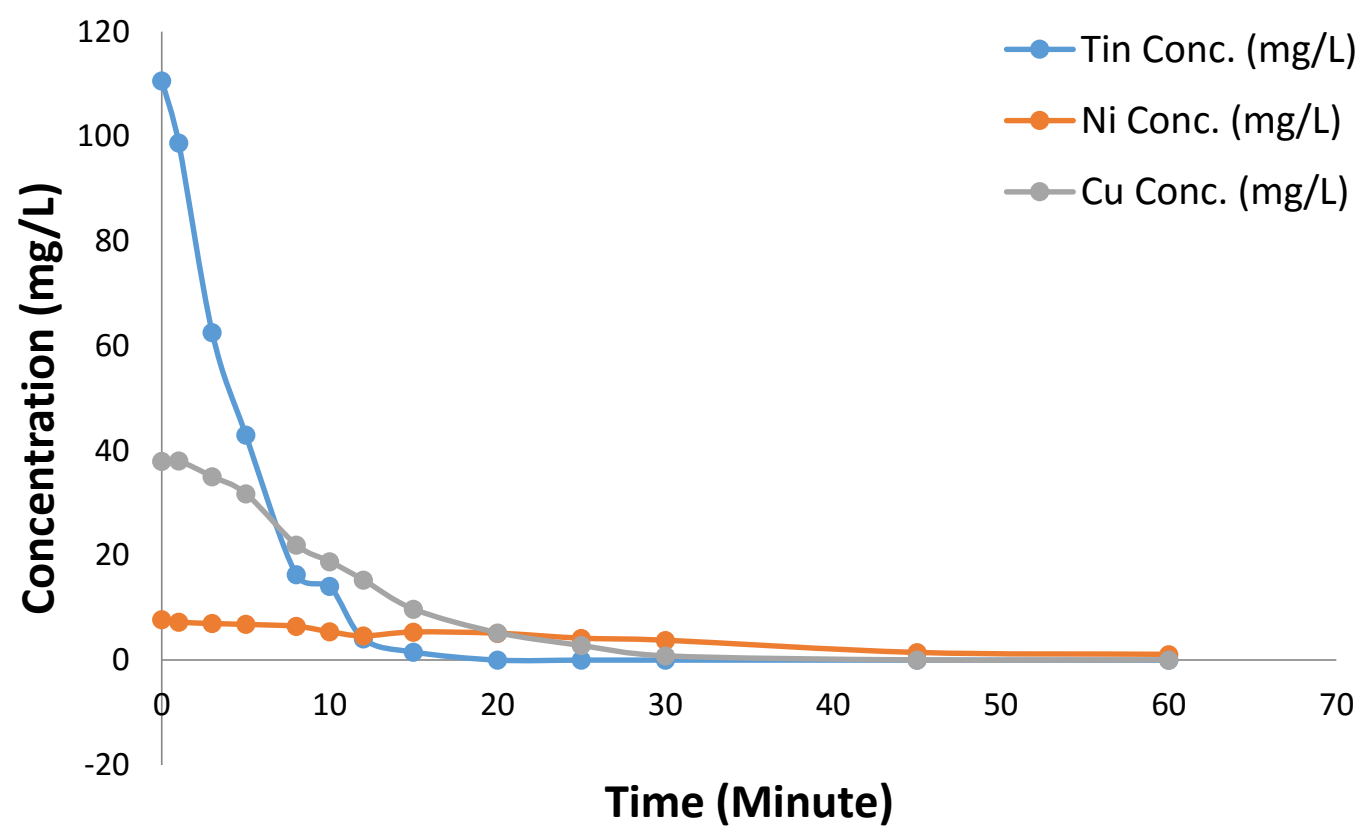

Figure 80: Metal Removal at 50 ASF 


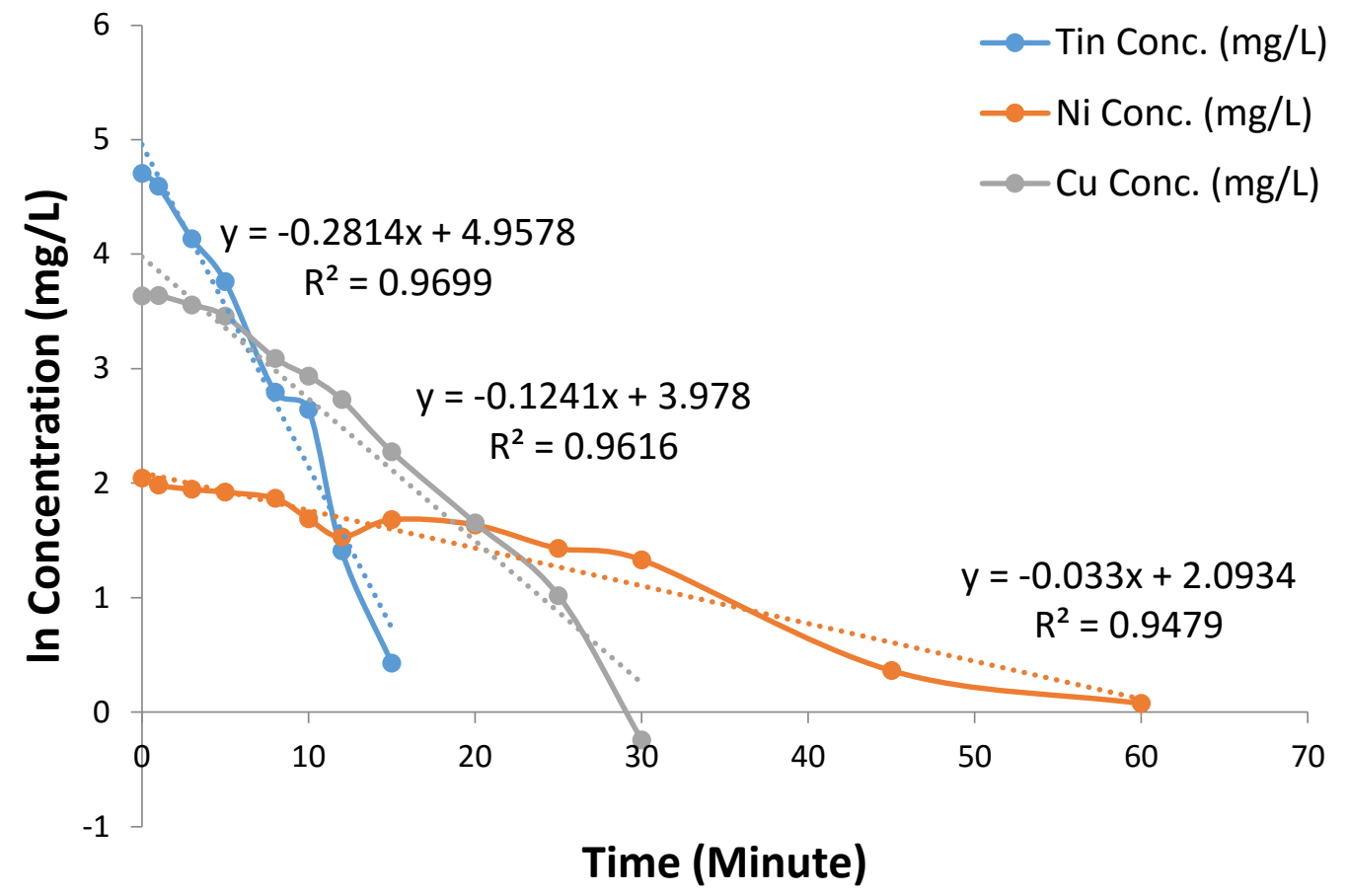

Figure 81: First Order Rate Constant Plot: Full Data, 50 ASF

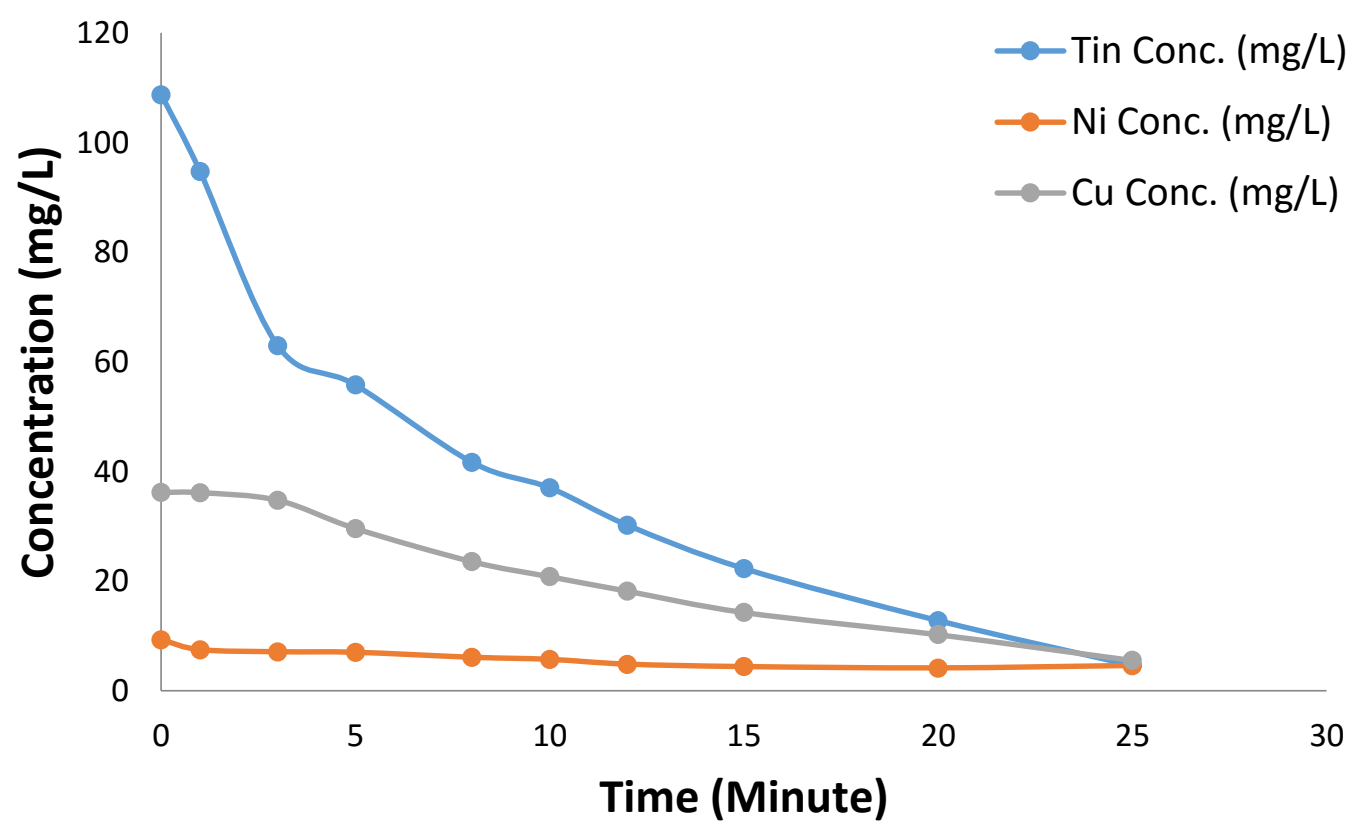

Figure 82: Metal Removal at 75 ASF 


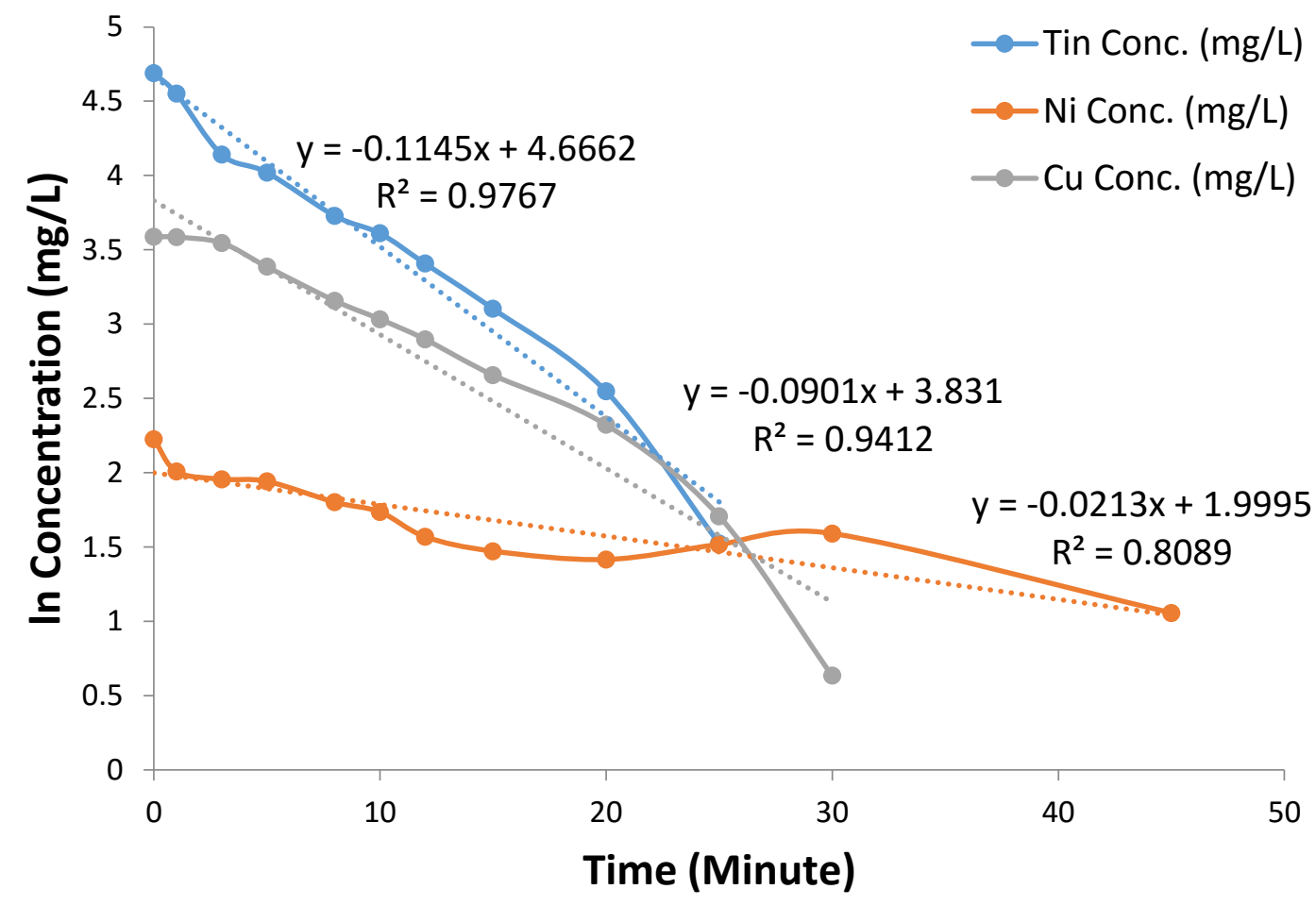

Figure 83: First Order Rate Constant Plot: Full Data, 75 ASF

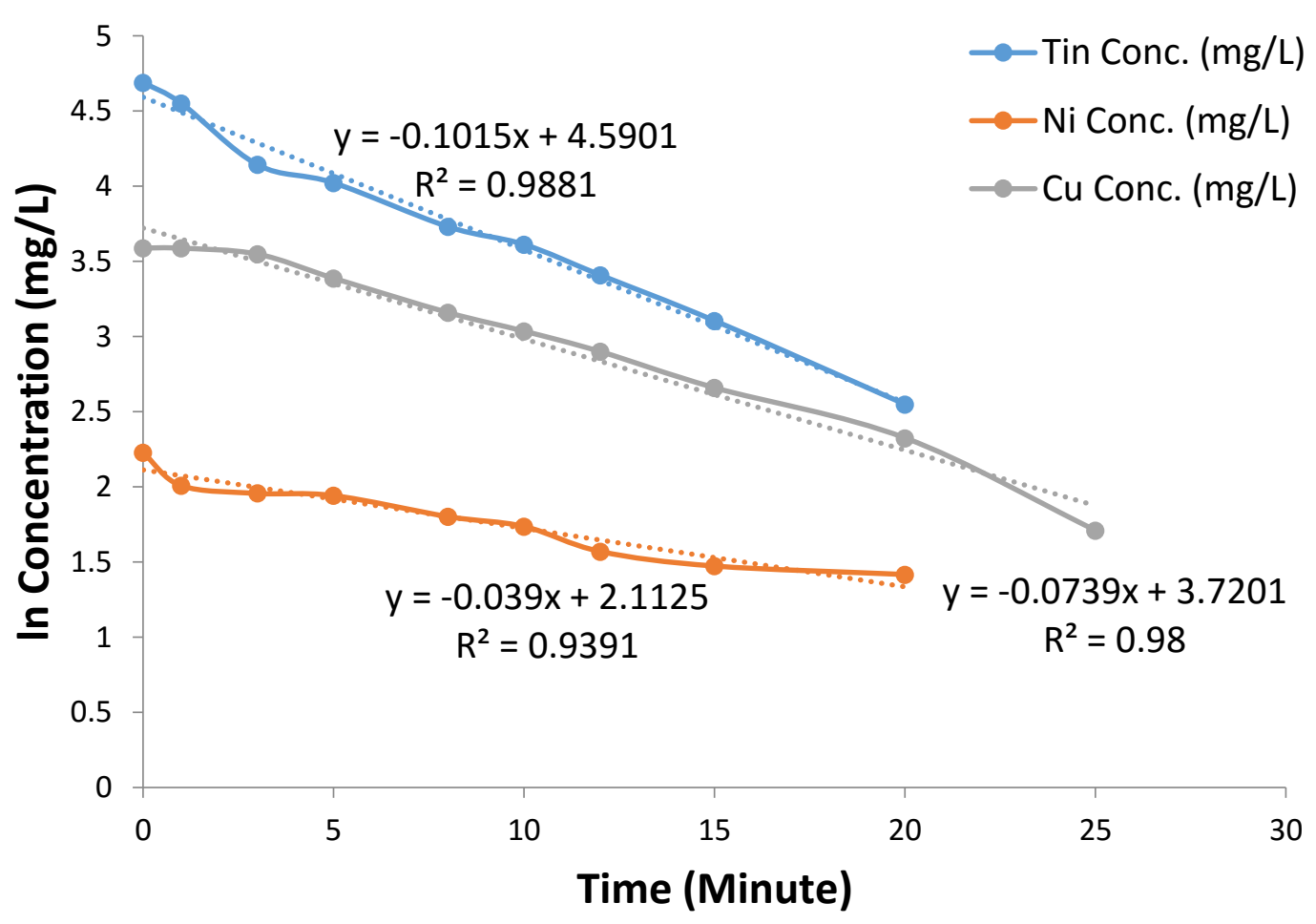

Figure 84: First Order Rate Constant Plot: Linear Region, 75 ASF 


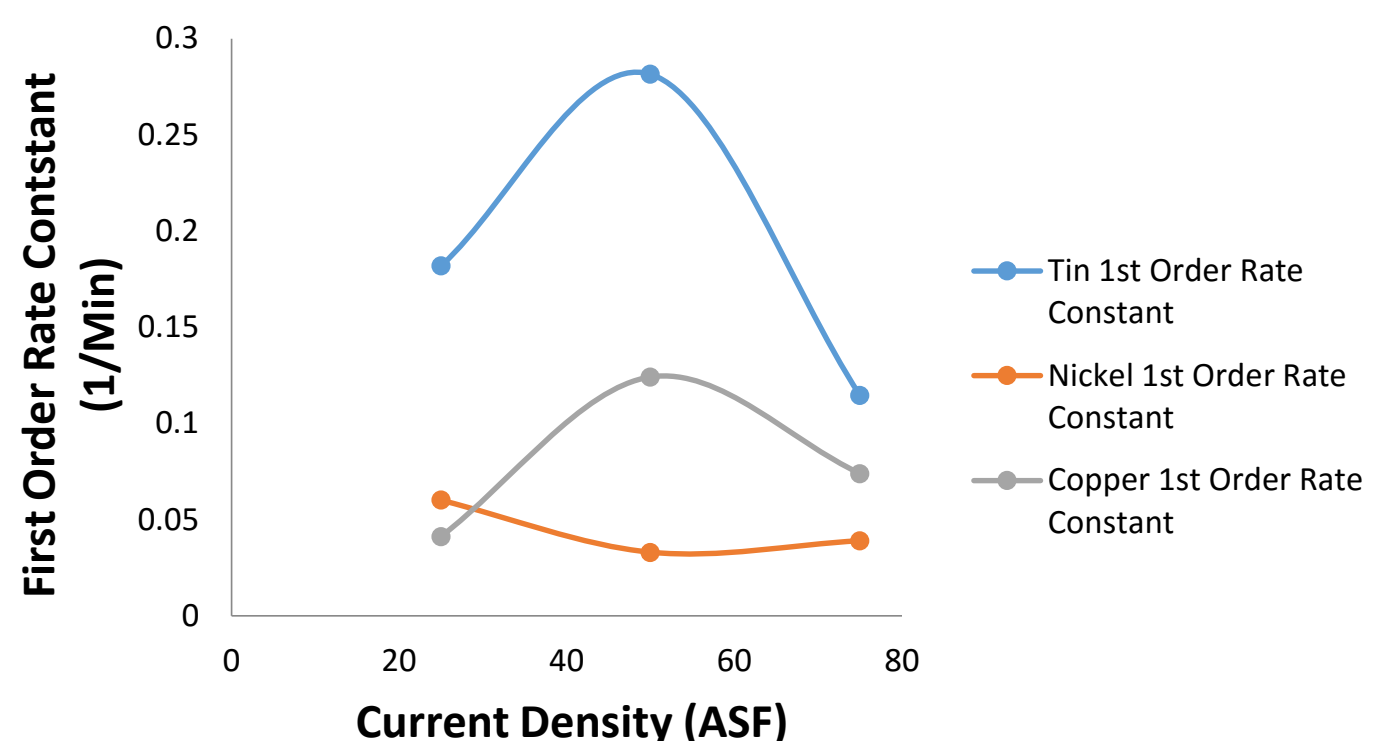

Figure 85: Rate Constant Plot for Optimization of Current Density

In all experiments the contaminant metal levels were reduced below EPA permissible discharge limits by minute 60 . This proved the first hypothesis correct. Electrocoagulation can be used to treat $\mathrm{Tin}^{+2}$ at a $\mathrm{pH}$ of 11 . The rate at which these metals were removed changed with current density as evident by the first order rate constants. Both tin and coper removal peaked at 50 ASF. Nickel removal didn't vary as much as the tin and copper with respect to current density. From this information the optimal current density chosen for spin speed and cyanide experiments was 50 ASF.

One would expect that as the current density increases so too would the contaminant removal. This is because the iron dissolution rate increases with current density and ultimately the iron hydroxide floc concentration rises faster. This was not observed during experimentation. Some explanation has already been given for this effect by Adhoum et al. 2004 and Senturk 2013. They postulated that as the bubble generation rate increases the iron hydroxide floc is swept straight to the top of the 
reactor. This decreases contact time with the contaminants and thus the rate of coagulation. This seems like a plausible explanation for the results observed in this experiment.

\subsection{EFFECT OF STIRRING AGITATION}

The next variable tested was the effect of increased stir bar agitation. Again the metrics chosen were final concentration, first order rate constant and $\mathrm{R}^{2}$ values.

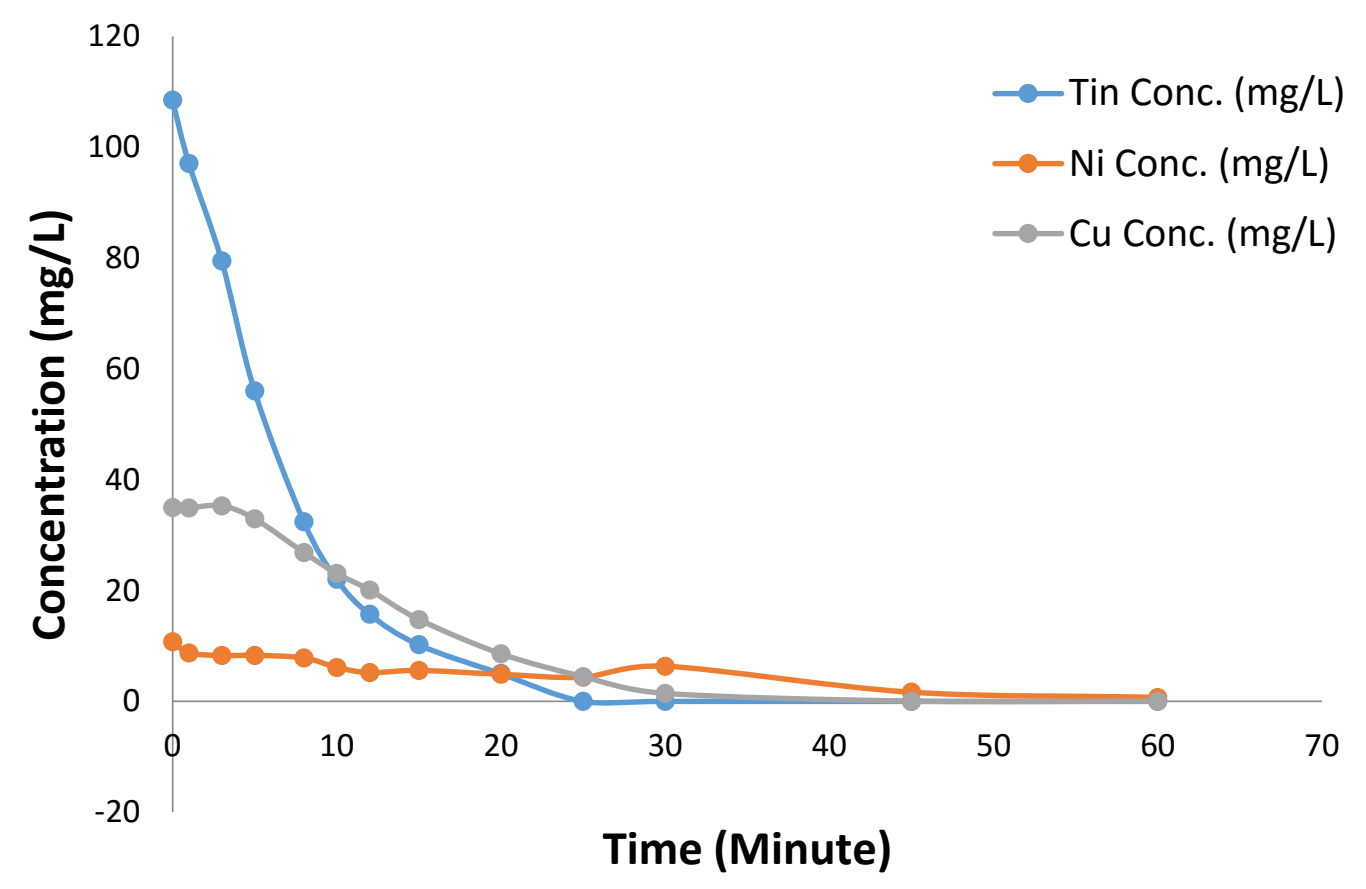

Figure 86: Metal Removal at 50 ASF and 50 RPM 


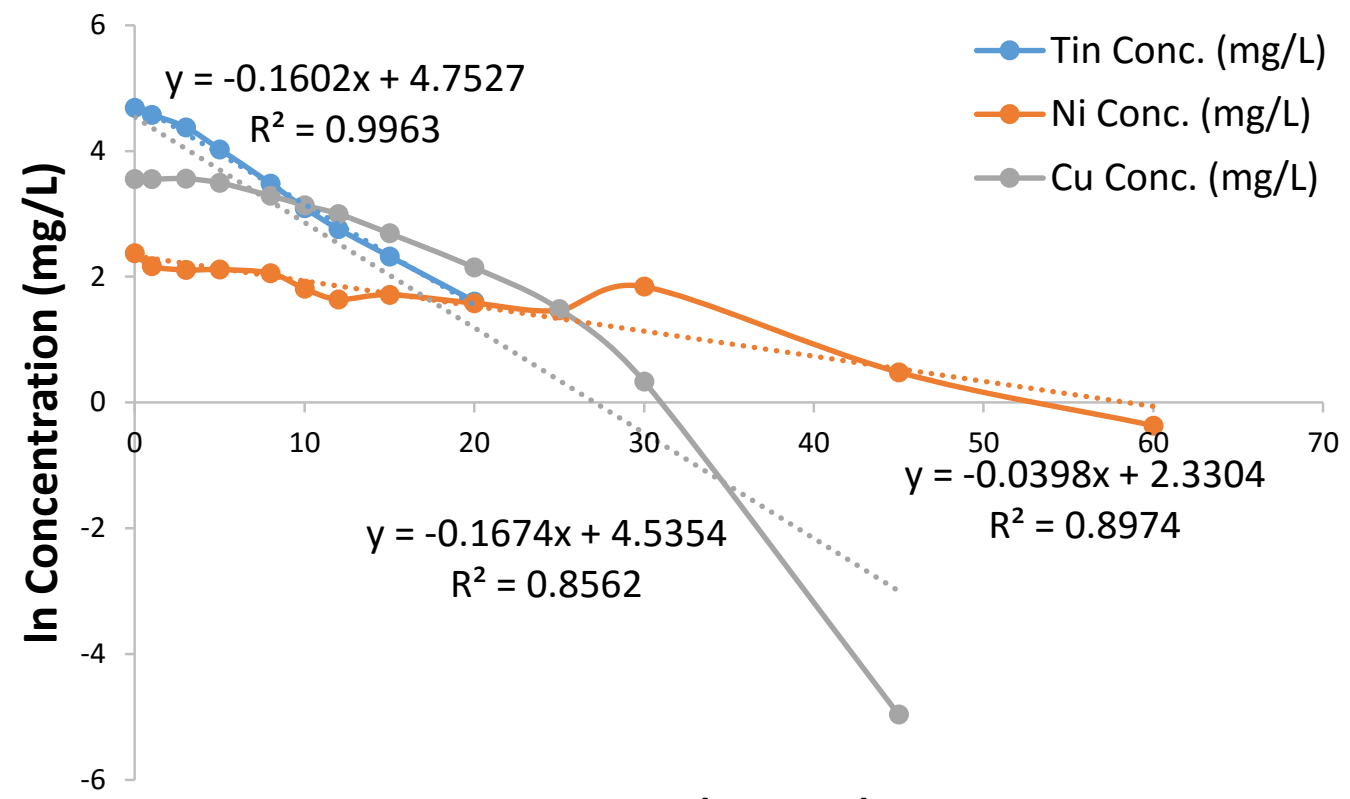

Time (Minute)

Figure 87: First Order Rate Constant Plot: Full Data, 50 ASF, 50 RPM

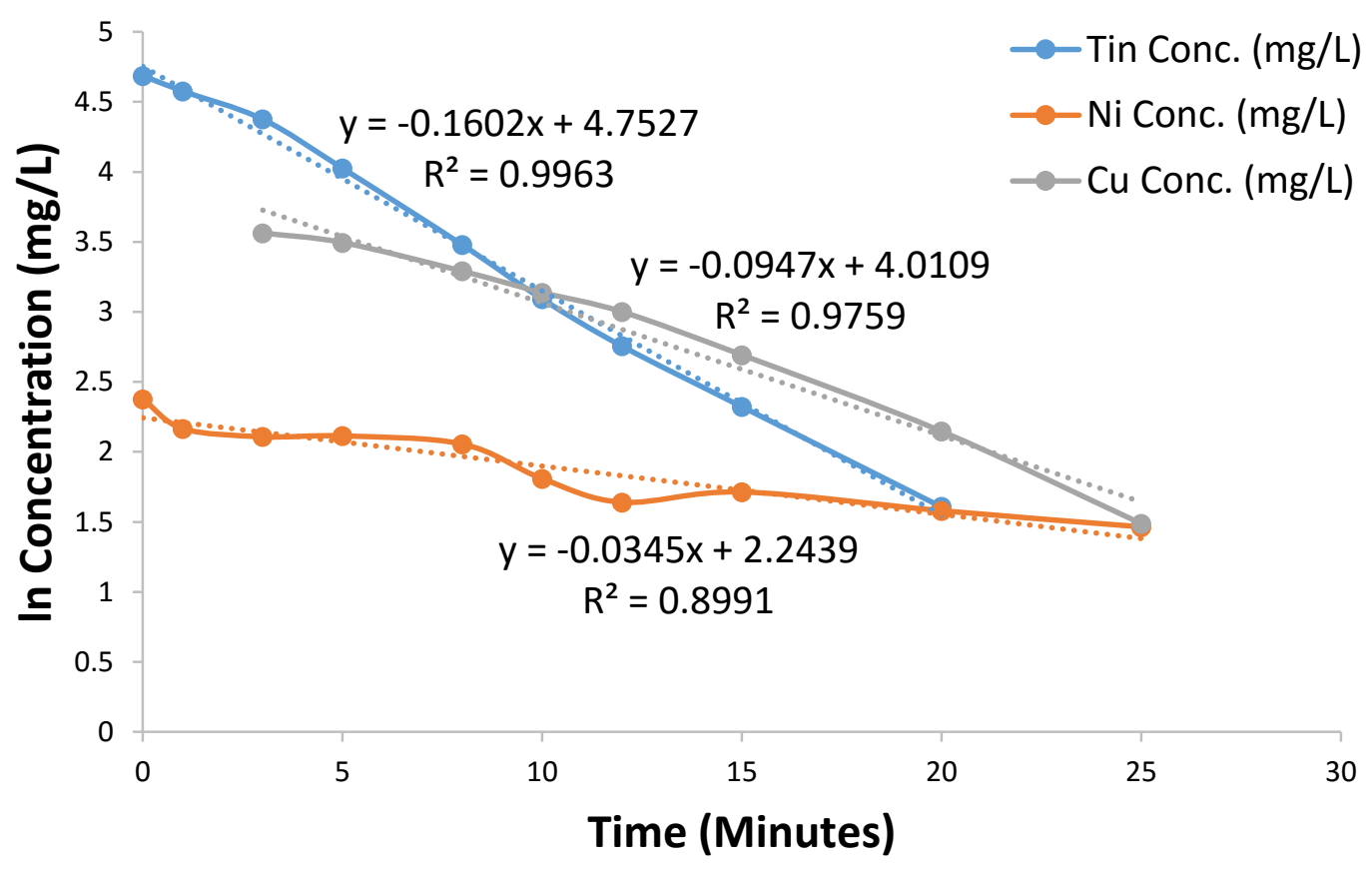

Figure 88: First Order Rate Constant Plot: Linear Region, 50 ASF, 50 RPM 


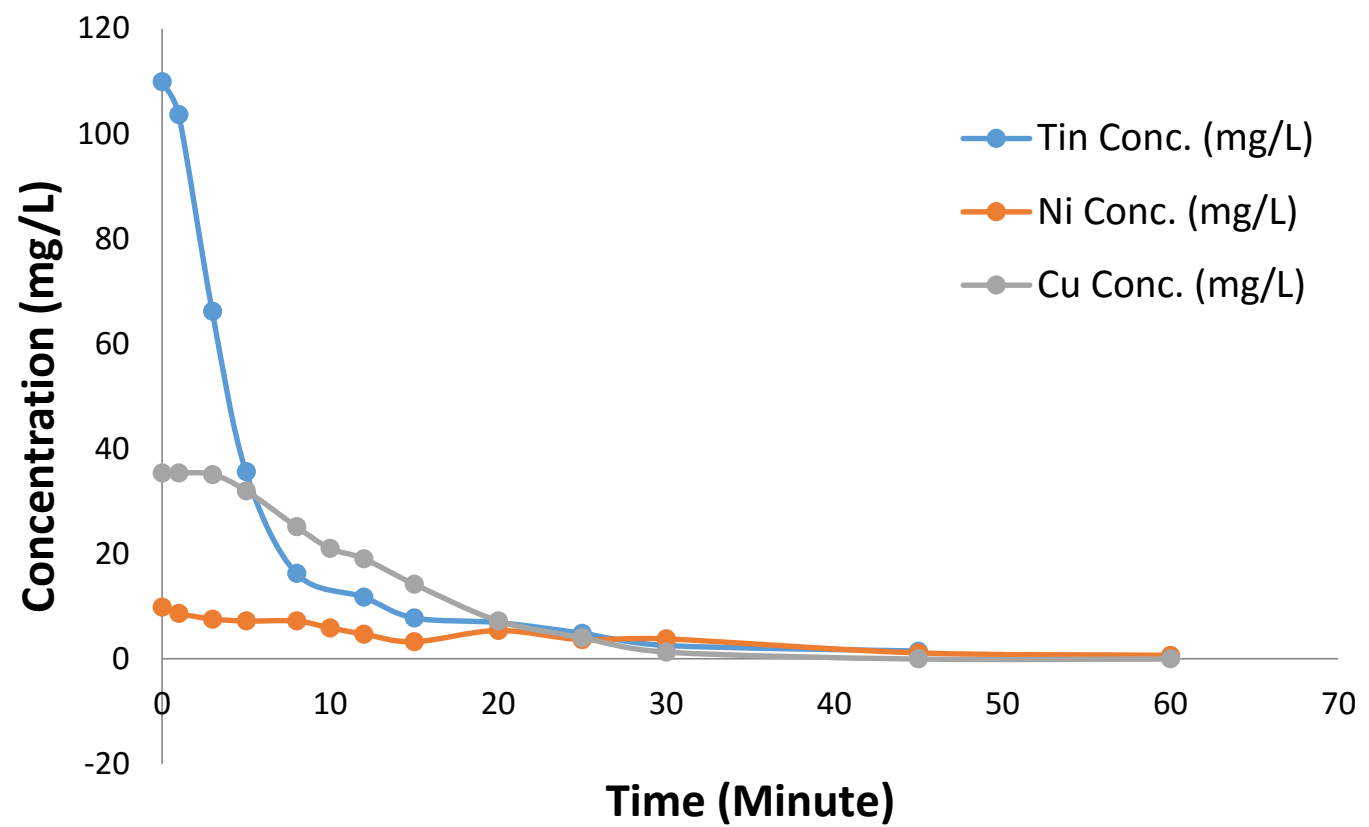

Figure 89: Metal Removal at 50 ASF and 100 RPM

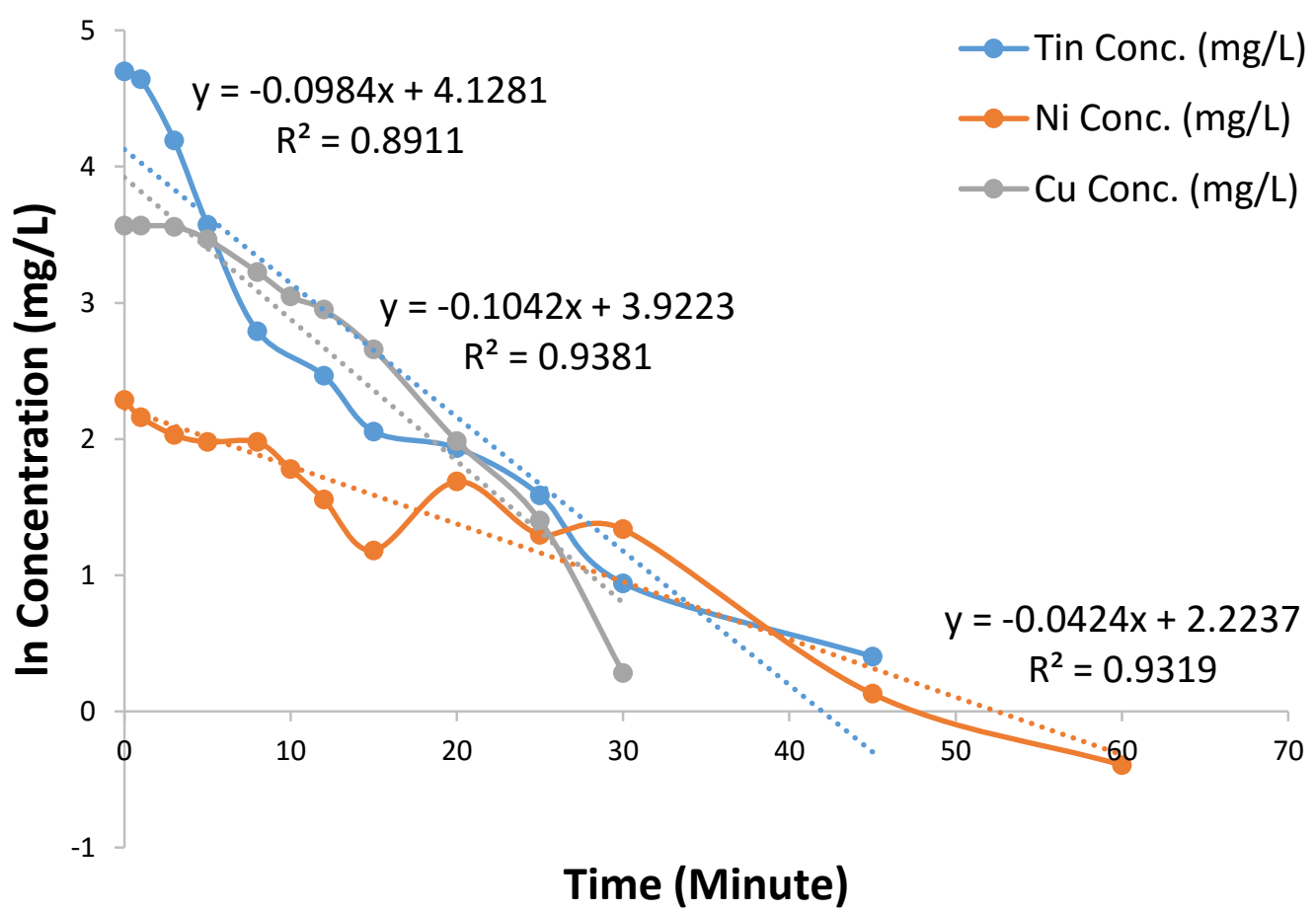

Figure 90: First Order Rate Constant Plot: Full Data, 50 ASF, 100 RPM 


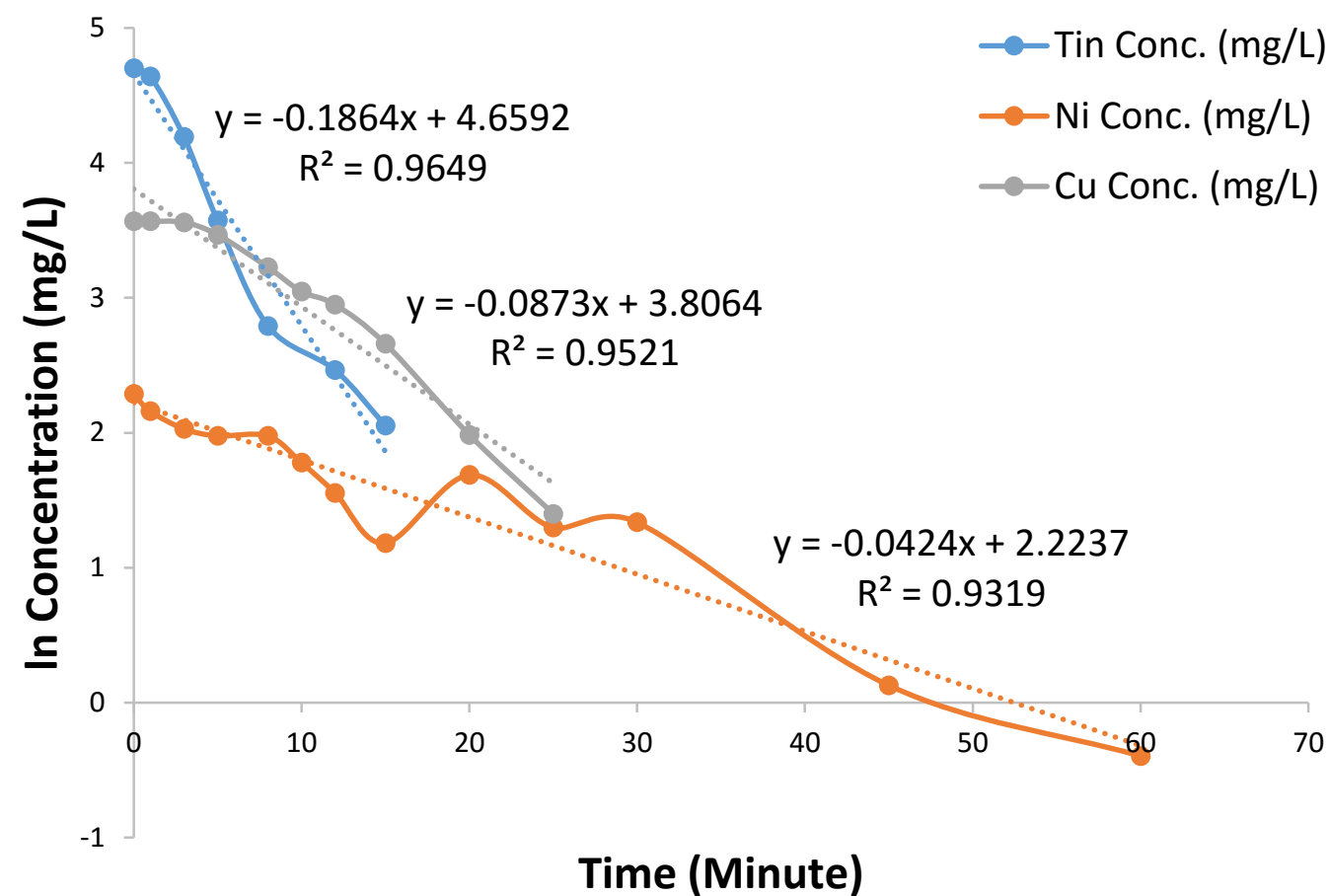

Figure 91: First Order Rate Constant Plot: Linear Region, 50 ASF, 100 RPM

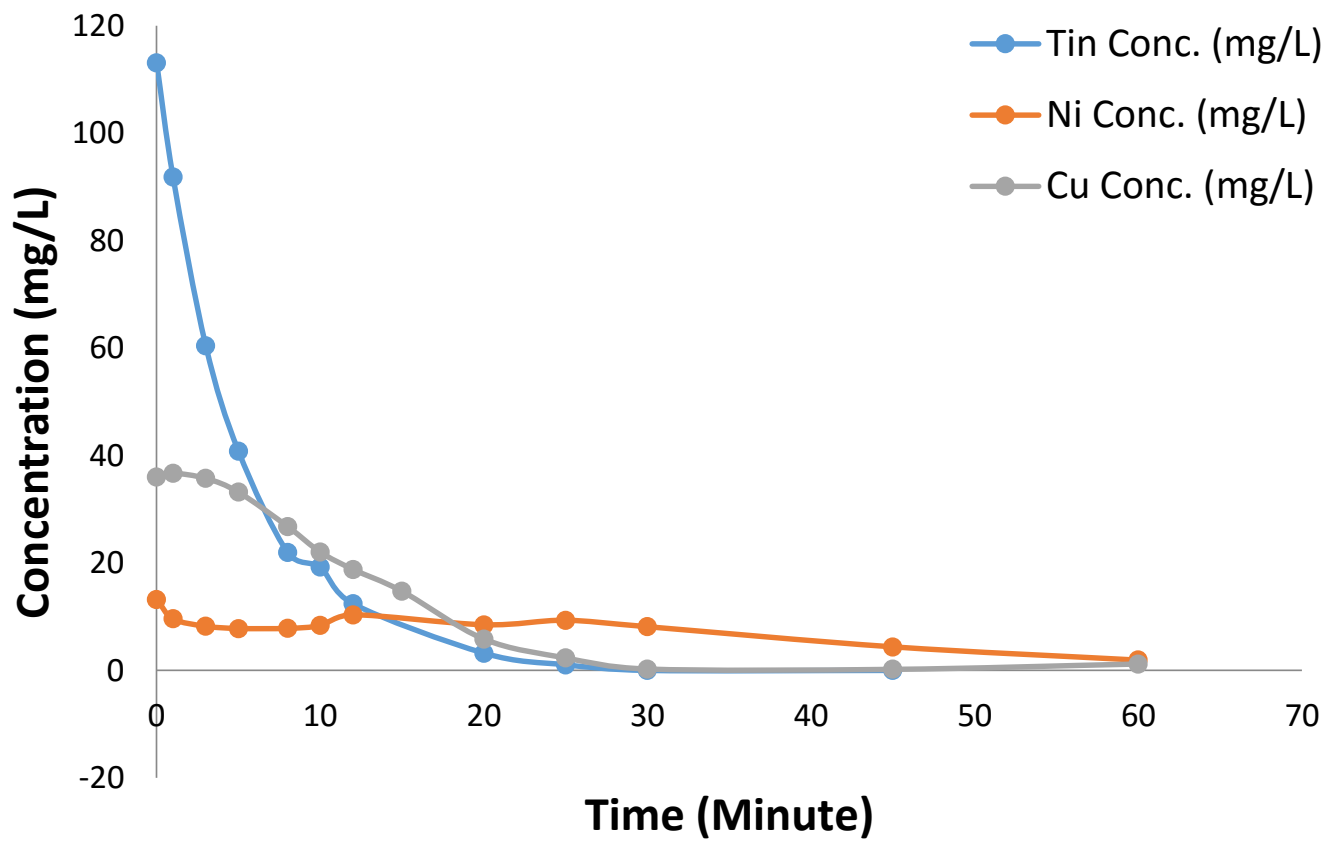

Figure 92: Metal Removal at $50 \mathrm{ASF}$ and $300 \mathrm{RPM}$ 


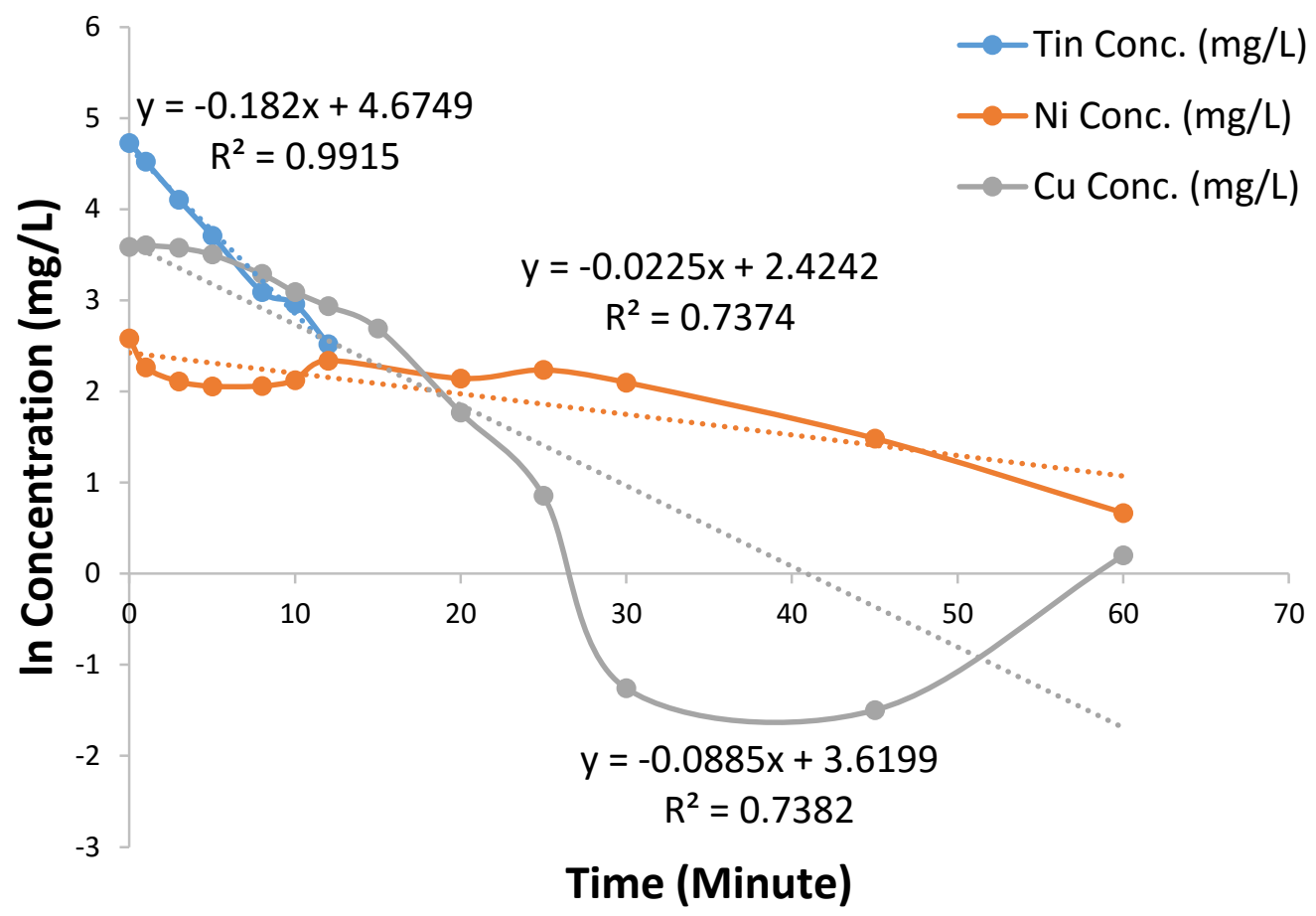

Figure 93: First Order Rate Constant Plot: Full Data, 50 ASF, 300 RPM

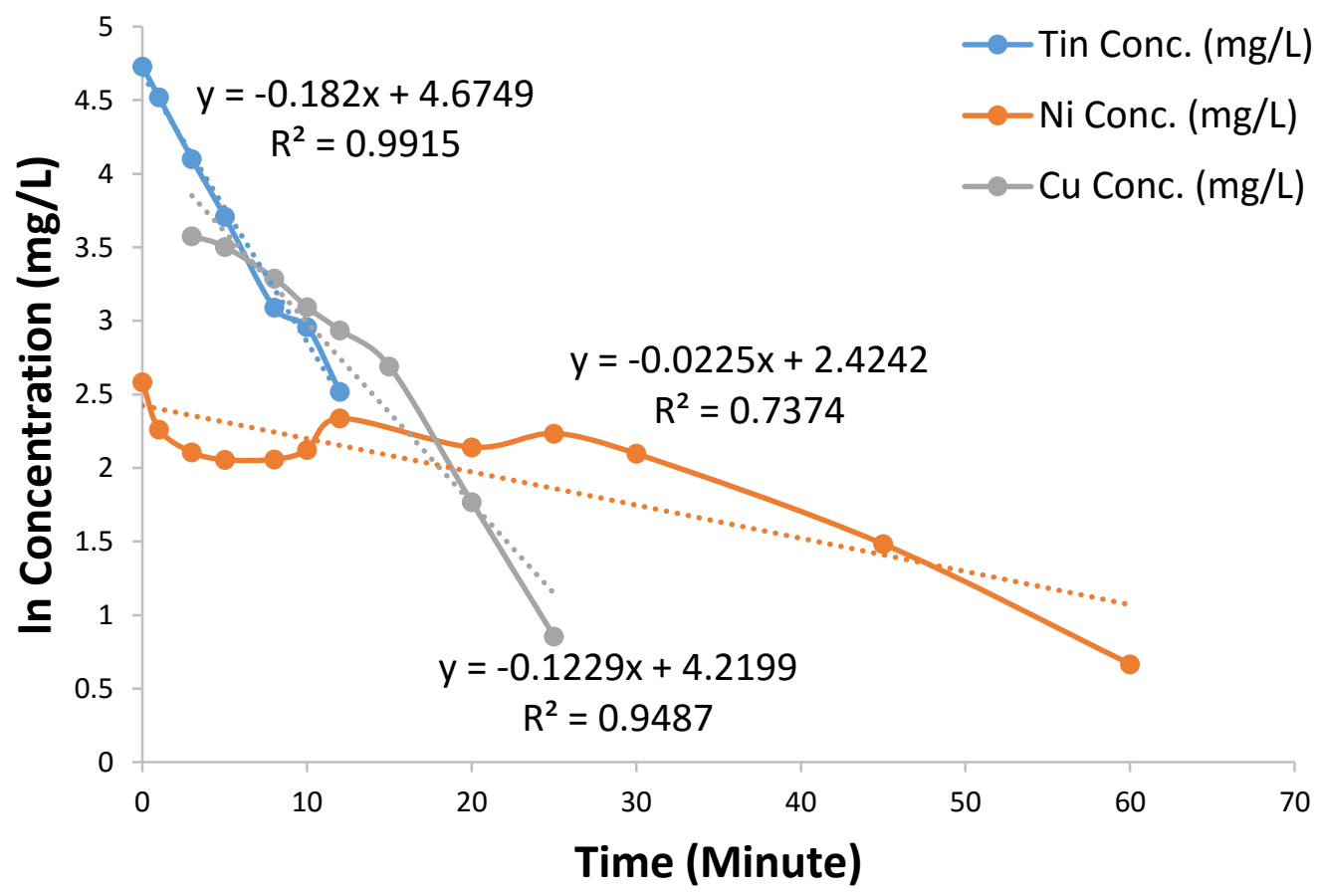

Figure 94: First Order Rate Constant Plot: Linear Region, 50 ASF, 300 RPM 


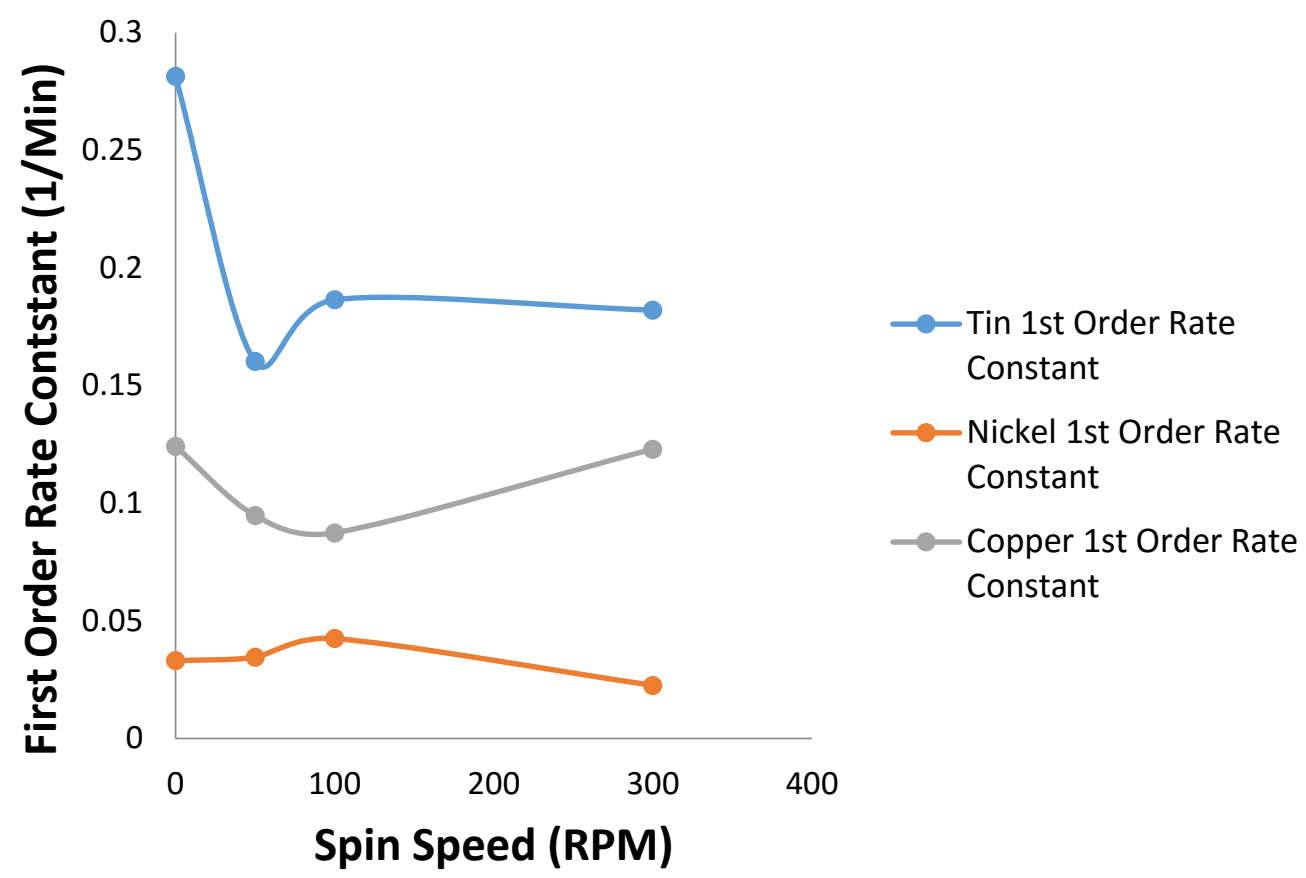

Figure 95: Rate Constant Plot for Optimization of Spin Speed

From the graphs above you can see that the greatest rate of contaminant removal for copper and tin occurred at 0 RPM corresponding to a first order rate constant of 0.1241 and $0.28141 /$ minute respectively. The removal rate for nickel was fairly constant from 0 to 100 RPM, with 100 RPM showing the highest constant of $0.04241 / \mathrm{min}$. It showed a slight downward trend after 100 RPM. Since this metal takes the longest for treatment and faster spin speeds would likely decrease the constant further, the testing was stopped at 300 RPM. It is important to note that copper was the only element to show an upward trend approaching 300 RPM which may continue to increase at higher spin speeds.

\subsection{DEPARTURE FROM FIRST ORDER KINETICS}

One distinct difference between the results here and those in literature is the departure from first order kinetics at low treatment times. Particularly in the 0 to 5 
minute range. This is best shown in the copper results repeated below, but can be found in all 3 elements.

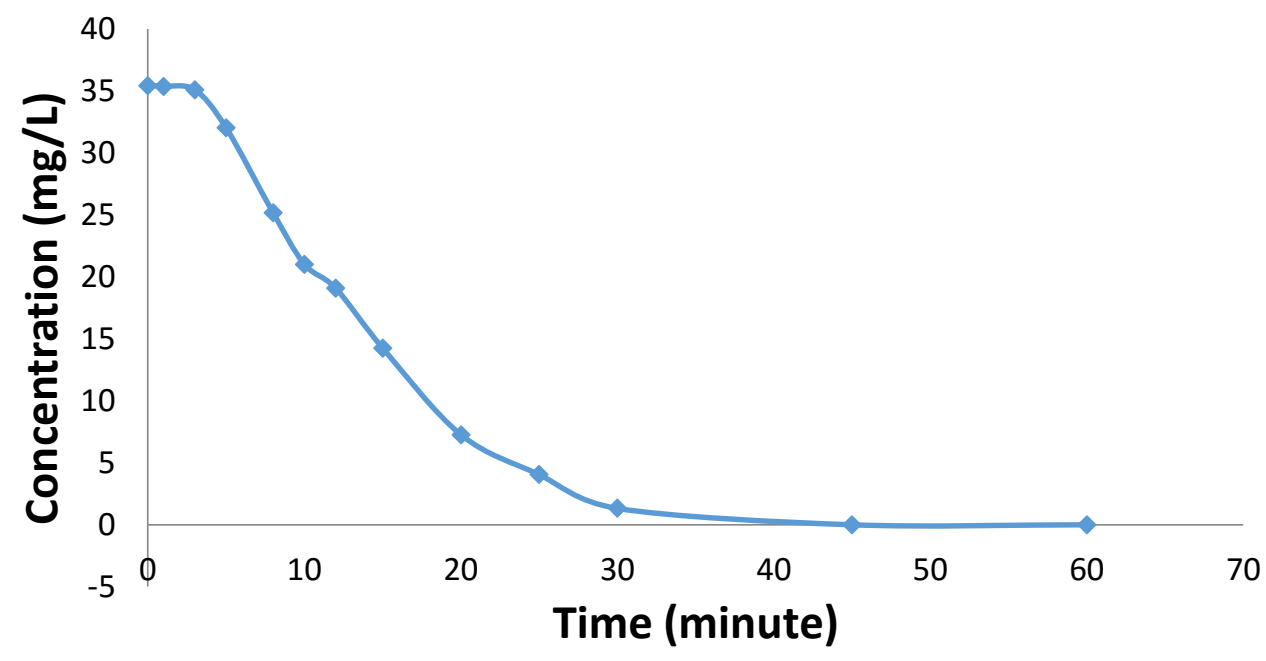

Figure 96: Copper Removal Plot demonstrating departure from first order kinetics at low treatment time (50 ASF, 100 RPM)

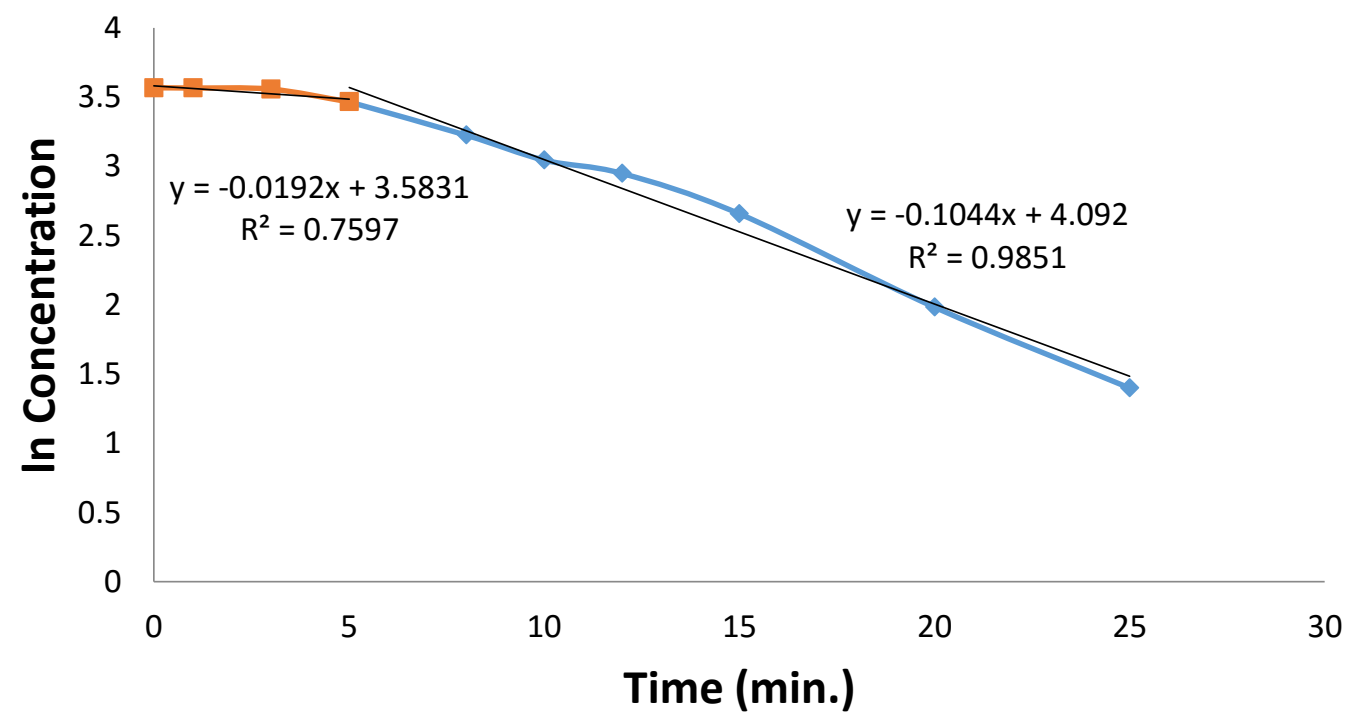

Figure 97: First Order Coefficient plot demonstrating departure from first order kinetics at low treatment time (50 ASF, 100 RPM)

One possible explanation for this deals with the hydroxide and cyanide equilibrium reactions shown earlier: 


$$
\begin{gathered}
\mathrm{Cu}^{+2}+2 \mathrm{OH}^{-} \leftrightarrow \mathrm{Cu}(\mathrm{OH})_{2(\mathrm{~s})} \quad \mathrm{Ksp}=2.2 \mathrm{e}-20 \\
\mathrm{Cu}^{+}+4 \mathrm{CN}^{-} \leftrightarrow\left[\mathrm{Cu}(\mathrm{CN})_{4}\right]^{-3} \mathrm{Kf}=2.0 \mathrm{e} 30
\end{gathered}
$$

As copper is plated out of solution the equilibrium in equation 70 shifts to the left.

This causes more copper hydroxide to dissolve to $\mathrm{Cu}^{+2}+2 \mathrm{OH}^{-}$which ultimately reacts with free cyanide to form $\left[\mathrm{Cu}(\mathrm{CN})_{4}\right]^{-3}$. Thus at low treatment times the copper concentration may remain fairly constant due to a slow equilibrium step, or until all the copper has completely reacted.

Another possible explanation is the competition between different metals for removal through the various mechanisms present. This could either be direct electrochemical reduction to the cathode surface or adsorption/enmeshment into the growing floc.

To test these theories another 3 sets of tests were run at $50 \mathrm{ASF}$, and 0 RPM. The first 2 varied the initial concentration of copper ( 24 and $72 \mathrm{mg} / \mathrm{L}$ ). If the equilibrium is to blame for the departure from first order kinetics then adding more copper should yield even longer departure times before first order kinetics set in. In contrast, the lower copper concentration should yeield shorter departure times.

The third test removed tin and nickel from solution focusing only on copper metal. To ensure insoluble copper hydroxide remained present, and thus the possibility of equilibrium effects, the cyanide concentration was lowered to $10 \mathrm{mg} / \mathrm{L}$. If competition is truly to blame then even with copper hydroxide present there should be an immediate decrease in concentration during operation. 


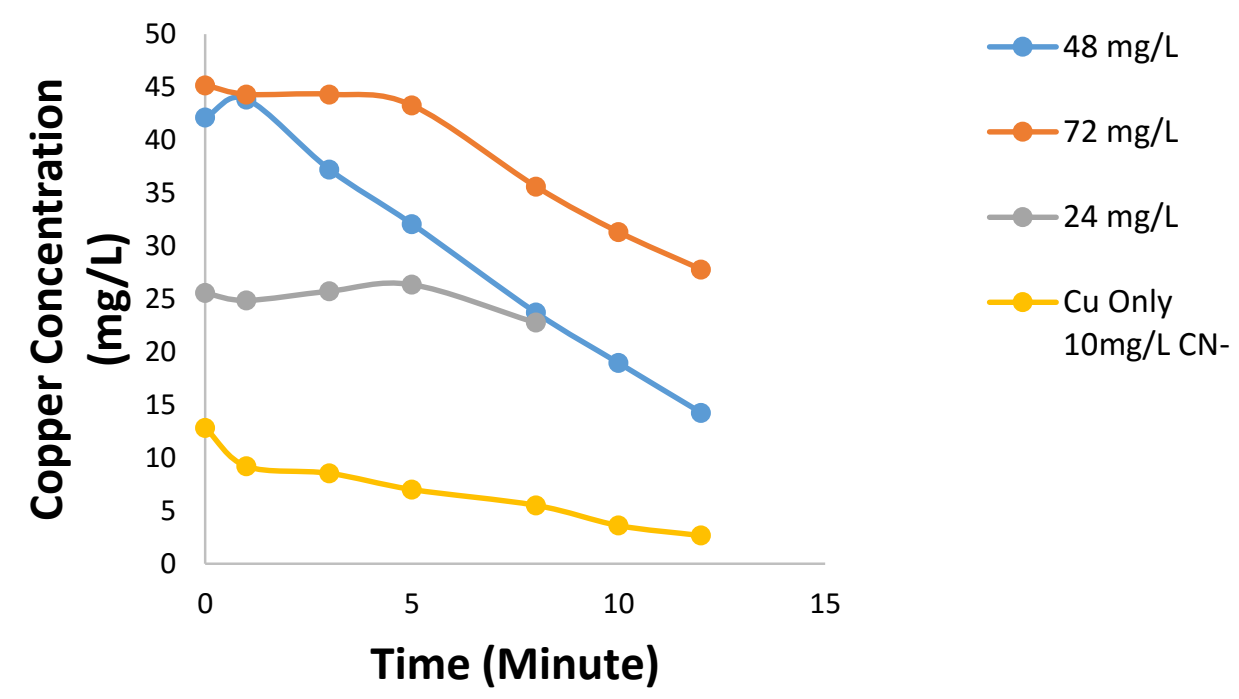

Figure 98: Influence of Initial Copper Concentration on First Order Reaction Kinetics

As you can see from the graph above, the only trial to show an immediate decrease in concentration during treatment was the "copper only" sample. This indicates the departure from first order kinetics at low treatment time is likely caused by competition for removal among the different metals. It also gives merit to the practice in the previous section of removing the low treatment times from some of the kinetic constant fits.

\subsection{CYANIDE REMOVAL: NO AERATION}

Using the optimized values from the metal removal experiments (50 ASF, stir speed of 0 RPM) cyanide removal was tested. To account for the increased treatment time shown in literature, experiments were carried out up to 2 hours and 40 minutes in some cases. 


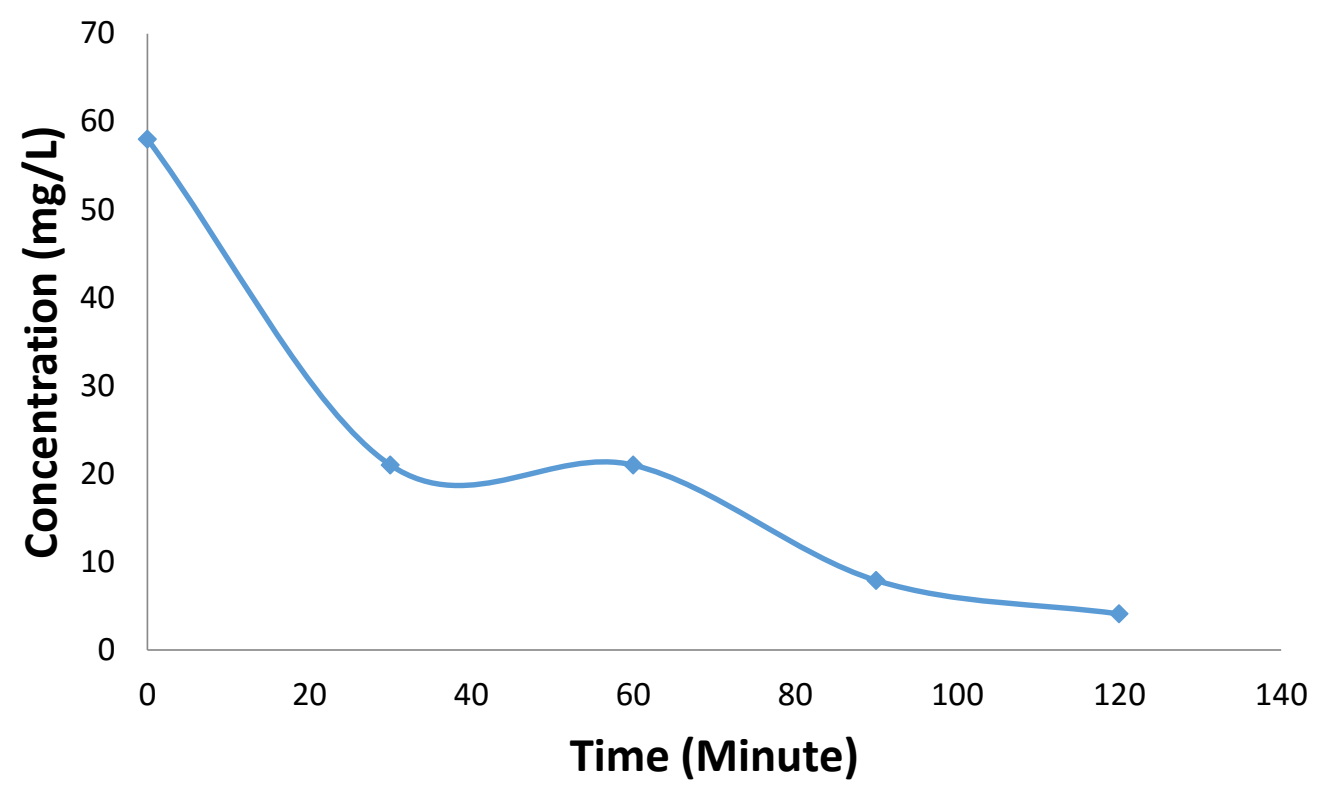

Figure 99: Cyanide Removal at 50 ASF, ORPM

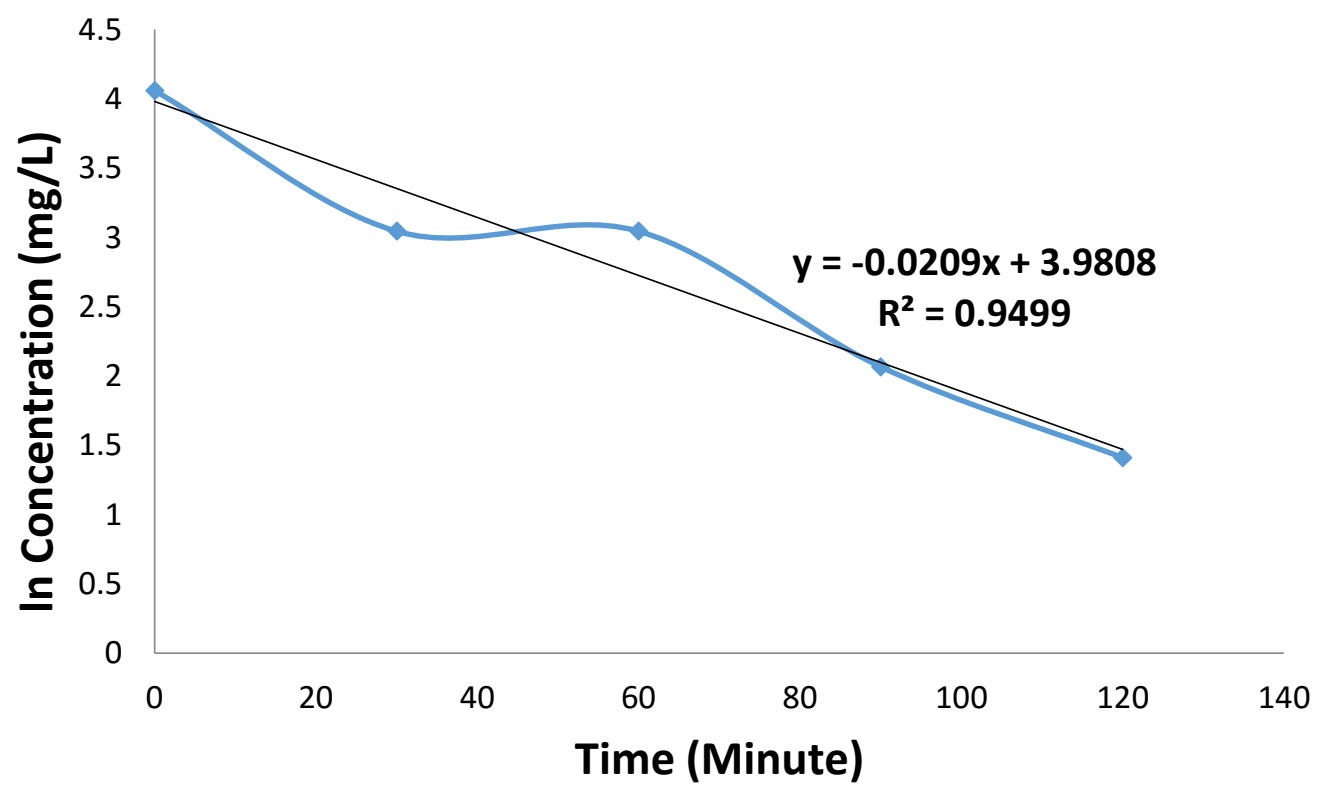

Figure 100: First Order Rate Constant Plot: Cyanide, Full Data, 50 ASF, 0 RPM Cyanide was dropped from $58 \mathrm{mg} / \mathrm{L}$ to $4.1 \mathrm{mg} / \mathrm{L}$ in 2 hours yielding a removal efficiency of $92.9 \%$. The cyanide removal also displayed first order reaction kinetics. 
However, as observed in the literature, cyanide removal occurred much slower than metal removal and thus becomes the largest contributer to operating cost.

\subsection{CYANIDE REMOVAL: WITH AERATION}

As stated in the experimental procedure section, Moussavi et al. was able to show an increase in the rate of free cyanide removal through the use of aeration. Though free cyanide and complex cyanide removal have been shown to exhibit different removal characteristics (Moussavi et al. 2011, Kobya et al. 2010), the use of aeration was also tested in this experiment. The hypothesis again being increased conversion of ferrous to ferric iron hydroxide would create a more gelatinous floc and should increase the rate of complex cyanide removal. Three different air flow rates were tested $\left(0.00209,0.004189,0.006283 \mathrm{ft}^{3} / \mathrm{min}\right)$.

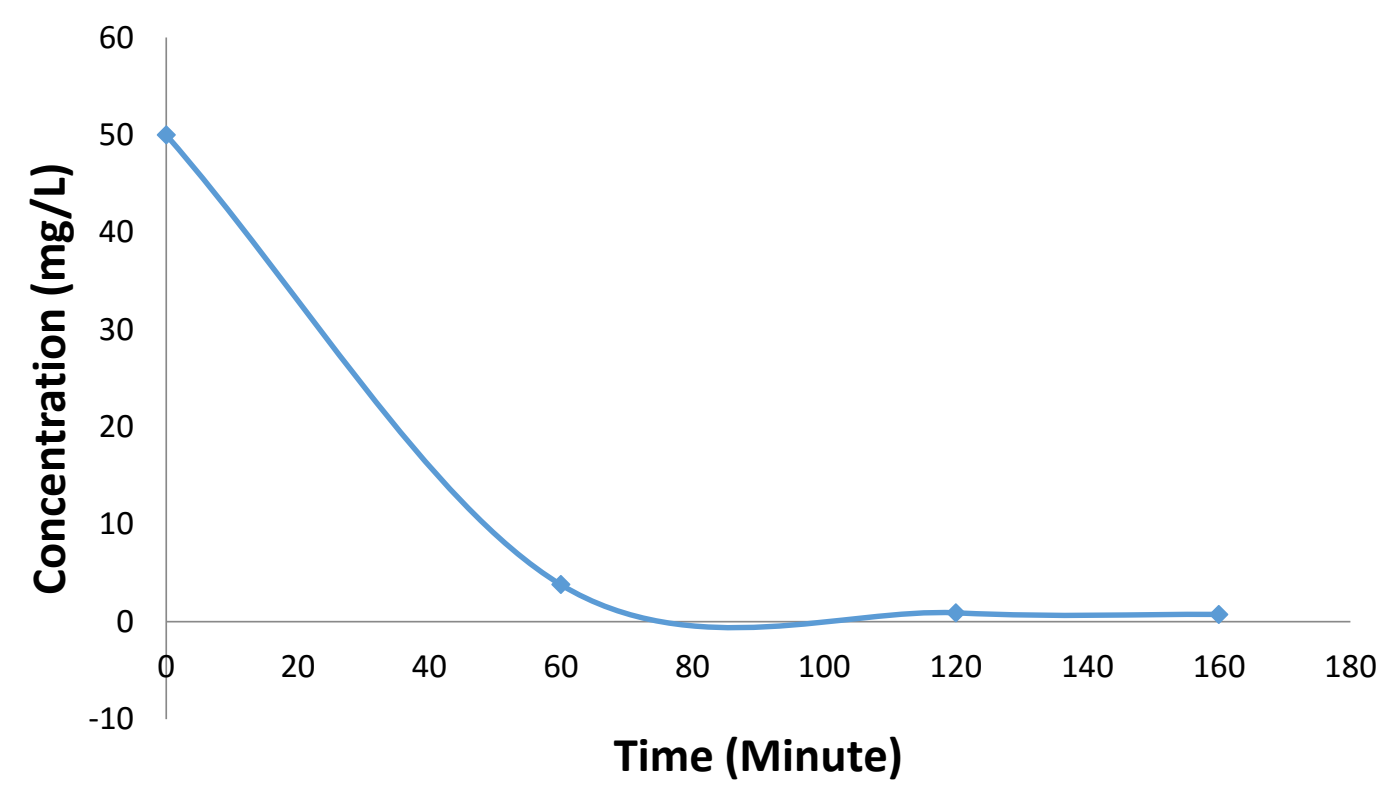

Figure 101: Cyanide Removal at 50 ASF, ORPM, $0.0021 \mathrm{ft}^{3} / \mathrm{min}$ Air Flow 


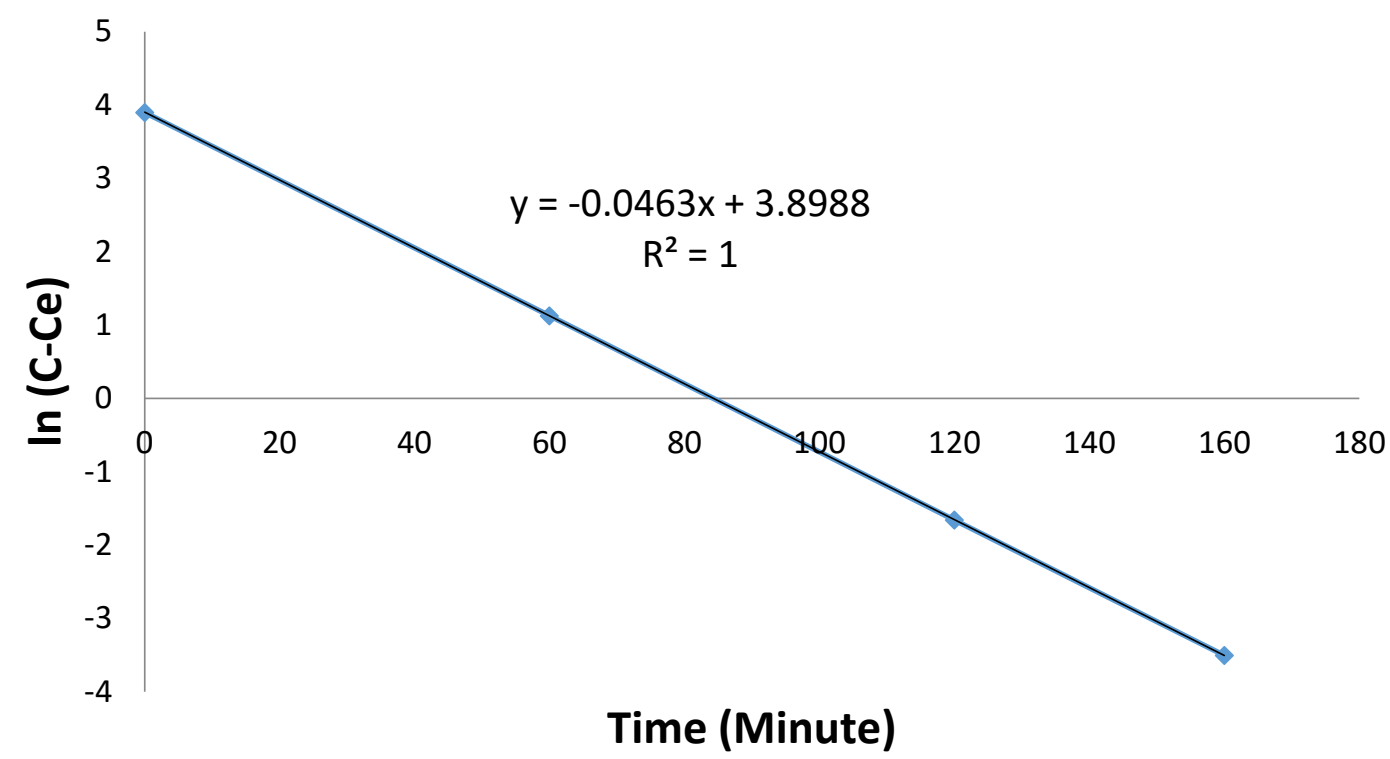

Figure 102: Pseudo-First Order Rate Constant Plot: Cyanide, Full Data, 50 ASF, 0 RPM, $0.0021 \mathrm{ft}^{3} / \mathrm{min}$ Air Flow, Equilibrium Concentration $0.72 \mathrm{mg} / \mathrm{L}$

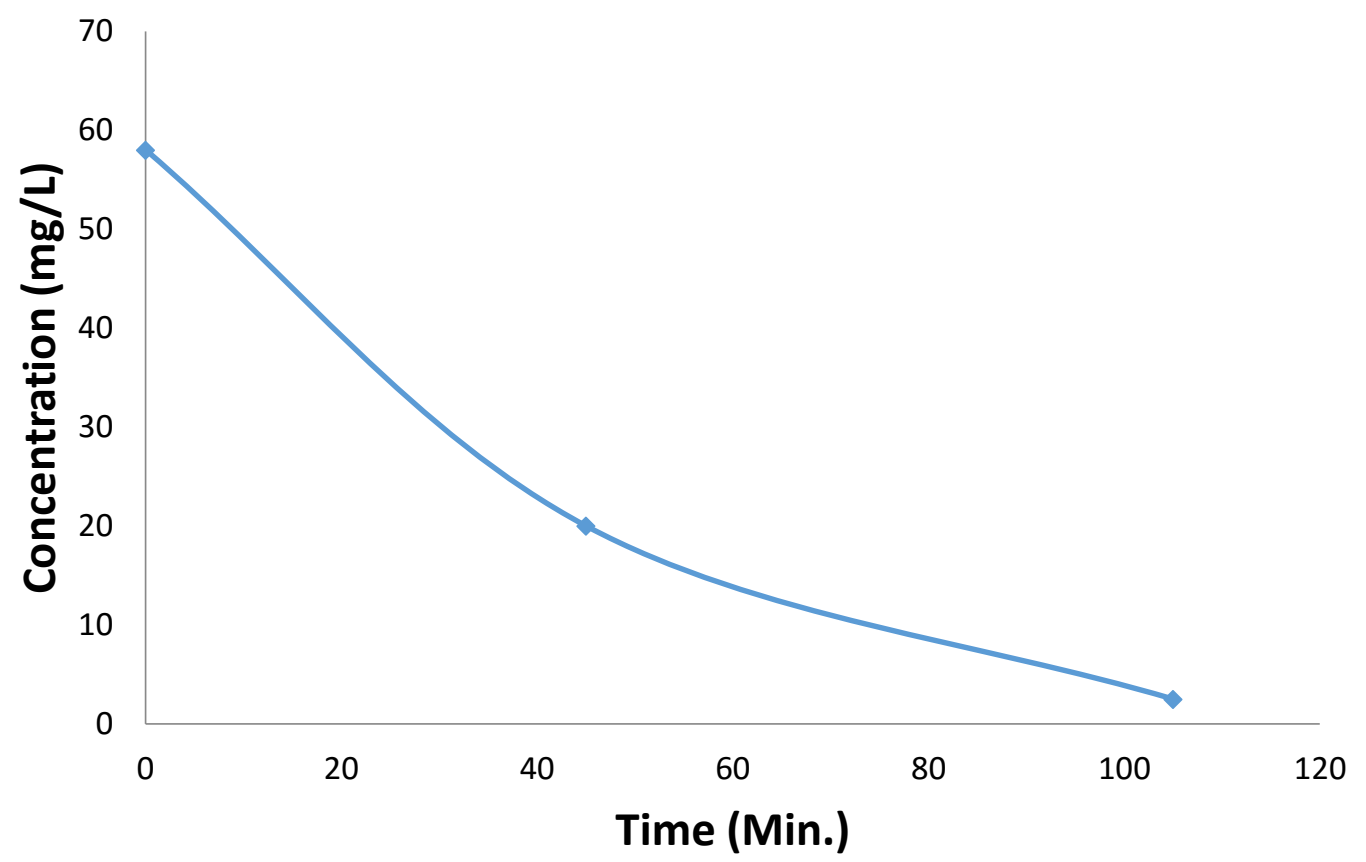

Figure 103: Cyanide Removal at 50 ASF, ORPM, $0.0042 \mathrm{ft}^{3} / \mathrm{min}$ Air Flow 


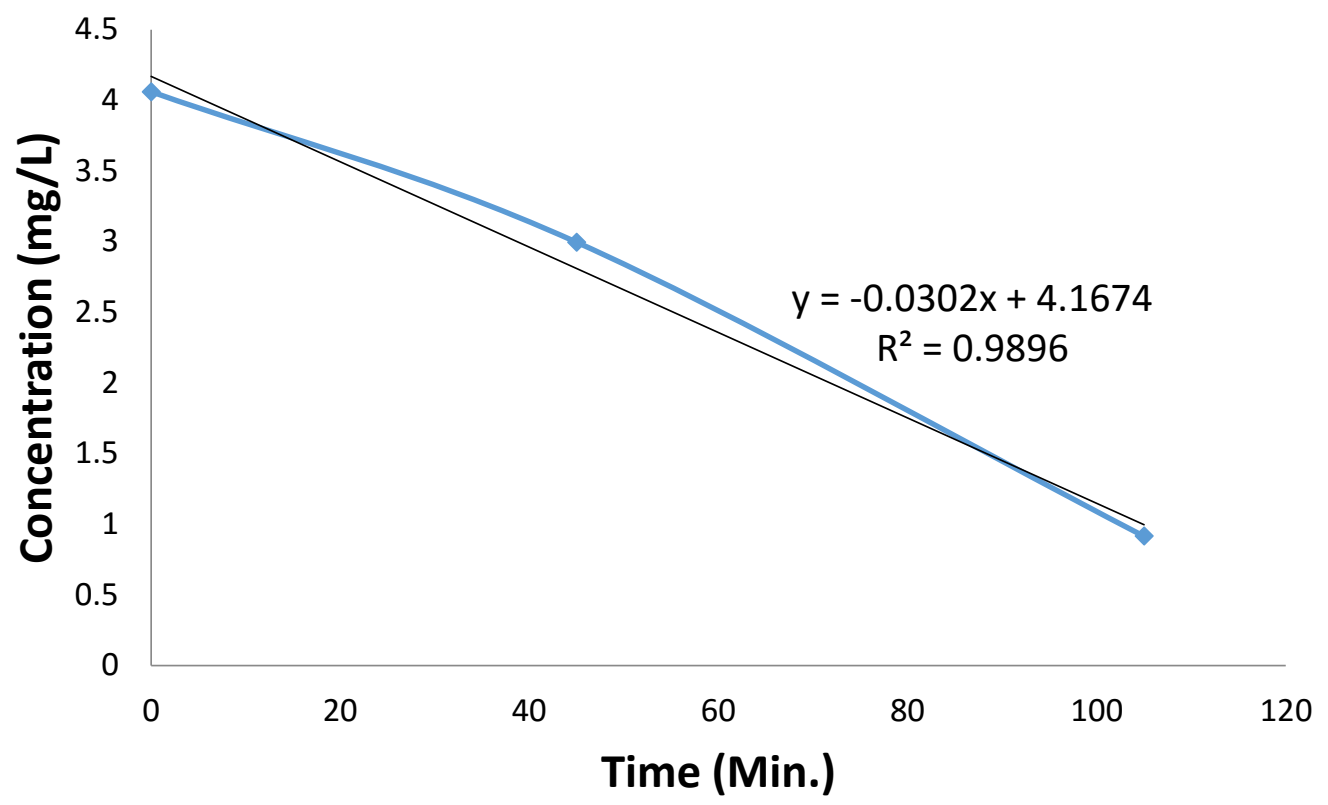

Figure 104: First Order Rate Constant Plot: Cyanide, Full Data, 50 ASF, 0 RPM, $0.0042 \mathrm{ft}^{3} / \mathrm{min}$ Air Flow

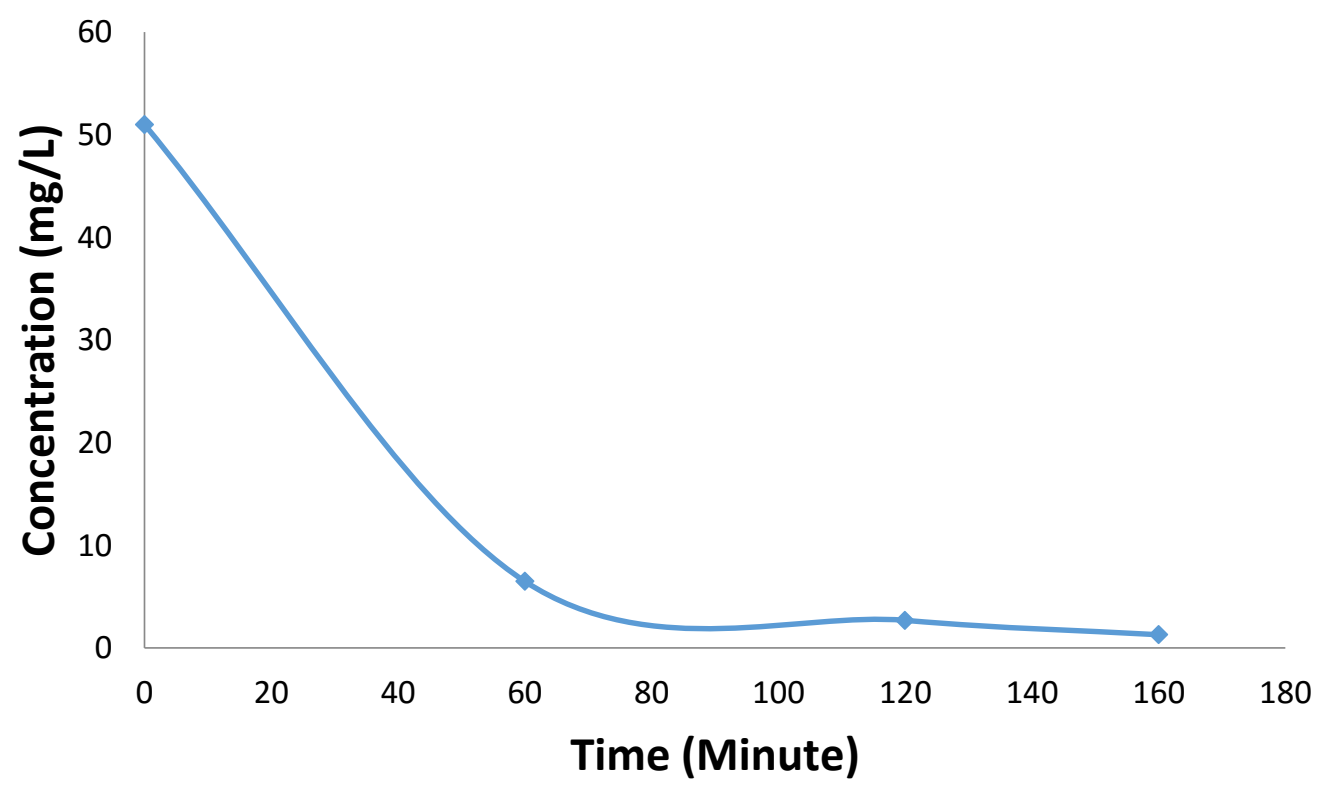

Figure 105: Cyanide Removal at 50 ASF, ORPM, $0.0069 \mathrm{ft}^{3} / \mathrm{min}$ Air Flow 


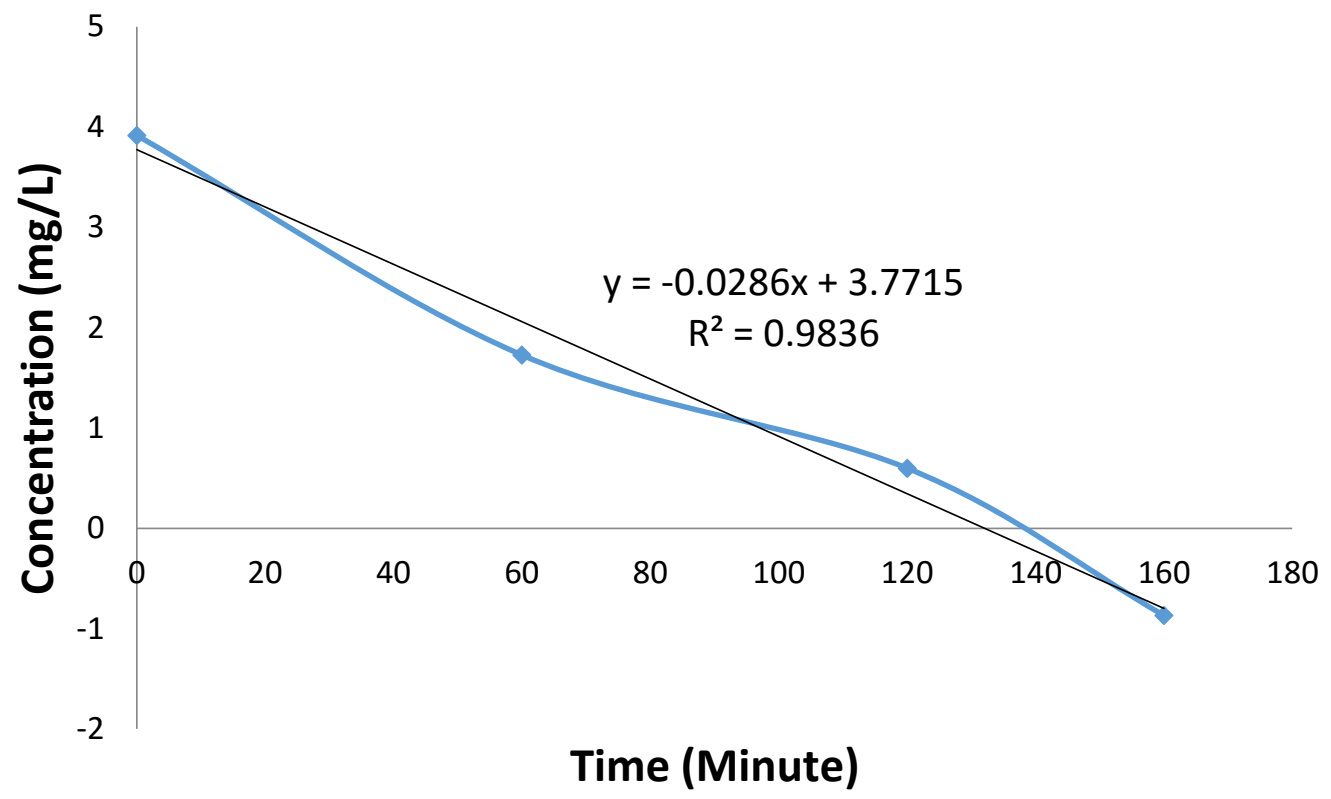

Figure 106: First Order Rate Constant Plot: Cyanide, Full Data, 50 ASF, 0 RPM, $0.0069 \mathrm{ft}^{3} / \mathrm{min}$ Air Flow

As you can see from the figures above, the use of aeration increased removal efficiency from $92.9 \%$ to a maximum $98.5 \%$ at a volumetric flow rate of 0.0021 $\mathrm{ft}^{3} /$ min proving the hypothesis correct. The concentration after 2 hours run time was $0.91 \mathrm{mg} / \mathrm{L}$ which is approximately 4.5 times less than what was achieved with no aeration $(4.1 \mathrm{mg} / \mathrm{L})$. The rate constants for the air agitated tests were $0.0209,0.0463$, 0.0302 , and 0.0286 for $0,0.0021,0.0042$, and $0.0069 \mathrm{ft}^{3} / \mathrm{min}$ respectively. These are important results because achieving a value less than $1.0 \mathrm{mg} / \mathrm{L}$ means the process is capable of meeting EPA discharge standards.

Using the pseudo-first order kinetic equation (54) along with a rate constant of 0.0463, initial concentration of $50 \mathrm{mg} / \mathrm{L}$, and equilibrium concentration of $0.72 \mathrm{mg} / \mathrm{L}$ yields a treatment time of $112 \mathrm{~min}$. to reach $1.0 \mathrm{mg} / \mathrm{L}$. Unfortunately, the more stringent level set by the Narragansett Bay Commission $(0.65 \mathrm{mg} / \mathrm{L})$ was proven 
unatainable during experimentation since the equilibrium concentration as time approaches infinity is only $0.72 \mathrm{mg} / \mathrm{L}$.

\subsection{METAL REMOVAL: WITH AERATION}

With the increase in removal efficiency shown for cyanide through aeration it also became necessary to test its affects on metal removal.

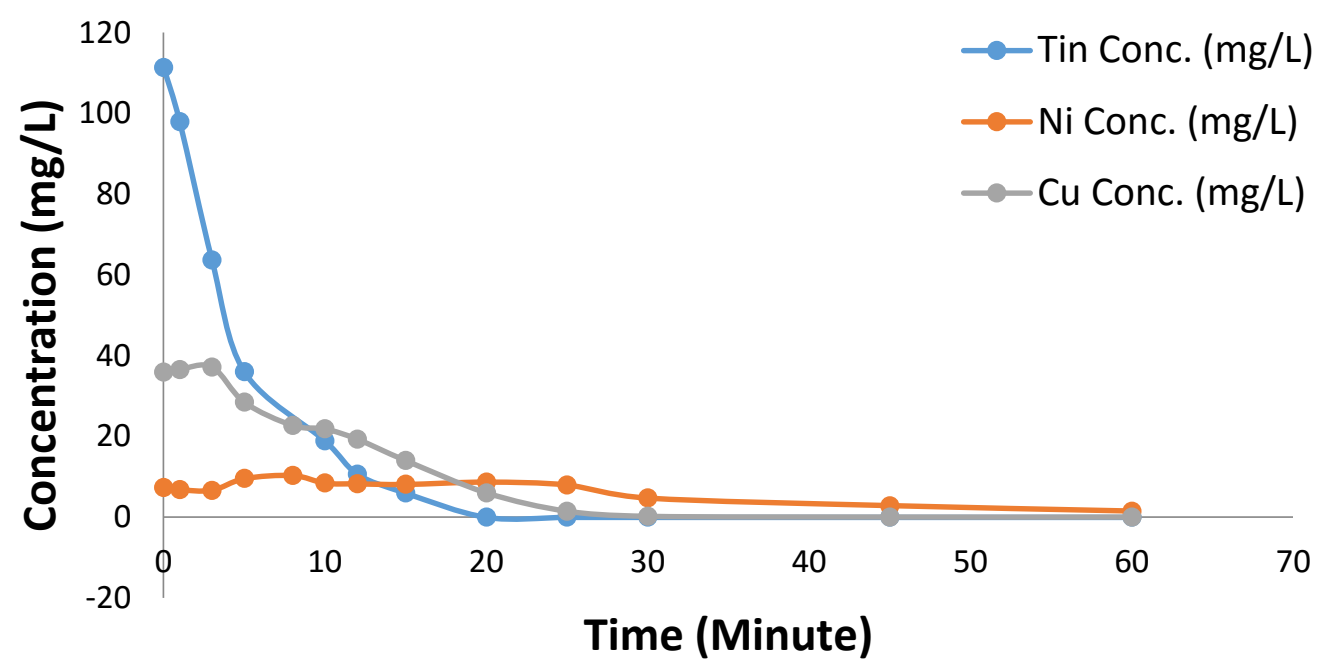

Figure 107: Metal Removal at 50 ASF, 0 RPM, $0.0021 \mathrm{ft}^{3} / \mathrm{min}$ Air Flow Rate

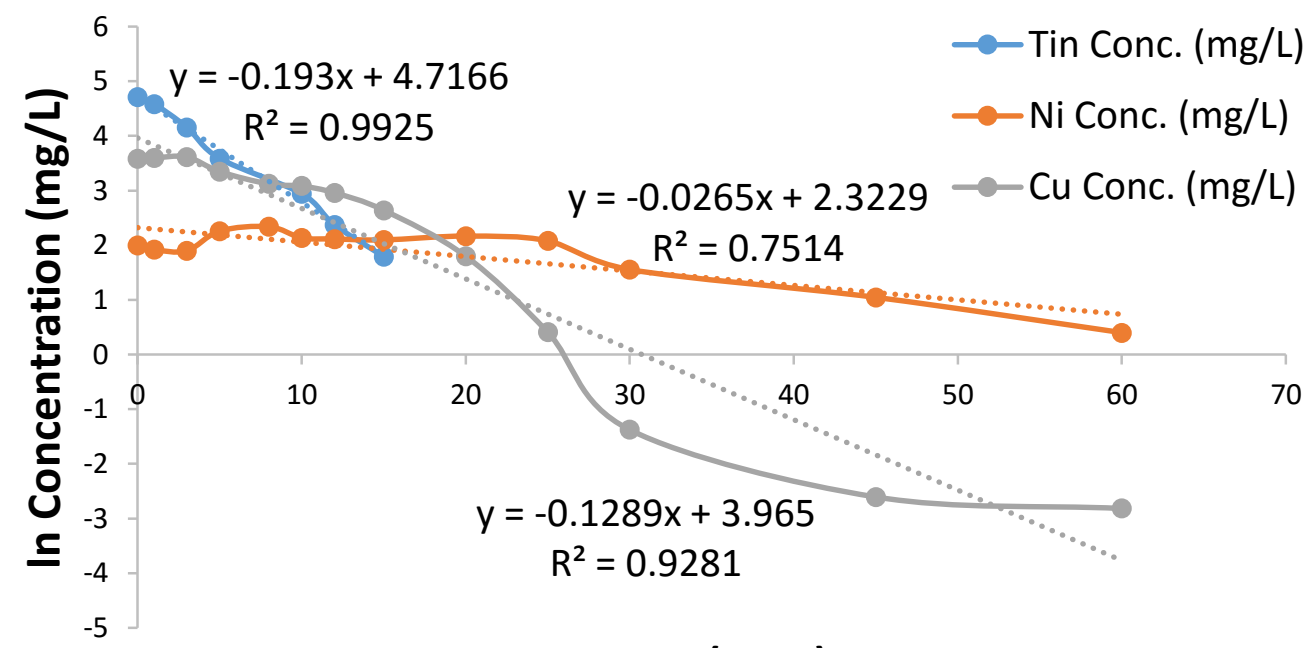

Time (Min.)

Figure 108: First Order Rate Constant Plot: Metals, Full Data, 50 ASF, 0 RPM, $0.0021 \mathrm{ft}^{3} / \mathrm{min}$ Air Flow 


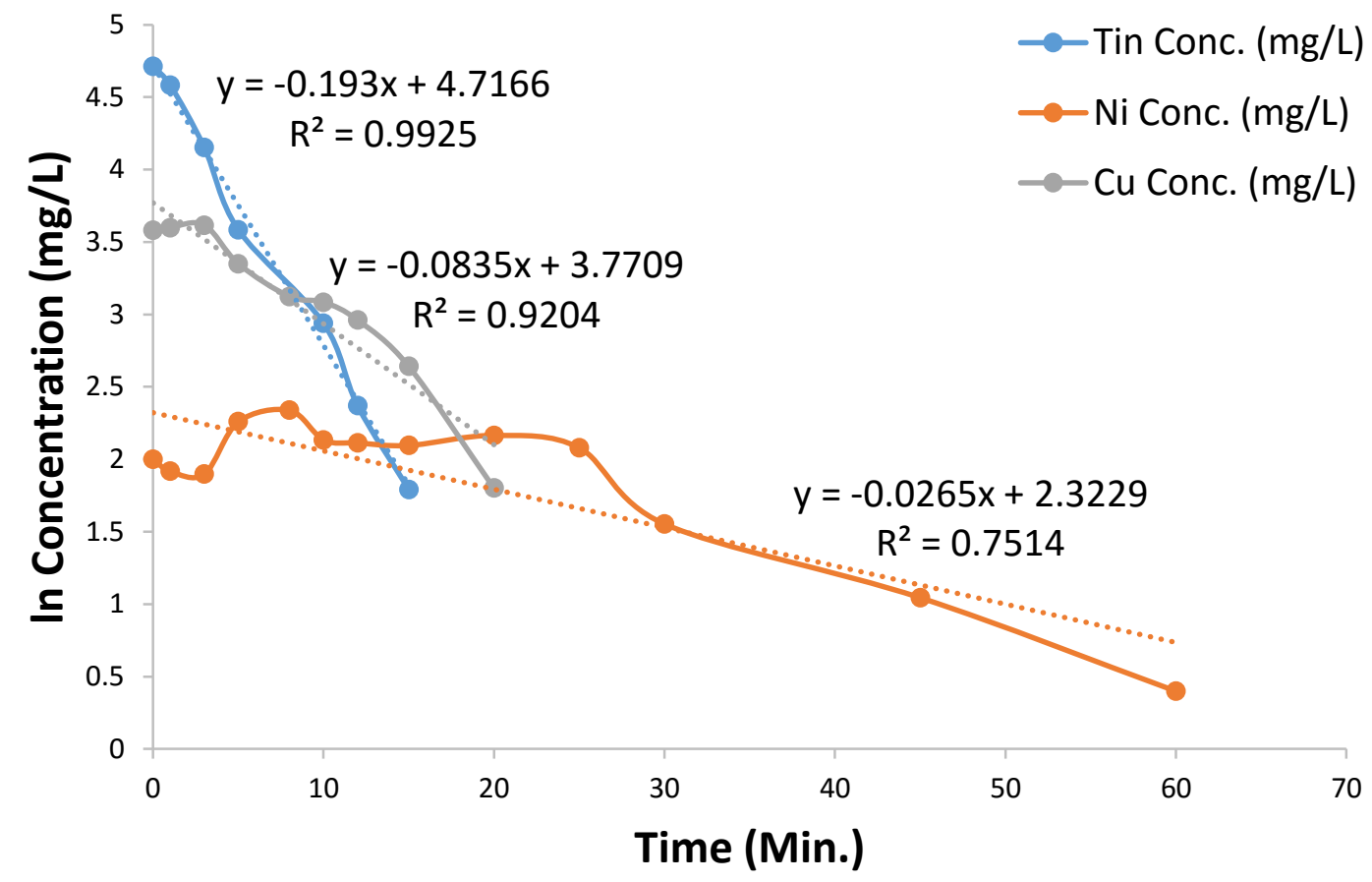

Figure 109: First Order Rate Constant Plot: Metals, Linear Region, 50 ASF,0 RPM, $0.0021 \mathrm{ft}^{3} / \mathrm{min}$ Air Flow

As you can see from the figures above, even with aeration, the removal efficiency was still enough to reduce metal concentrations to EPA permissable levels. Interestingly there was a reduction in rate constants when aeration was added. In the initial trial done with no aeration at $50 \mathrm{ASF}$, the rate constants were $0.2814,0.1241$, and 0.033 $1 /$ min for tin, copper, and nickel respectively. With aeration, rate constants of 0.193 , 0.0835 , and $0.02651 / \mathrm{min}$ were recorded for tin, copper and nickel respectively. The use of aeration generated large bubbles which greatly increased solution agitation. It is possible the shear created when the bubbles rose to the top of the vessel caused breakage of the floccules and slowed the adsorption process. In future experiments the use of a more fine/diffuse air source may show greater efficacy. 


\subsection{INSOLUBLE ANODE}

When running these experiments it quickly became apparent that electrocoagulation and hydroxide precipitation were not the only methods of metal removal occuring. As you can see in the picture below, the cathode at the end of each experiment showed a copper colored hue.

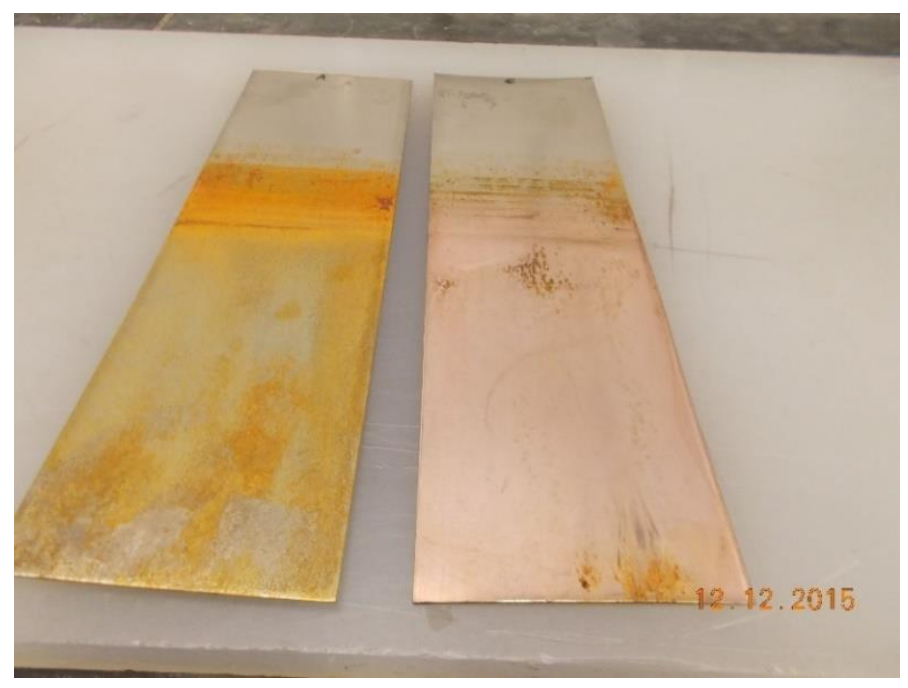

Figure 110: Anode (Left) Cathode (Right) After Electrocoagulation Trials Showing Copper Plating.

This copper layer indicates direct reduction of copper metal from solution to the cathode during operation (electroplating). Electroplating is strongly dependent on solution agitation at high current density. This may explain the increase in removal rate experienced by copper at higher spin speeds. It may be that with no agitation, electrocoagulation is the main method of removal. At low spin speeds of 50 and 100 RPM there is enough agitation to induce breakage and reduce flocculation efficiency. At higher agitation levels the main mechanism may shift to electroplating due to availability of metal ions at the cathode surface.

To better understand the role of electroplating in these experiments another test was devised using an insoluble anode. With an insoluble anode, electrocoagulation is 
not a removal mechanism. This is because the anode no longer supplies iron ions to the working solution. A platinized titanium anode was chosen for this trial due to availability. Tests were run at $50 \mathrm{ASF}$ and $300 \mathrm{RPM}$ for comparison.

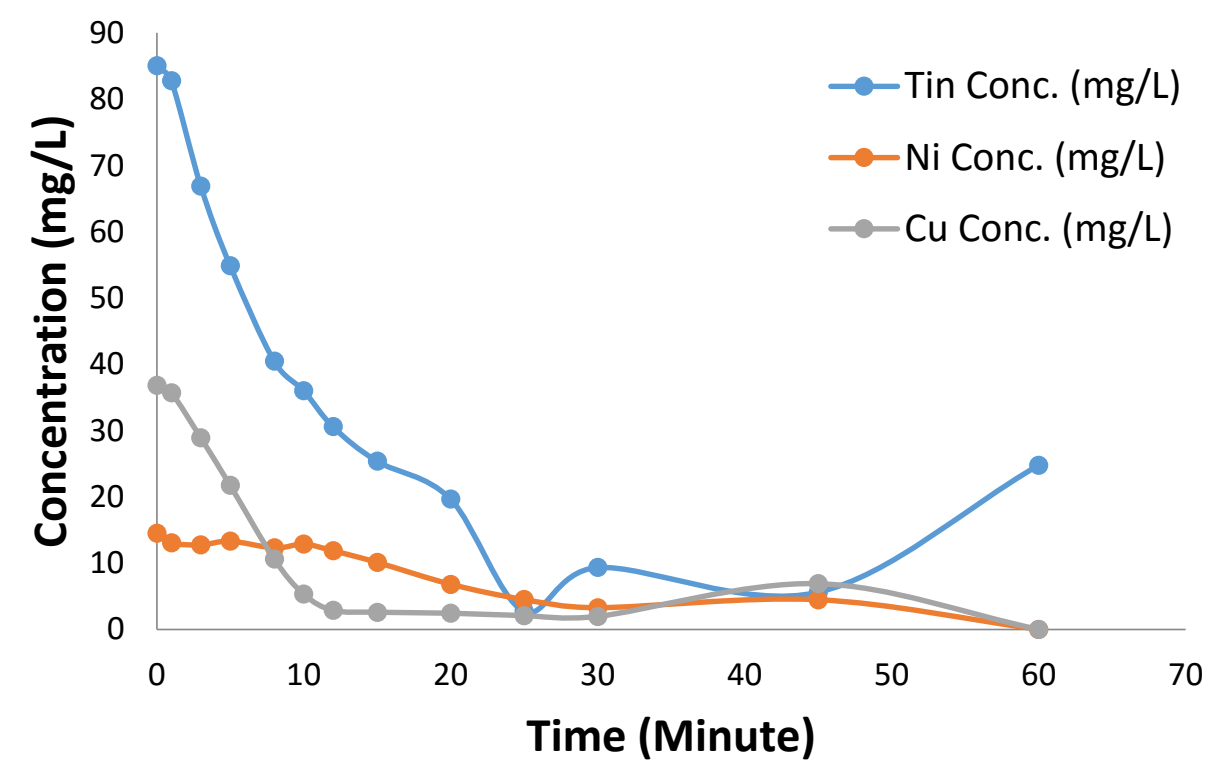

Figure 111: Metal Removal at 50 ASF, 300 RPM, Platinized Titanium Anode

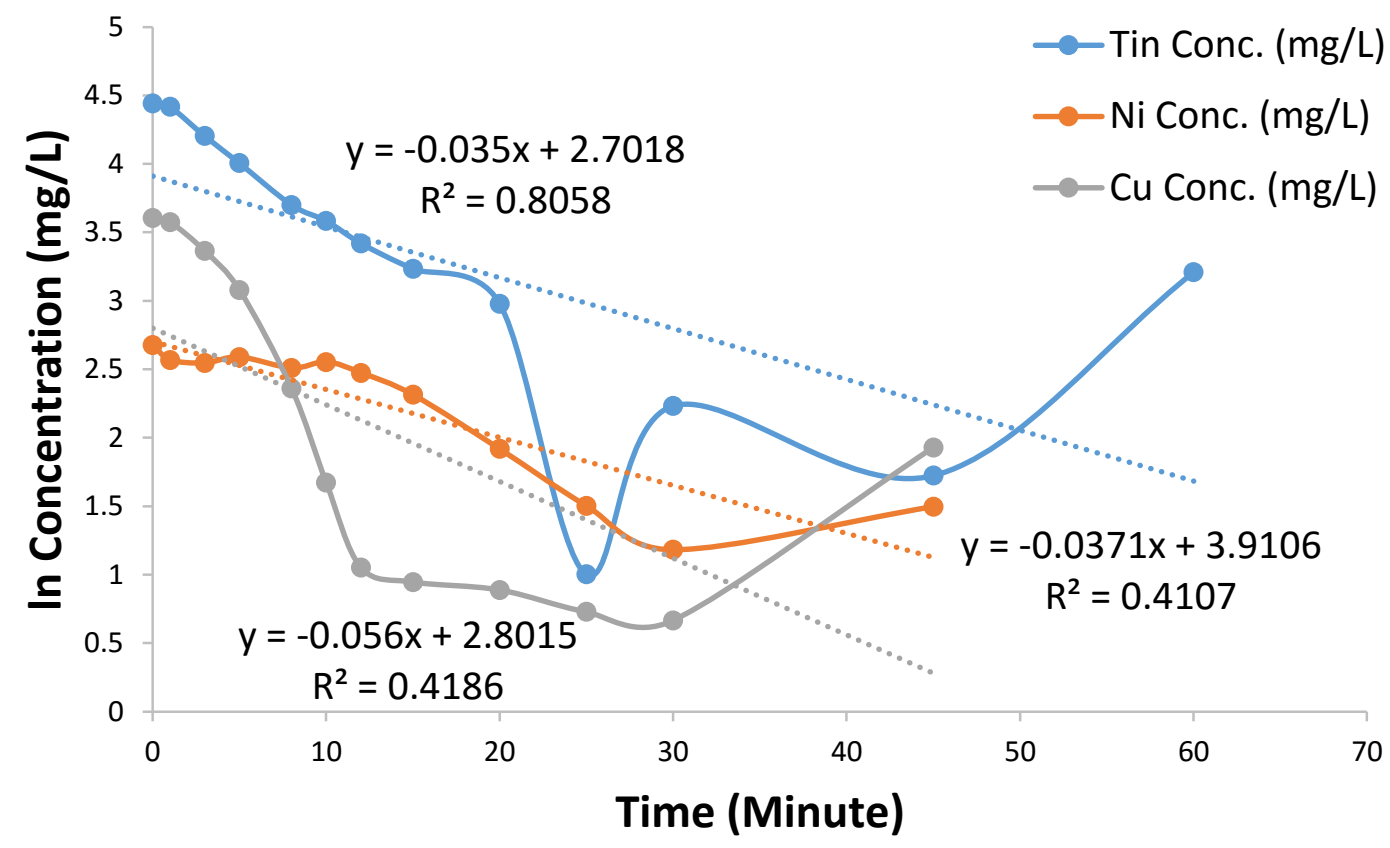

Figure 112: First Order Rate Constant Plot: Metals, Full Data, 50 ASF, 300 RPM, Platinized Titanium Anode 


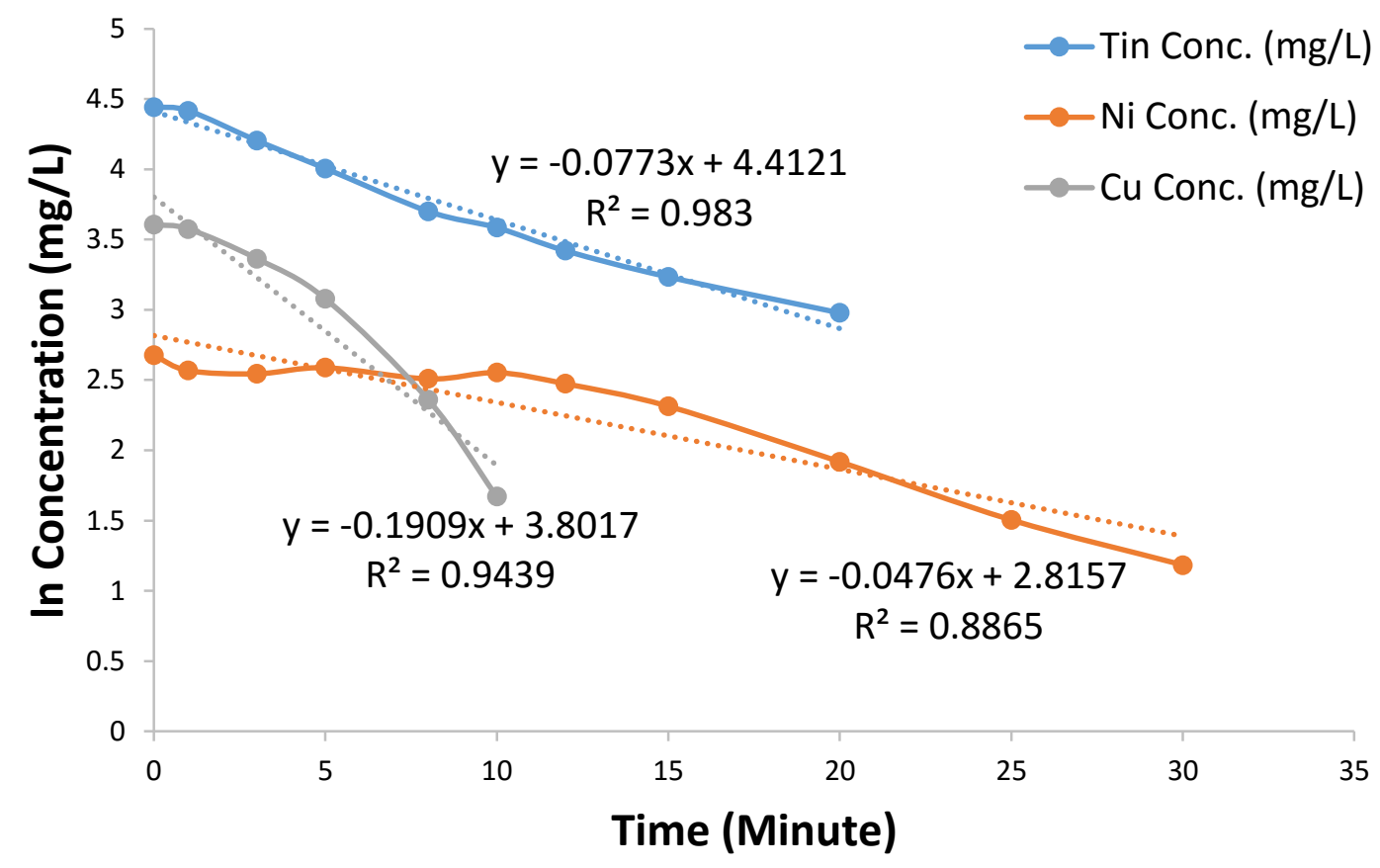

Figure 113: First Order Rate Constant Plot: Metals, Linear Region, 50 ASF, 300 RPM, Platinized Titanium Anode

None of the metals were reduced below EPA admissable levels with the platinized titanium test. During the first 20 minutes of tin treatment the first order rate constant was $0.07731 / \mathrm{min}$ compared to $0.1821 / \mathrm{min}$ when a soluble anode was used. This may indicate that electroplating and electrocoagulation act synergystically with each other to decrease the contaminant concentration but further studies would be needed verify this.

The copper concentration displayed zero order reaction kinetics when using a platinized titanium anode with a rate constant of $3.314 \mathrm{mg} / \mathrm{L} * \mathrm{~min}$. This removal rate is much higher than tests run with an insoluble anode and resulted in reduction of metals about twice as fast as when electrocoagulation was used. However, the metal concentration never reached EPA admissable levels even after 45 minutes of 
treatment. In this case it seems that electrocoagulation may actually play an inhibitory role in the early stages of copper treatment then help to reduce metals further at low concentrations.

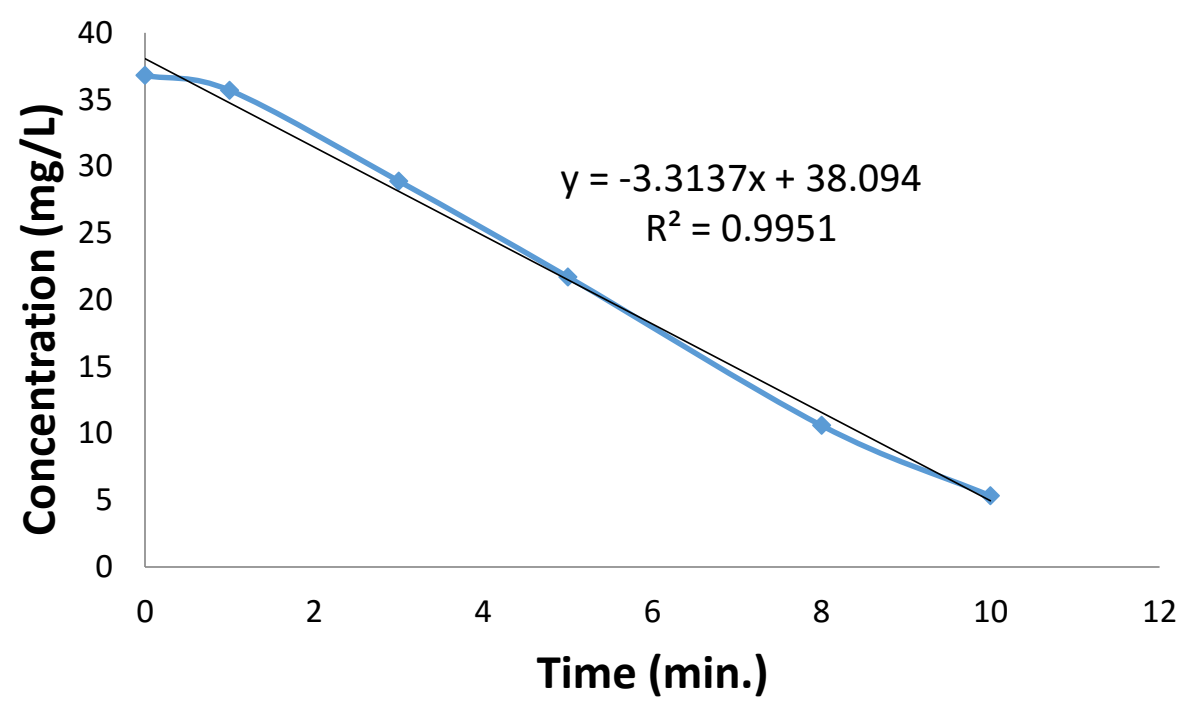

Figure 114: Zero Order Reaction Kinetics Displayed for Copper Removal Using an Insoluble Anode 


\section{CHAPTER 5}

\subsection{CONCLUSION}

The goal of this thesis was to determine whether or not electrocoagulation could be used to treat metals in effluent streams common to the high speed electroplating industry, with a secondary goal if continuous treatment was plausible. As described in this thesis, tin is an important metal in high speed electroplating. An in-depth literature search, indicated that electrocoagulation had not been considered for tin removal to date. Thus, the first part of this study showed that electrocoagulation could be used for the treatment of wastewater laden with tin and could be used to reduce concentrations down to EPA permissible levels.

This study also set out to test the ability to treat all of the metals common to the high speed electroplating industry and cyanide simultaneously in a single vessel at a pH of 11 . This information was necessary if the system was to be used continuously in the future. The study showed that simultaneous treatment was possible at a starting cyanide concentration of $50 \mathrm{mg} / \mathrm{L}$. Using a relatively simple setup, tin, nickel, and copper could be reduced to EPA dischargeable levels in under an hour.

Cyanide treatment proved to take the longest with a treatment time of 112 minutes. This treatment time is excessive and thus, becomes a limiting factor in treatment due to operating costs. Additional aeration treatments were determined to be the only way to achieve EPA discharge levels in a cost effective manner. This is due to conversion of ferric to ferrous iron, which creates a more gelatinous floc that is better suited to cyanide coagulation.

Finally, the electricity and iron costs were estimated for the electrocoagulation 
process. The current electrocoagulation process ran for 112 minutes, at 4.6 amps, 6 volts and treated 2.5 liters. This yields an electrical consumption of $0.0206 \mathrm{kwh} / \mathrm{L}$ and an iron consumption of $3.83 \mathrm{~g} / \mathrm{L}$.

\subsection{FUTURE WORK}

The present work shows feasibility of an electrocoagulation process to treat both metals and cyanide in solution. It also raises a few questions, which must be answered by additional research before the technology can transferred to the end users; the wastewater treatment industry. The following issues need to be addressed before future research can focus solely on making the process more robust and cost effective.

The first and most obvious issue is an extension of the present research: that is to investigate continuous processing or continuous treatment of the waste streams generated by the electroplating industry. All testing to date was carried out in a batch

process and thus, it is critical to determine how the batch process would translate into continuous one.

Figure 76 shows the effect of cyanide concentration on metal concentration. The present research showed that treatment using the electrocoagulation route is possible up to a starting concentration of $50 \mathrm{mg} / \mathrm{L}$ cyanide. The pseudo-first order rate law for this process indicates that the lowest final concentration possible for this initial concentration is $0.72 \mathrm{mg} / \mathrm{L}$. To better understand the limitations of the process, further research should focus on the maximum initial cyanide concentration permissible to deliver a final concentration below the EPA limit of $1.0 \mathrm{mg} / \mathrm{L}$. 
Experiments run with an insoluble anode showed that electroplating was at least a part of the removal mechanism. This opens the possibility that future experimentation could reduce the operating cost of the system. If a system employing two sets of electrodes is used, the iron consumption and treatment time may be reduced if only one of them is an insoluble anode such as platinized titanium. Optimization of factors such as individual current densities and/or cycle times may be important. 


\section{APPENDIX A: ATOMIC ABSORPTION PROCEDURE}

All elemental concentrations in this thesis were obtained by atomic absorption spectrometry (AAS). In atomic absorption a ground state atom of the target element absorbs a specific wavelength of light. The more atoms in the beam path, the more light which is absorbed. By making fine measurements of this absorbance it can be used to determine the relative amount of certain elements suspended in solution.

The work contained used the PerkinElmer Pinnacle 900f, one of the newer models made by PerkinElmer. The following were the standard conditions chosen during experimentation:

\begin{tabular}{|l|r|r|l|r|}
\hline \multicolumn{5}{|c|}{$\begin{array}{l}\text { Table 5: Standard Atomic Absorption Conditions for Cu, Ni, Sn } \\
\text { (Analytical Methods for Atomic Absorption Spectrometry) }\end{array}$} \\
\hline & $\mathrm{Cu}$ & $\mathrm{Cu}(2)$ & $\mathrm{Ni}$ & \multicolumn{1}{l|}{$\mathrm{Sn}$} \\
\hline Wavelength & 324.8 & 222.6 & 352.5 & 286.3 \\
\hline Slit Size (nm) & 0.7 & 0.2 & 0.2 & 0.7 \\
\hline Relative Noise & 1 & 7.9 & 0.47 & $>1$ \\
\hline Characteristic Concentration (mg/L) & 0.077 & 1.1 & 0.39 & 3.5 \\
\hline Characteristic Concentration Check (mg/L) & 4 & 50 & 20 & 160 \\
\hline Linear Range (mg/L) & 5 & 50 & 20 & 180 \\
\hline
\end{tabular}

The relative noise is a factor used to quantify the variability of the signal. A lower value corresponds to a more stable reading. The characteristic concentration is the analyte concentration required to achieve a $1 \%$ absorbance signal at the specified wavelength. This corresponds to a signal of 0.0044 absorption units. The characteristic concentration check is the analyte concentration required to achieve a signal of 0.2 absorption units. It represents a concentration high enough to reduce natural variation and ensure the machine is operating correctly. Finally, the linear range represents the maximum concentration where the absorbance signal is linear with respect to concentration. Up to this concentration only a single standard needs to 
be used. Above this concentration the absorbance signal begins to curve. More standards must then be used to account for this curvature.

The wavelengths in the table above were chosen due to linear range, low characteristic concentration, and the 6:3:1 rule for each element. This rule states that the concentration of your lowest standard be at the top of the linear range with your next 2 standards 3 and 6 times this initial concentration (Analytical Methods for Atomic Absorption Spectrometry). The following standard concentrations were chosen to encompass the range of values expected in the testing.

\begin{tabular}{|l|l|l|l|}
\hline \multicolumn{5}{|c|}{ Table 6: Standard Concentrations Utilized During Experimentation } \\
\hline Element & $\begin{array}{l}\text { Standard 1 } \\
(\mathrm{mg} / \mathrm{L})\end{array}$ & $\begin{array}{l}\text { Standard 2 } \\
(\mathrm{mg} / \mathrm{L})\end{array}$ & $\begin{array}{l}\text { Standard 3 } \\
(\mathrm{mg} / \mathrm{L})\end{array}$ \\
\hline $\mathrm{Cu}$ & 5 & 15 & $\mathrm{~N} / \mathrm{A}$ \\
\hline $\mathrm{Cu}(2)$ & 50 & $\mathrm{~N} / \mathrm{A}$ & $\mathrm{N} / \mathrm{A}$ \\
\hline $\mathrm{Ni}$ & 20 & $\mathrm{~N} / \mathrm{A}$ & $\mathrm{N} / \mathrm{A}$ \\
\hline $\mathrm{Sn}$ & 30 & 180 & \\
\hline
\end{tabular}

All blanks and standards were made to mimic the working solution. This included the addition of $5 \mathrm{~g} / \mathrm{L}$ sodium chloride. The addition of sodium chloride served 2 purposes; reduction of matrix and possibly ionization interferences. A matrix interference occurs when the flow characteristics of the working solution vary from the standards. This includes factors such as density, viscosity, and surface tension. By making the standard and blank with sodium chloride the densities will remain close. Ionization interference occurs when the energy of the flame is high enough to ionize the target metal rather than induce an excited state. This can be reduced by the addition of compounds which ionize easily. Alkali metals are typically used, and thus the sodium serves this purpose.

The detection limits of nickel and copper are lower than tin at the wavelengths chosen. This is a product of both the weaker signal from tin and the fact that Materion 
Technical Materials employs a pure acetylene flame. Greater accuracy may be attainable with a nitrous oxide enriched flame, but this was unavailable during testing. To better quantify the statistical accuracy of tin at low and high concentrations, 10 readings of each were taken with blanks in between. The blank reading before and after was averaged and subtracted from the concentration reading. The following formula was used to determine the detection limit:

Detection Limit $=\frac{\text { Standard Concentration } \times 3 \times \text { Standard Deviation }}{\text { Mean }}$

Assuming a normal distribution, using 3 standard deviations in the formula means that readings at the detection limit are correct within $\pm 33 \%$.

When calculated for tin it shows a detection limit of approximately $8.5 \mathrm{mg} / \mathrm{L}$. The statistical results are displayed below.

\begin{tabular}{|l|r|r|r|}
\cline { 2 - 4 } \multicolumn{1}{c|}{} & $\begin{array}{l}\text { Average } \\
\text { (mg/L) }\end{array}$ & Standard Deviation (mg/L) & \multicolumn{2}{l|}{$\begin{array}{l}\text { Individual Detection } \\
\text { Limit (mg/L) }\end{array}$} \\
\hline $30 \mathrm{mg} / \mathrm{L}$ & 0.00507 & 0.000221359 & 3.929457448 \\
\hline $\begin{array}{l}180 \\
\mathrm{mg} / \mathrm{L}\end{array}$ & 0.03085 & 0.000746473 & 13.06630542 \\
\hline
\end{tabular}

\begin{tabular}{|l|r|}
\hline Ratio of Means & 6.084812623 \\
\hline $\begin{array}{l}\text { Overall Detection Limit } \\
\text { (mg/L) }\end{array}$ & 8.497881433 \\
\hline
\end{tabular}

Table 7: AAS Detection Limit for Tin Metal

If you recall, the average monthly discharge limit for tin in the state of Rhode Island is $2.00 \mathrm{mg} / \mathrm{L}$. This means that at very low concentrations the results may be skewed. An alternate analytical method may be required in future work to ensure the $2.00 \mathrm{mg} / \mathrm{L}$ threshold is met. To minimize the effects of the low detection limit on the rate constant graphs, a larger initial concentration of $160 \mathrm{mg} / \mathrm{L}$ was chosen. 


\section{BIBLIOGRAPHY}

Adhoum, N., Monser, L., Bellakhal N., Belgaied J. Treatment of electroplating wastewater containing $\mathrm{Cu} 2+, \mathrm{Zn} 2+$, and $\mathrm{Cr}(\mathrm{VI})$ by electrocoagulation. Journal of Hazardous Materials B112 (2004) 207-213.

Akbal, Feryal, and Selva Camc1. "Copper, Chromium and Nickel Removal from Metal Plating Wastewater by Electrocoagulation."Desalination 269.1-3 (2011): 21422. Web.

Al-Shannag, Mohammad, Zakaria Al-Qodah, Khalid Bani-Melhem, Mohammed Rasool Qtaishat, and Malek Alkasrawi. "Heavy Metal Ions Removal from Metal Plating Wastewater Using Electrocoagulation: Kinetic Study and Process Performance." Chemical Engineering Journal 260 (2015): 749-56. Web.

Amarnath, J., Rahan, S., Kumar, S., Removal of cyanide and heavy metals from gold plating industrial waste water, Journal of Chemical and Pharmaceutical Sciences, Volume 7 Issue 4, October - December 2014, pp. 281

Analytical Methods for Atomic Absorption Spectrometry Revision E. PerkinElmer Instruments LLC. Copyright 1964-2000

Dermentzis, K., Christoforidis, A., Valsamidou, E., Removal of nickel, copper, zinc and chromium from synthetic and industrial wastewater by electrocoagulation, International Journal of Environmental Sciences, Volume 1 No 5, 2011, pp. 697

www.eia.gov/electricity/monthly electricity. December 15, 2015 
Environmental Protection Agency Method 9014-5, Cyanide in Waters and Extracts Using Titrimetric and Manual Spectrophotometric Procedures. July 2014

Evans, D. Fennell., and Håkan Wennerström. The Colloidal Domain: Where Physics, Chemistry, Biology, and Technology Meet. New York: Wiley-VCH, 1999. Print.

Ghernaout, Djamel, and Badiaa Ghernaout. "Sweep Flocculation as a Second Form of Charge Neutralisation - a Review." Desalination and Water Treatment 44.1-3 (2012): 15-28. Web.

Greenberg, A., Clesceri, L., Eaton, A., Franson, M. Standard Methods for Examination of Water and Wastewater $18^{\text {th }}$ Edition, 1992

Griffith, W.P., "Cyanide complexes of the transition metals.” Quarterly Reviews, Chemical Society Issue 2, 16, 1962, pp. 188-207

Hassani, G., Nasseri, S., Gharibi, H., "Removal of Cyanide by Electrocoagulation Process.” Analytical and Bioanalytical Electrochemistry Vol. 3, No. 6, 2011, pp. $625-634$

Hill, John W., Ralph H. Petrucci, Terry W. McCreary, and Scott S. Perry.General Chem-istry. Upper Saddle River, NJ: Pearson/Prentice Hall, 2005. Print.

Holt, P., Barton, G., Wark, M., Mitchell, C., A quantitative comparison between chemical dosing and electrocoagulation, Colloids and Surfaces A: Physiochem. Eng. Aspects, 211 (2002) pp. 233-248

"Hydrogen Cyanide." Hydrogen Cyanide. National Institute of Standards and Technology, n.d. Web. 12 Oct. 2015. 
Kobya, M., Demirbasb E., Parlaka N.U., Yitita S., Treatment of cadmium and nickel electroplating rinse water by electrocoagulation. Environmental Technology Vol. 31, No. 13, 1 December 2010

Lide, David R. CRC Handbook of Chemistry and Physics: A Ready-reference Book of Chemical and Physical Data. Boca Raton, FL: CRC, 1994. Print. pp. 5-71

Matteson, Michael J., Regina L. Dobson, Robert W. Glenn, Nagesh S. Kukunoor, William H. Waits, and Eric J. Clayfield. "Electrocoagulation and Separation of Aqueous Suspensions of Ultrafine Particles." Colloids and Surfaces A: Physicochemical and Engineering Aspects 104.1 (1995): 101-09. Web.

Meinshausen, Lutz, Soumik Banerjee, Indranath Dutta, and Bhaskar Majumdar. "Mitigation of Tin Whisker Growth by Dopant Addition."Volume 2: Advanced Electronics and Photonics, Packaging Materials and Processing; Advanced Electronics and Photonics: Packaging, Interconnect and Reliability; Fundamentals of Thermal and Fluid Transport in Nano, Micro, and Mini Scales (2015): Web

Moussavi G., Majidi F., Farzadkia M. The influence of operational parameters on elimination of cyanide from wastewater using electrocoagulation process. Desalination 280 (2011) 127-133.

Parga, José R., Munive, G. T., Valenzuela, J. L., Vazquez, V. V., and Zamarripa, G. G. "Copper Recovery from Barren Cyanide Solution by Using Electrocoagulation Iron Process."ACES Advances in Chemical Engineering and Science 03.02 (2013): 150-56. Web. 
Rajeswari Raja T., * Namburu sailaja, Impact of Heavy Metals on Environmental Pollution, Journal of Chemical and Pharmaceutical Sciences, JCHPS Special Issue 3, October 2014: 175 Web.

Schesinger M., Paunovic M., Modern Electroplating $5^{\text {th }}$ Edition, Wiley, October 2010

Senturk, E. "The Treatment of Zinc-cyanide Electroplating Rinse Water Using an Electrocoagulation Process." Water Science \& Technology 68.10 (2013): 2220. Web.

U.S. Environmental Protection Agency Office of Water Programs, TREATMENT OF METAL WASTESTREAMS A FIELD STUDY TRAINING PROGRAM. 1990

Vik, E., Water Res., 18 (1984) 1355

Zeta-Meter, Inc. "Everything you want to know about Coagulation \& Flocculation" April 1993. Print 